46. 1072

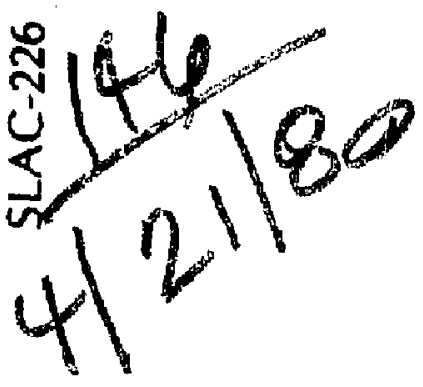

SLAC-226

\title{
ELECTRON TRAJECTORY PROGRAM
}

\section{MASTER}

William 3. Herrmannsfeldt

SLAC-Report-226

November 1979

Prepared for the Department of Energy under Contract Number DE-AC03-76SF00515. 


\section{ELECTRON TRAJEGTORY PROGRAM"}

Will1am B. Herrmannefeldr

Stanford I-inear Accelerator Center

Stanford University, Stanford, Callfornta 9430s

November 1979

Prepared for the Departmenc of Energy

under Contract Number DE-ACO3-765F00515.

Priated in the United States of America. Avallable from National Technical

Information Service, U.s. Department of commcrce, 5265 Port Royal Rond,
Springfield, Virginia 22161. Price: Printed copy $\$ 6.50$; fiterof 1che $\$ 3.00$

This aujerocdes SLAC-51 and SLAC-166.
The SLAC Electron rrajectory Progran is deseribed and inseructions and examples for users are glven. The progran is spectflcally writeen to compute trajectories of charged particles in electrostatic and magnetratatic focusigg systems Including the effects of space charge and self-aggnetic fields. Scarting optlons tnelude Child's Law conditions on cathodes of varlous shapes. Elther recangular or cylindrically symmetric geometry bo; be used. Hagnetic flelds ma be spectfled using arbltrary conflgurations of coils, or the output of a magnet probram such as Polsson or by an externaly calculated array of the axial fleldt.

The progrum is ayaflable in IBM FORTRAN but can be easily converted for use on ocher brands of hardware. The program is intended to be uged with a piotter whose incerface the user wust provide.

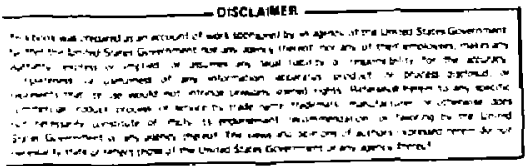


TABLE OF COITENTS

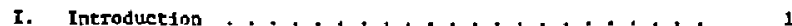

IT. Applicarion ................ 2

III. Implementution ................ 3

Iv. General Description ...............4 4

v. Polsson Equarton Solver ...............

A. General tescription .............

B. Problem Input .............. 10

1. TItle and Fotential cards .......... II

2. Magnetic F1eld Data. . . . . . . . . 17

3. Joundary Input .............. 19

4. Special Boundary Conditions .......... 27

5. Boundary D1agnostice ........... 28

c. Po1 Egon's Equation ............. 29

vi. startins conditions ............... 32

A. Univergal Parameters. ........... 33

B. Bquipotential Plots ............ 46

c. Platting Controla ............. 48

D. Magnetdc pielde .............. 49

8. General Cathode and GiNCARD .......... 59

F. Spherical Cathode ............ 67

G. Gard starting .................. 71

1. Format for Uner Spectfled Data ....... 72

2. Use of Program Generated Carda ........ 74
4. Rectangular Coordinates with Cyltudtical Berams 75

fi. Laplace's Equarton Applicacions .......... t8

I. Dlelectric Boundarles ............. 79

vII. Trajectory Calculations .............. BI

VII i. Trajectory Analyats ............... 85

Appandix I - Derivation of Equations of Hotion. ...... B

Appendix 11 - General Newnann Boundarties .......... 95

Appendix III - Instrucetion Comments frow the Pragrim .... 97

Appendix IV - Sample Plotter Interface Program . . . . . . 104

Appendix v - Graphic Examples of Various Problers ...... 107

References ...................... 108 
LIST OF FIOURES

1. Secelon of megin nit golution of Polkgon's equation ..... g

2. Ermmp le of preparation far a problem ......... 12

3. Fortrar data prepart-d for the problem shown in Fig. $2 \ldots \ldots$ is

4. Output liating of boundary data for the problern of E1g. 2 , 24

5. Bastc zometry for opherical cathode configurations defining the loput parameters .............. 68

6. Plotted thput of gomple prablem ghow in Fig. $2 \ldots 70$

7. Phase mpace calculation f ge problear shown in Fig. $2 \ldots . .86$

B. Sampis output foz a very high pnrveance gun ....... 107

9. Sampla output for a hollow bear gin . . . . . . . . . . 208

10. Sampla output for a gyrotron gun .. . . . . . . . 109

11. Sample output for a klygtron gun ............ 110
I. INTRODUGTION

Th1s report 19 intended as a user's reference manwal for the sLAC Electron Irajectory Progran. It contains all the currently relevant material fron the earlfer publications about this program which were SLAC-51 and SLAC-166. "n add1tion, I have fncluded sperific Ins:ruczions cor using a nuber of the spectal features which have been added to tive prograw. These features have ustally been incorporated as a direct result of the needs of scme particular user and $I$ wish co take this opportunity to express thanks to everyone tho has at some time or other suggested tmprovenencs to the program. I think ve hove all bencficed by this open process and it is for the purpose of making all theare features better available that this report 15 being prepared. The most recent version of the prograd has benefited greatly from sowe careful program house cleaning, including a complete reviston of the plotting sections, making the problet of frterfacing with othct plotter systems much essier. It is a pleasure to acknowledge the contributions of Glen Horcmannsfeldt in maktng these Iuprovements. 


\section{APPLICATIOH}

The suac Electiod optics Program 18 specifically written to calculate electron trajectories in alectrostatic and mggetostatic fields. Polseon's equation fo solved by fintte diffecence equations using boundary conditions defined by apecifying the type and position of the boundary. Electric fields are determined by differentiating the potential distribution. The electron trajeccory equation are fully relativistic and aceount for all possible electric and tragnetic field corponents. Space charge forces are reslized through appropriate deposition of eharge on one cycle followed by another solution of Polason's equation which is to tura followed by another eycle of trafectory calculations.

The program may be uged in elther rectongular or cylindrical coordinateg. A opecial op:tion allows cpaco chorge forces in a cylindtical beam to be calculated in a rectangularly symetric array of electric and magmetic fields, Hagnecic fields are read fo either as axial strengths or as arrays of colle uith specified coordinates and currents. The preferred tecturique of defining the magnetic ficld is to calculate the axial field from an atbitrary conflguration of golenolds. Altematively, the program accepte the output data from a magnet design program, which can tnclude the effects of saturable iron. In cylindrical coordinates, the moguetic flelds are axially syumetric. Off-axis fleld zomponeats are calculated by a bath-order expanrion of the radfrl coordinate. In rectangular coordinateo the external field ia assumed to be normal to the plane of the problem, which is assumed to be the medisn plane. off- gedtan plane cooponents are calcutaced by expansion of the perpendicular coordinaze.

Electron trafectorles may be started by three methods:

1. Chlld's lav for spherical geonetry based on Picrce gebtetry.

2 Child's lav for generallzed cathodes including effects of holes, shados grids and other irregularictes.

3. Direct Input of the starting conditions, Including the qutput from previously run problems.

The progran is designed to yield a combination of printed and platted output. Printec output includes all innut data, maps of the potential F1elds, starting conditions for each cycle, ard final conditions for each cycle, Flocsed output $t_{6}$ ande for che erafectary calculations and for equipotentisi Inned. Plotted output may be obtaines fox selected eycles alvays including the last cycie.

\section{II. IMPL EMIFTTATION}

The program is wefiten in IBM-style FORTRM IV. Reasonable application requites about $400 \mathrm{~K}$ bytes of total storage. Runnlag tiaes vary greatly with the problem and the computex. Howlever a "typteal" problem run on an IBM 370-168 takes about 2 minutes.

The program te degigned for use with a computer controlled plotter. Data needed for plotetng are placed on an extemal storage device (diak) from which they ace called by a plocter treefface progras. Such a program calling standard culcomp routines ts a rallable and fan be used as a midel for users with other plotter oystems. 


\section{GEHERAL, DESCRIPTION}

Starting with the Inpur boundary description, the program first solves Laplace's equation (1.e., Polsenn's equation without space charge). The result of this calculation, together with all the boundary information is then printed.

Wext, the EIrst Iteration of electron crajectories is started. These are taftiated by one of four scnemes: (1) "GENERaL" cathode in which electrong are atarted asastang child's law hotds near a surface designated as the cathode; (2) "SPFERE" for a opherical cathode (cy11ndrical in rectangular coordinates) in which the electrong are assumed to be enitted at right angles to the surface defined by a radius of curvature and a radial limic. Child"s law for space charge lfolted current Is again uged. (3) "CARTS" in thich the speciflc starting conditions for each rag are spectfied. (4) "GENCARD" which combires the vorgat1lIty of "CARDS" with the assumptions of ChLld's law Erom "GENERAL."

On the first Iceration cycle, space charge forces are calculated from the asoumption of paraxial flow. As the rays are traced through tbe progran, space charge is computed and sto fed in a scpatace array. After all the electron trajectoriea have bech calculated, the program begins the seconid cycla by solving Poisson's equation with the space charge from the first 1teration. For problems recting the pafaxial assumptions, especially if relariviatic electron beams ate involved, thd one cycle nay be suffictent to solve the entite prohled.
Subsequent iteration cycles (as many as are requested) follow the above pattern. The child's las calculations for the starting conditions ate remade for every cycle. Perveance converges through the iterative. process by averaging the perveance used for the previous cycle with the perveance calculated directly frow the solution of Polsson's equation.

Aa additional starting opeion 1s "LAPLACE" Intended for any appl1chtion of Luplace's equation not Involving electron ray tracing. In this case the number of cycles is used slaply to improve the accuracy of the solution to Laplace's equation. The "IAPLACE" option inciudes a provision for 10putting arbitrazy data in the "space charge" array.

The program alvays operates in toro dimensions; efther $R$ and $z$ in sylindrical coordinates or $Y$ and $X$ fn rectangular coordfnates. The rectongular coordinate output retains the $R$ and 2 labels however. Electron orbits are calculated through azimuthal changes (labsled "PHI") referenced to the $z$ axis. In rectangular coordinates, PHI fs actually the third Cartegian coordinate.

Magnetic flelds, except for the self-magnetic fleld of a beam, are Input directly in one of three ways: (1) by spectfying the fteld along the $z$-axis, (2) by spectfying a set of colls (giving pogition, radius and current), or (3) by using the vector potential output from a magnet program. In cylindrical coordioates, the field is interpreted as an axigl zagnetic field with radial term as required by Maxalell's equarions. In rectangular coordinateg the Fleld 1s 1ntorpreted as going in the PBI direction, i.e., at right angles to the plane of the problem. The rectangular coordinate field is assumed to extend to infintey in $Y(R)$ and 
The PHI - O planc (the plane of the problem) ls asstrued to be the median plane. The $B_{x}\left(B_{z}\right)$ torag are celculated for PHI 0 from Maxuell's equations.

Self-magnetic theld are calculated for bech coordinate aystema from the current in the rays on the present cycle. It is generally asaumed that the rays are sequentially numberted from the axis outuards. The self-magnetic fleld calculation assumes all the current fror the prevtous rays lies on the axis fn an infinitely long conductor. If che ray being calculated crogeg the last preceding ray, then the current from that ray to dropped, However, if the ray continues to cross other rays, then the current from those tays is only dropped if the ray goes belou the minimum radius of a previous ray. If several rays cross che axis, the regidis are apt to be somewhat incorrect, dopending of course, on how gignificant the self-magnetic field 1s. Note that if the selfmagnetic fleld is very ajgnificant, then almost by definition, one is desilnb with a very tritense relativisic bear. This problem is generally better suited to the paraxial tay an, roach, as solved in the flrst cycle, or to a progran Buch as EBQ (by Art Paul of LBL) which handzes the canceliation of gpace charge by self-magnetic ficid drectly, ratiter than by tine ofi-gettlug effects of two large tertas.

In rectanguiar coordinates, the self-magnetic field acsunes symetry about the $y=0(R=0)$ plane. If this is not correct, or if for other reasons it $1 \mathrm{~s}$ destred to turn off the self-mignitic fleld, then an external fleld of strength zeto can be spectfied. In any case, in rectangular contiontes, the gelf-magnecic fleld functions only if there is no exteraal ficld.
A single variable contrals plot:lng. IE this vartable, MI, is set to zero to reject all plotting, then on the first and lasc cycles every tenth point that would have been ploted is printed so thec it may be hand plotted. Mommally at iesst the last cycle is plotted. The first cycle may a's, be plotsed or one may even plot every cycle. All plots may include equipotential plots. aficher separate of overlafd ufth the crajectorj plors. If there is an extersal magnetic field, then this field is also plotted, overlaid on the trafectory plocs. Firally, there are a pair of simple plots; current denatty us, radius and alpha vs. radzuss. (Alpitg $=\tan ^{-1} d R / d z$ ).

\section{v. POISSON EQUATION SOLVER}

\section{A. General Description}

The progran contalns a subroutine which reads in data cards describing the boundary conditions and colculates the coeffictents o: the finte difference equations for each mesh polnt within the problew. Other subroulines are made to proceed to generate the solution to Folsson's equation wiich watch those boundary cordtitlong. The solution is found in terms of a set of points which fum a rosh of idedtical squares. It io recogalzed chat a provision for a rectangular mesh (1.e., different horizontai and vertical spactng) yould fmprove the utility of the progran and $1 \mathrm{~L}$ is planned to incorporate this feature as sopo as posstble. The potential is calculated for each intersecrion of the mesh. Figure 1 shows a small section of the mesh. 


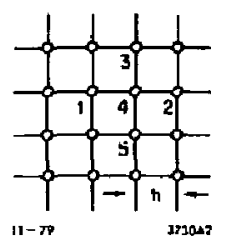

F18. 1. Section of mesh for solution of Polsson's equation.

In rectangular coordinates, the finlte difference form of Polagon's equation is

$$
v_{2}+z_{2}+v_{3}+v_{5}-4 v_{4}=\text { (R.H.) }
$$

where the $V^{\prime}$ s refer to the numbered points in Fig. 1 and R.H. Is the value of the right-hand alde of zolsaon's equation at point 4 when writcen in the form

$$
\nabla^{2} v-(\text { R.B.) }
$$

All equations use the teah space, $h$, as the basic unte, so $h$ does not appear explictely.

For probleas with cylindrical symmetry, the finite difference equation becomes

$$
\mathrm{RV}_{1}+\mathrm{RV}_{2}+(\mathrm{R}+1 / 2) \mathrm{V}_{3}+(\mathrm{R}-1 / 2) \mathrm{V}_{5}-4 \mathrm{RV} \mathrm{V}_{4}=\mathrm{R} \times(\mathrm{R} . \mathrm{H} .)
$$

where $\mathrm{R}$ 1s the digtance in megh units from the axis of sytretry to the point st 4 .
A number of references ${ }^{1-6}$ BIve the dertvation of these equationg and the spectal equations at boundarteg. Three types of boundartes are of Interest. A Dirtchler boundary is that boundary on which the potential is knom. In an electrogtatic problem, this would be an electrode fixed at a given pocential, An ordinary Neumann boundary is one which lies coincident with the mesh and on which the normal derivative of the potential 18 known. In practice, the only value of the normar derivative that is ever known is zoro. Thus, for example, the axis of symetry of a cylindrically cymecric device has the nomal defivative equal to zero and 18 a Neumann boundary.

However, the axis of a cylindrical aymetry problem ta a special case tor which the difference equation is

$$
v_{1}+v_{2}+4 v_{3}-6 v_{4}-(\text { R.R.) }
$$

The difference equation for ordinary Heumann botndartes parallel to either axis can be derived from Eqs. (1), (3) or (4) by aeteing the pocenc1als which straddle the boundary equal to each other. Thus a vercical Neumann soundary in cylindrical coordinates has the form

$2 R v_{(1,2)}+(R+1 / 2) v_{3}+(R-1 / 2) v_{5}-4 R v_{4}-R \times($ R.H. $)($ off-axis)

where the subscript 1 or 2 applies to the point inside the problew.

The third type of boundary to the general Neymann boumdary, 1.e., one which does aot 1 te wlong a mesh 11ue. It 1a always assumed that the normal derivactuc is zero. The program has a proviaton for overridting the Internally computed differece coffeficiente and it is fensible $t$. 
hand calculate difference coefficients for a keneral Neumann boundary. Hovever, In practical applications to electron optes problang, it is almast never necessary to 80 to such extremes.

A spectal case of general Neumann boundary which can be handled eastly is the $45^{\circ}$ Nevrann boundary. A11 that is required is to specify each successive point using the ordinary ite mann condition for roch Coordintes; 1.e., both oELYAR and DELTAz = v. A t1lt $3 \dot{i}$ boundary that 1s aifificlently far from the area of nost interest can frequently be adequately approximated by a combination of nomal and $45^{\circ}$ Nemann botondaries.

\section{B. Iroblem Inpur}

In this section the rules for problem tnptst wll be describes using an actual example and following through the process card by card. The nes user 18 urged to read this section carefully while the old uset or reader trying to gain 30 overall famillaricy with the program may well skip this section. In this section esprecially, no atrimpt will be made to be concise.

Condenged instructions for problem Input are printed at the head of the bource 11ating and are tntended to be up-to-date. A copy of the currene yerston of these ingtructions in printed in Appendix 11 . The reader should follow the instructions which are relevant to this discusslon whlle studying the exrmple.

Except for the TIM.E, boundary input, and ray starting cards, all Input to the program to by mcans of the MAMELIST option by which certain variables are defined at the place in which the program expects them.
The definitions are by means of short defining statements, e.g., RLIM a SO. A given set of these statements alay be placed on one card, but the number of data cards used is unitportant. Each set of taputs is preceded by a designator, e. 8. , GINPUT 1 , which must begin in column 2 , Newer usc colven 1 of any HAMgist card. The MAREIST block fo cloded by an GENo entry.

Preparation for running a problem consfsts of making a suitable scale drawing on graph paper. Figure 2 shows the region between cathode and grid for the SLAC injection gun. Figure 3 is the 1ine-by-1ine 1fatLng of the input data.

\section{Ticle and Potential cards}

(Tit1e) The first card of the data set is the titie card. The contents of this card will appear at various points in the printed output and as the title for the plots.

The second card is sinpur1, starting in colums 2 .

the following reparks about array limita apply speciffcally to the current verston of the progras. It is acigested that tost problems should wse abour 5000 mesh points although there are occasions when wuch smaller, or somevilat larger, numbers of mesh points are useful.

The third card ls the potential card, It contains the bastc Inforwation for selting up the program.

(RIIM) RLIM is the maxtinum stue of the problikn area in the radiol direction. RLIM can be made larger than necessary if it is desired to affect the way plote are scaled.

RLIM Ls a postefve integer; the present linit is 100. 


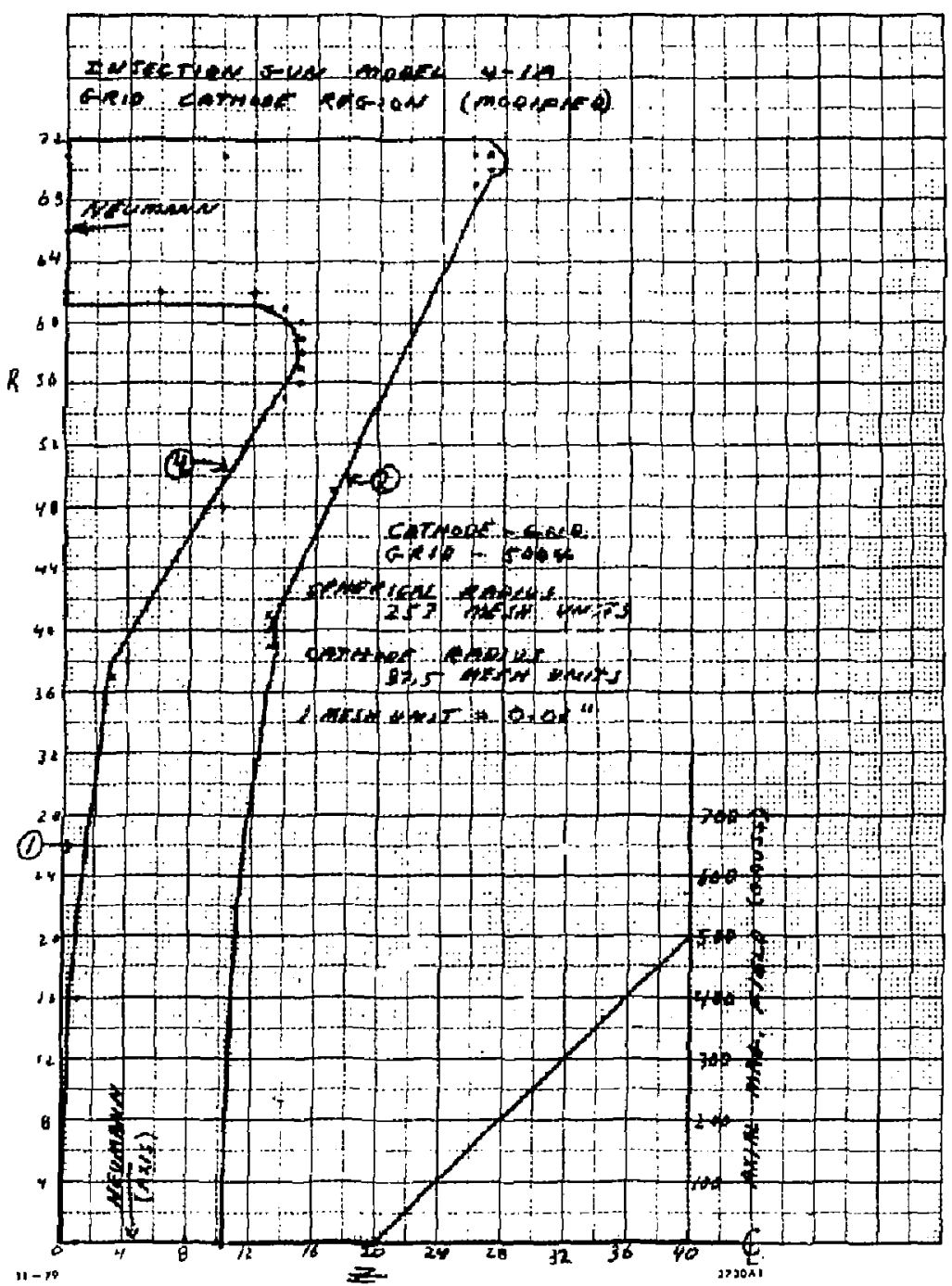

F1g. 2, Example of preparation for a problem. 


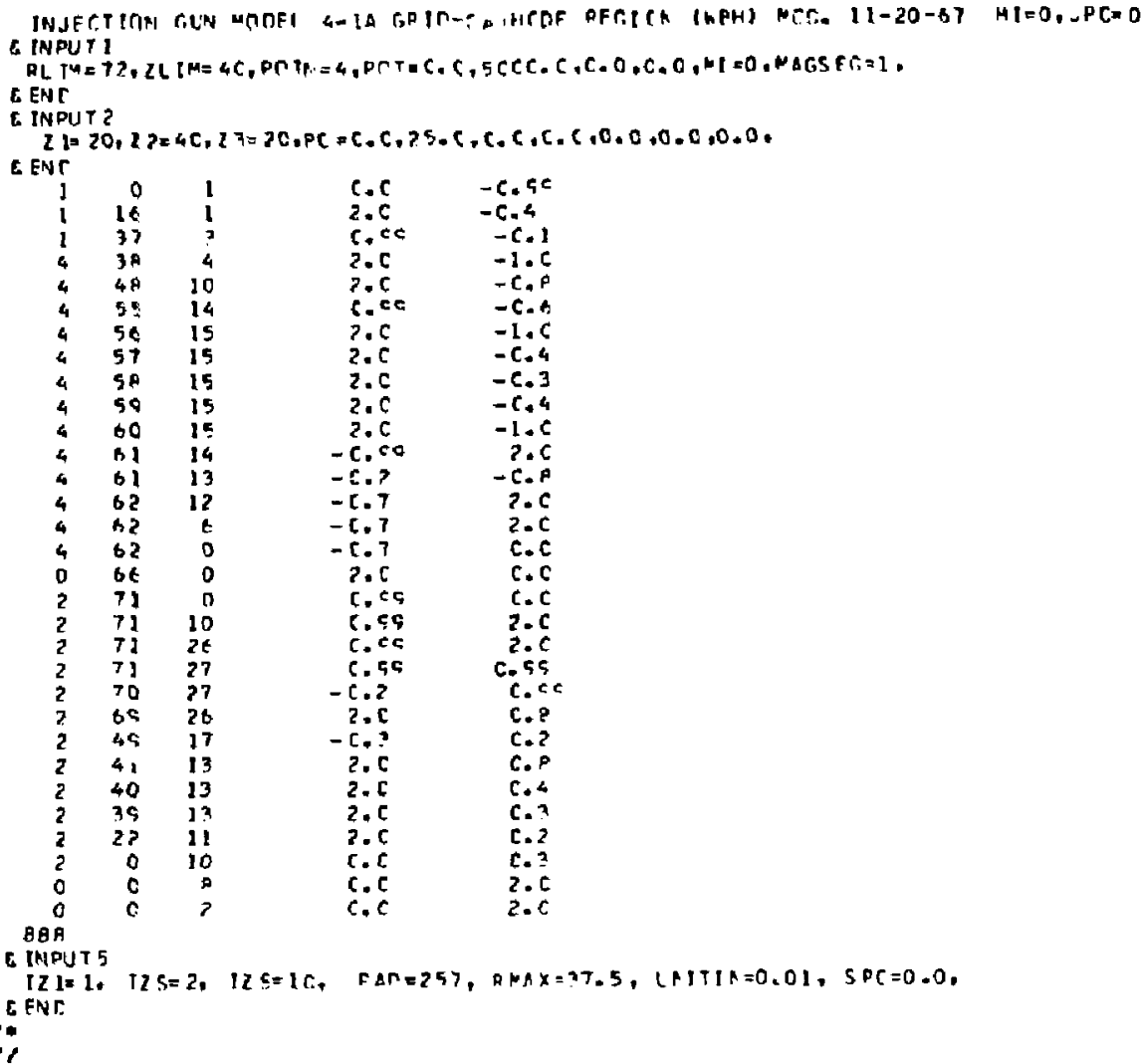

Fig. 3. FORTRAN data prepared for the problem shown in Fig. 2 . 
(ZLIM) ZLIM 18 the maximum size of the problem in the axial direction. A larger than necessary value of ZLIM also affect the vay the plots are scaied. If an attempt is made to create a boundary which exceeds the LImIts RLIM by ZLLM, or goes negative, error messages are printed and the program will not attexpt the solution of Poisson's equation.

ZLIM is a positive Integer; the present lidit 15300 .

Note that although the problem area Is (RLIM +1$) \times(Z C I M+1)$ mesh pilits the actual requirement is for (RLIM +1$) \times($ ZLTH +2$)$. (Ar extra colum is required as a buffer.) The present limit for the cotal axea 1s 9001 mesh points.

(ROTN) POTN $1 \mathrm{~s}$ the number of potentials which are to be read in. There may be reasons to asbign different numbers to parts of surfaces which are at the same potential. Normally the cathode fill be potentlaI nuraber 1 and the anode will be number 2. Usually the grid, if any, w111 be number 3. A focus electrode, even if at cathode potental, should be asaigued a different number to enable the general cathode starting method to be applied. The present lifit for POTN is 101.

poTw is a positive integer for cylindriral symetry.

POW Is a megatfye integer for rectangular symerry.

BECTANGUAR-coorbikAtes. The code to the program to switch to rectangular coordinateg is the sign of POIN. If POTN is negative, the program assumes rectangular symerry and a message: *AkRECTAnGULAR COOROINATES, PHI IS TRANSVERSE appesrs 1mededately after the list of potentials.
rri(I) The rext nubers are the elcments of the Jrray of potentials. They are read in in order from 1 to FoTN. Potentials are carried in double precision which means that up to 15 significant sectaral figures can be used. Exaraples of valid eays of punching 250 volts are as follmws: 250., 250, 2.5E2, 2500E-1, 250.000. Fer NAMElist, the 11s: necd eunsiat only of POT = (string of potentials separated by comnas).

POT(I) is an element of an zxray of floating point numbers.

Negacive poentials are trdicated by a mftem sign, e-gh, -250 . Nebative potentials are percitted but it is preferable to avold using them. Since a constant can alyays be added to all potentials, it is possible to aake the cost negative potential refo. The reason fit avolding negative numbers is that space charge is negative and some diagnosrfes of the output are sjmplified if there are no negative potentials. On the other hand, cetcain problens huve a s; wetry that can be quickly examined if a symetry plane or surface is made to be zero by heving equal + and - potentials. Then negative potentials are certainly desirable.

Sote that if 15 acceptable to fnclude potentials corresponding to potential nubers which are not used by the probleas. One reason for coing this is to get a desired set of equipotential lines on the plotecr autput.

The prograc 15 intended to be run using engineerting units. Thus potentials are in volts and cagnetic fields are in gauss. If a problem does not use tagnetic fields or relativistic energues, there is no rea son not to scale the putentials. The gerveance and ruming time vill

$\mathbf{I} \mid \boldsymbol{k}$

$-\cdots$

?.

- 
not be affected. However, there is also nothing gained by scalins. of coures, when a problem has been tun at one set of potertials, all the gealing rulcs of electron optica may be applied to avold the cost of running the problem again.

(MI) MI La a eate number which determines the selection of plots.

If MI = 0 there are no plota generated. However, every tenth point of the trafectories $1 \mathrm{~s}$ printed for the first and last cycles.

The following tabla, rep-1nted from the condensed Instruetlons, shaus the ava1lable opeiong for MI

Cycle for which electron

crajectorles at

$$
\text { Initial \& Final All Final }
$$

Plote vich equipotentiat 1 ines superimposed on trajector

separate ploto of equipotentsa line?:

No I ulpotentinl lines:
4

23

56

$8 \quad 9$

MII is a positive integer or zero. If MI to aegative it is tnterpreted as a deliberace boundary error for help in debugging boundaries.

TYME = X THE - 5 MAX. PROBLEM RIN TIME (MIN.)

TYEE 19 used to make an internal check of how much time is being uged to guard ngninst running out of compucer time, as spectfied on a JOB card, Just before prinetng and plotting the cesults. The cses special nachine language subroutines to measure actuat use of clu time which in the parameter used to deternine JOB time and charges in a multitask envirorment. Th1s avoids gross variations in time due to the presence of other jobs on the system, The subrowelne aust be suppliad by nor-
Stan?ord uscrs on sult their hardwaxe or, al cernatively, dumby subroutincy may be used to defcar this fexture. The program oniy tests for TyME pnce eact cycic and determince that there is adequate ctme luft to a. the extra ploteing, etc., that is involved in the last cycle, based on the previous cycle Lfme. When tiae appears ifaited, the prograto cuts out Internediate cycles, wikh a note that:

TEERF IS NOT ENOUGH TTHE TO DO THE SPECIFIED NURBER OF CYCLES TYMF. does not need to correspond exactly to the job card. The user may whis to madify the walue according to his expertence, or dtsable TME waldely by setting it such larget than his job card time.

LSTPOT $=1,2$ or 3 causes the program to print a table of the potenmals of all the aesh points. Th1s is the tast iseful diagnogte avariable for the poisson solution and, when studied together wlth the equipotential plot, can siou quite suble errots. The drfaule value: 1.5TPOT $=0$, suppresses this output and thus saves quite a lot of printis: if the same or a very simflar boundary $1 \mathrm{~s}$ run any timos. The chalces for ISTPCiT cause the printing of the fitst (LAPLACE) solution (LSTPOT = 1), Ir the last solurton (ISTPOT * 2), or the solutions frod both the Etrat and linst cycles (LSTPOT $=3$ ).

The paraseter MACSEG controls two of the four pasalbie vays of reading in magnetic flelds. The example case will be explatned in the mitxt paragroph.

\section{Magnetic Field Data}

Electron optics calculations include the effects of any external awerctic fieids that nay be present. The finput nethodg for mageetic fiolds have been greatly revised and will be triated lacer in a spectal 
Eection. If there are excerwal tagnetic flelds then the liput could occur at this point. The paraneter MaGSEg signals that oegments of magnattc farld sata will follow; one segment for maGSEG = 1 , erc. The

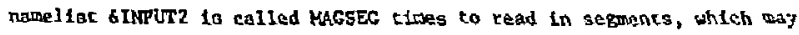
be anythigg from constents to gtxch order polynomial functions of 7 .

Plesse note that this discussion is only included here to explatn the GINPUR2 namallat tats card in Fig. 3. It 16 grossly incomplete an an rxplanation of the magnetic field situation whici will be found in an expanded form in section VI-D.

The example problem contalns a meaningless magnetic field Inserted only an an cxample. The magnertc field plotted on the right-hond side of Fig. Z shows an axisl field gtarting at $z=20$ golag from 0 co 500 gauss in 20 mesh units. A stxth order expression ts uged by the program to fit the fiolda on any segment of the axts. The date on the carct aro ZI and 22 , the liwits of the range of the segment being described; 23 , che oxigin for the segrent being described, and seven coefficterts for che equation:

$$
\operatorname{BZA}(z)=\operatorname{CBC}(n)(z-z 3)^{n-1}
$$$$
\Omega=1 \text { to } 7
$$

21,22 and 23 are tntegers.

$\mathrm{BC}(n)$ is an element of a seven nember regl array.

The parametera 21,22 andz 3 are read in by siople utatements (22 - 100, etc.) and are defaulted to 0, ZLIM and 0, respectively. The coeffictence, BC, ate read in as an array by $B C=$ (string of coeffictente geparated by comas).
A sccond opzion (MACSET $=-1$ ) allows the axigl array to be read in directly. Sel section VI-n for a description of this fentur..

3. Boundary Inpuf

The mals thing for a user of the progtam to lcarn $1 \mathrm{~s}$ the technigue and cenventtens used to input boundary dara. Sin-e the priniry applicetion for the prograd is for electrostatic optics, the temunology used will be appropriate to that elass of problew. Each 11ne on the table in Fig. 3 repreasents ppe datik card for the problem in Fig. 2 . The input

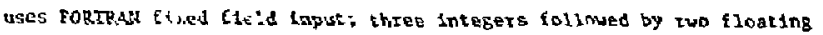
point aughers. Ihis fined fleld format requites one card for cach point.

The infef sature of the input routines 13 the ability to fill in fer eegmente of thi problea that the programser skips. Th1s saves a great deal of iabor sinec a cyptcal problen which uses perhapg 300 boundary points tay be specifited with about so cards. This erchnique will be callec "fitting" in the description for the ability of the projram to fit a curve to ingee specsfied data polats.

Wo sypes of botndaries are used: Dirtchlet boundartes are those on which the potential is known. Newainn boundaries are those on which the normul derivative of the potent 131 is known.

Dirlchlet boundarles are used to represenc meral suriacis. Neutano boundartes represent gaps between surfaces and must be chosen so that the norati romporent of the field is zero since that ts the only value thit is over know in practice. Thus the cathode is a ofrtchlet boundary and the axis is a keumanic boundary in a cyplcal example. Neuann boundartes can meat at a corner. 
For electrostatic problems It has been found satigfactory to reatrict Reumsn boundaries to Ife nlong mesh Ifnes, Dirichlet bowdnrhes may have any shape desired although the mest spacing lintts the resolution of the sanllegt decalls which can be effectively used. slanced Heumann boundaries are posstble however, ar 1 the inpur technlque vill be degcribed later in this section.

A boundary point 1o defined as any mesh point less than one tassh unte frow the boundary of the problem, but always vithin the uoundary. The points on a Neueasn boundary are alunys boundaty pointa. The points on a Dirleblet boundary are never boundary points. This difference, which fo taherent in the formulation and not just a progtam coarention. gives rige to a code to determine which type buundary lo being spectsied. Thus, 1 the diatance from a golnt to a boundary in elther the a or? dircetion ta zero, then that boundary ig defined as a Neuman boundacy.

1. Potential number, integer, corresponds to the surface nubers denoting elewents of the array por $(n)$ descrabed earlier.

2. $R$, Integer, the value of the radial coordinate of the mesh at the boundary golne.

3. 2 , inceger, the value of the axial coordinate of the mesh at the boundary poinf.

4. DELTAR, floating point, the distance frow the megh point to the boundary in the radial ditection. DELTAR is negative if the boundary intertects the radtal line at a point in the winus direction from the mesir point. If the intersection is greater thurs one meeh unie from the boundary point then the intersection 1 is not signiftcant. Any number greater than 1.0 could be usud but typically the discance Is spectfied as 2.0 if it 19 greater than 1.0 .

5. OELTAZ, flont lng polnt, the distance frase the mesh point to the boundary in the $i$ or axial direction. The game rales as fot DELTAR, above, apply.

In the case of a polnt on a Neunann boundary, the potentlal nutber is not signiticant. If the point is giaultaneously within one gegh unit if a Dirichlet boundary, then the potential number is the number for that surface. Otheruise te is custatenty to punch a zero for the potenAal nunber. It is mportant eo reallze that a xcro for the potential nuster is noe the cade nusber for a Newann boundary. Repeating, the cude ior a Numann boundary ts a zero for DELTAR if the boundary is par11:0: to the axls. If the trutidary is a radua plane. then the code 19 T) F.LAL = $D$.

$A$ sesin point camnot simultancously be a boundary poine for two irfechet surfaces at difecent potentials. This is not usually a problep for the progranget. However, ehcte can be situacions when it is necessary to make sobe adjusterent in the problem to avold a sicustion in which, eifhce DEITAR or FELTAE should have two values, or In which DELTAR and JELTAz refar to two different gutfaces in which neither is a Neunang boundary.

Sote that thla also mears that a single point cannot be a cauplete row or a cooplete columin. A colurn nust have a top point and a bateom porint, each of which has a Deltak butween -1.0 and +1.0 . Since one polint camnot have bott of chese, one poinc carrot be a columr. The same 
thing applies to rows. However, the program appliet takts for the colunns oniy.

Boundary polnte must be read in in sequential order. Adjacent points mugt be withln one mesh unit in both $R$ and $z$. If a trindary point is noc within onc aesh unit of the previous point, then a spectat procedura gtarts with L'te purpose of determinting and filling in the dissIng polite or points. This procedure, referred to as "fitting," fito a second degree equation to the three boundary poincs defined by the wo cards referred to above and the immediately next eitd. The equacion is either of the Iorms

$$
\text { R }=A z^{2}+B z+C
$$

SLOPE $\leq 1.0$

$$
z=A^{\prime} R^{2}+B^{\prime} R+C^{\prime} \quad \text { SLOPE }>1.0
$$

depending on whother SLOPE - ABS[ $(22+1) A+B]$ is lesa than or grcater than untty.

Use of fytting domands some cate and understanding on the part of the uacr. It should not be used on curves with more than one curvature or on curves that go through too 1arge an angle, f.e., never more than $45^{\circ}$. It is more useful on long fcralght or slight', cutving segrents.

Three poirte alwaye define a segmenc and if the third point is mitasing or goes around a corner to another segment, the result will be chantic.

The programmer muot realize that each boundary point may actually def tive two paints on the surface at the intersections in the $R$ and $Z$ directions. If both polnts do not 1 le on the same segment, the resules are unpredtctable. This ts a comon difficulty ar instide corners of pirfchlet boundaries. The solution ts to propije a data card for one extca polint in cach direction frow the comer.

In the spectal, but quite comon, case in whieh one of the surfaces at a corner is a Meumann toundary, the frogram eakes account of the corner anblgulty and no extra cards are required.

The busndaxy output listing shom on Fis, 4 will now be examined In detall as an example, Notlce that there are seven columans; POINT, CARD, potential, R. 2, Deltar, deltaz. The POISt colum 1n just the point nuber. The CARD colums contafins a sequential number if such a card exists; otherwige it contains a zero. The remalning columing concain the Itentical dat, as are found on the cards, or the data rasulting from ficting. If is useful to compate Figs. $\gamma, 3$ and 4 as the following discussion progresses.

Card number one: Potential number one, (cathotu), $\mathrm{a}=0,2=1$, (th1s ig the usul stare:ng place), DSLIAR $=0.0$, (code for tieunam boundary l. long the axis), DELTAZ $=-0.99,(-1.0$ could have been used but 1.0 for the DelTA terms can result in some confusion for the fitting routine). The poine $R=0, z=0$ could also have been used but it $1 \mathrm{~s}$ risky to use -0.01 , for example, for DELTAX becusse the curve could try to cross the $\mathrm{Z}$ - 0 11ne before $\mathrm{R}=1$, thus resultiog $1 \mathrm{n}$ a point with two values of DELTAR, 0.0 and scre positive fraction. Thls would also have the result of adding another colum to the problea utthout Increasing the resolution or the actual area, thus resulting in a fractional sluw down. Thus 0.99 n 0.999 is f reguently used for DELTAR or DELTAZ. 


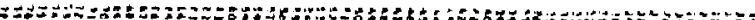

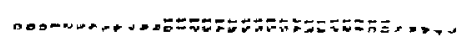

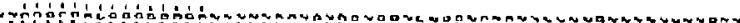

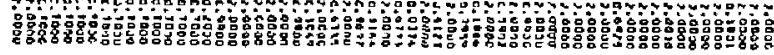
3rong

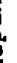

品

(2)

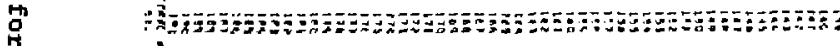

案

7

高

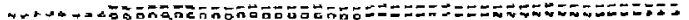

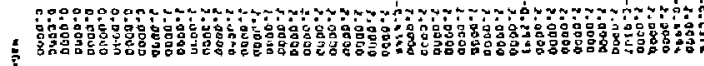

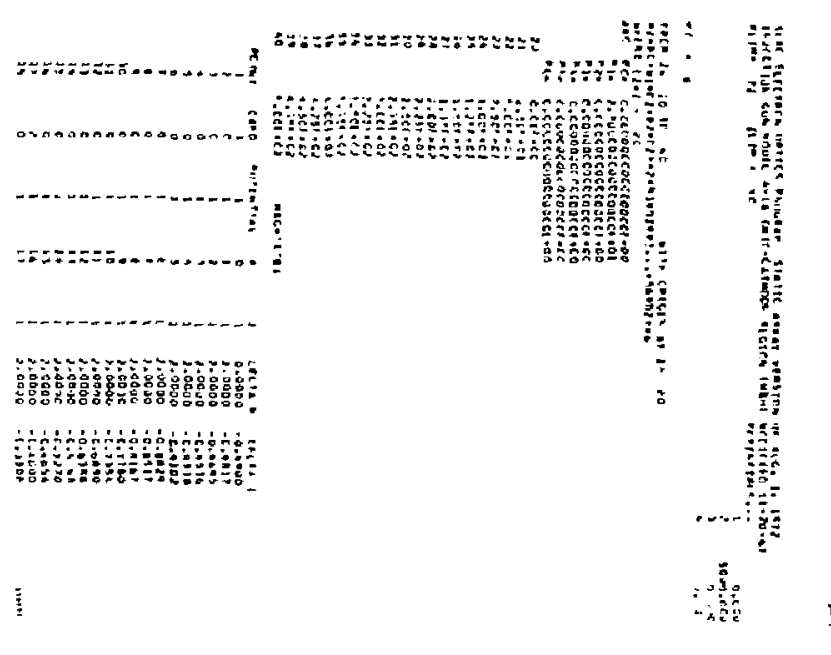

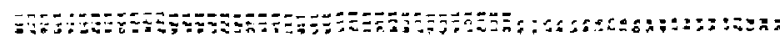

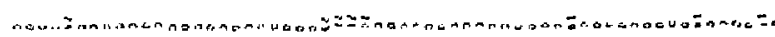

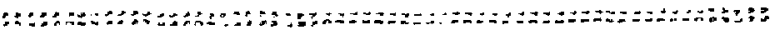

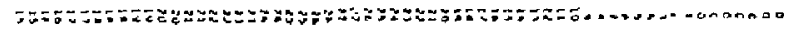

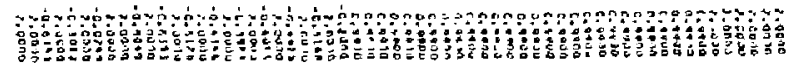

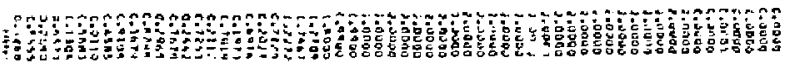

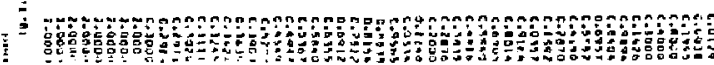


Card number tuo: POT $-1, R=16, z=1$, DELTAR = 2.0, DELTAZ $=0.4$. since $R=1619$ wore than one unit from $R=0$ on card onc, the automate fltting routine will be called. It will read the next ward which gust also be on the cathode surface. The DETTAR $=2.0$ indicates that the boundary does not cross vithin one mesh uni: in the $\mathrm{R}$ direction.

Card number three: POT $=1, R=37,2=3$, DELThR $=0.99$, DELTAX = -0.1. Both DELTAR and DELTAZ refer to the game curve Bepment, ac there to no anbiguity for the flteing. This is the third card for the fitting set for the cathode. The coordinates of the polnte through which the curve will fit are: $(r=0, z=0.01),(r=16.0, z=0.6)$ and $(\mathrm{r}=37.99,2=3.0)$. It w11 use $\mathrm{Eq}_{\mathrm{q}}$. (3) rather than $\mathrm{Eq}_{\mathrm{q}}$ (2) because the absolute value of the slope is greater than one.

Card number four: POT $=4, R=38,2=4$, DELTAR $=2.0$, DELTAZ = -1.0. POT $=4$ 1s used to perwt the focus electrode, whtch th1s surface is, to be distingulshed from tha cathode. The -1.0 for Détas ls Inadvisable sut works on the firse point of the set of three.

Wo fitting atnce $R$ and 2 are 1 mesh unit from thase on card 3.

Card number five: POT $=4, R=48, Z=10$, DELTAR $=20$, DelTAZ $=-0.8$. This card esuses the automate fitelng procedure to be called.

Card number bix: POT $=4, R=55, z=15$, DELTAR $=0.99$, DEJTAZ - -0.6. This to the thitd card of the ser and fits the stralght section of the focus electrode.

The nexe several carde deftne the boundary around the point on the focus electrode. The logic should be obvious by inspection. Fiering is used for the top of the focus electrode,
Card nuber sixteen: POT $=4, \mathrm{R}=62, z=0$, DELTAR $=-\mathrm{t} .7$, DELTAZ * 0,0. This cord 18 inceresting becauee te defines the end of the segtrent to be fit along the top of the focus electrode and the beglunts; of the Neumann segment along $z=0$. Becainse of the Neumann condition (DELTA $=0.4$ ) the progran recognizes the comer condition and $f 159$ to the point $(\tau=61.3, x=0.0\}$.

Card number seventeen: POT $=0, R=65,2=0$, DELTAR $=2.0$,

DFITA2 $=0.0$. This is a case vhere one aight forget to skip a poinc and make $R=63 \ldots$ don' $c$. Also note espectally ine DELThR $=2.0 .$. thorc 1s wo surface in the $R$ direction for more than one thesh wit, even though the point lies right on the Neurann boundary.

Card number elgheeen; POT $=2, R=71, ?=0$, DELTAR $=0.99$, DERTAZ $=0.0$. Potental $z$ is for the anode, which is the fole played by the gun grid in this example. The 0.0 for DELTAZ signifies the vertical Neumann boundary. Note that this card is used to begin the next fitting segment,

Card number tuenty; POT $=2,8-7,2=27$. DEZTAR -0.99 , DELTAZ $=2.0$. This is al "extra" card i.iserted to .uvold the cotaer anblofulty which would ofcur if the fitting program had to use the next card which pointg to two different line segments of the same surface.

Cards number twenty-one and cwenth-two: For $=2, \mathrm{R}=71$ and $\mathrm{R}=70$, $z=27$, DELTAR $=0.99$ and 0.2 , and DELTAZ $=0.99$. These two catds form a short colum to ayold a columin of length one at the corner. Clcatly they do not agcee with the design surface, but the losation is such that the d1screpancy cannot af fect the solution. 
The last three boundary cards define the Nemana segment on the ax1.s. Note that the last card, $P O T=0, R=0, Z=2$, JELTAR $=0.0$, Detraz $=2.0$. specifies the point immediately adjacent to the first point, thus empletely defining the boundacy. The boundary must be comm pleted in this woy without ever repeating a boundary point.

The next card, vith $6 B 8$ io the POT field, or any other potential number greacer than PorN, terminatem the boundary inpue. The next step In the program to to calculaze the difference equations and to perform sorase checks of the boundery data.

\section{Special Boundary Conditions}

A curved or glanted Neumanb boundary, except fot $45^{\circ}$, requites the general teuman conditions. The epecinil case of a $45^{\circ}$ Neurann boundary 1s correcty deacribed in boch beLtAR * 0 and DELTAZ = 0 . General Neurann and other boundary condftions guch as dielectric surfaces, may be put in as calculated values by overuriting the dhfference equations calculated by the program. The norwal ending to the boundary daca is by a pocential number greater thin FoTN. If 999 1s used, the program will comence reading cards containing $R$ and $z$; the coordinates of an existIng boundary point, and $\mathrm{DI}, \mathrm{D2}, \mathrm{D3}$ atd $D 5$; the Eour coefficlents of the difference equation ior the point $(R, z)$.

$R$ and $Z$ are fategers locating an existing boundary point. Di, D2, D3 and DS are the reul postive coefficients of the dtfference equation at $(R, Z)$.

Any aumber of such cards way be used in any sequence. An $R$ value grearer than flily terminates this Input,
Dielectrie materials ady be Finulated by special butndary values at the dielectir stirface. The rules for this are sumarized tn the condensed instrucetons and wll be explained In Saction VI.I.

5. Boundary Diagnosties

If the inpur data are aeceptable, the next message printed on the Putput is: SPECTRAL RiDIUS $=0.995$. The spectral radius io a constant used sy the progran for the znvergence of the solution of Poisson's equation.

\section{BOLNDARY ERROR IN COIUMN $\mathrm{XX}$}

If chis messuge apperiss sumethere in the middle of the listing of boundary data, it is a signal that the boundary data have exceeded the 1 imles of the probiem, $O \leq R \leq R L l y$ and $0 \leq Z \leq Z L I M$, or that the boundiry data have exceeded the saaximum number altoved whych is 901 . Thus, this message appears if the boundary enlculation goes into a loop. Loops usual ly result from an error in bounday feting an might bc caused by orfeting one of the three points ot a ifie segoent. sortatly the prokrais will atcempt to plet up the boundary computartion snd carplets the listing. Hovevet, the problet will not attempt to run and there my be other encors caused by the progran in trylng to interpret the sesc of the Loundary.

BOLNDARI ERROR IN COLLTA $x x$

If this message appears at the ond of the boundary $11 \times t$ ing if indientes that the program checks have found an arror. The program checks ate based ot the requirencent that each column must have a top and a botcora. Slnce there can be sore than one segment co a colurs, the requirerent cranslates fo mean that thete wust be an even number of ends for 
ench value of $z$. An end is defined by a DELTAR value between +1 and -1 , Thus the programer need only deternine why there are not an even number of such points for the Indicated colvan.

Note that there are similar shecks which could be rade but aren' $t$. Each rov must have two ends also, but no such check is included. Also obviously a bottom end must have DELTAR between 0.0 and $-1.0,1, e .$, not Breater than 0.0 . This and ginllar boundary existakes are left to the programer's care to prevent or correct.

\section{BOUNDARY ERROR OR MII NEGATTVE}

If this message appears at the end of the boundary Iisting the programer must check for messages of the previous two types. If there art none, and he has set MI regative, thep the boundary data have passed the progeram checks. It 18 worthuhtle for the programet to laok at all the output carefully to cateh other boundary errors. The programet should also always endeavor to get at least onc plot teicluing equipotential Ifines of any gev geopetry. Unsuspectud crrots frequeptly become glarIngly obvious on examiation of a plat. The optiongl printout of the cable of potentials caused by LSTPOr $>1$ should always be used for a vew or revised boundary configuration.

\section{c. Polsson' e Equation}

After reading the boundary inpur, and before reading the starting conditions, the program makes the first golution of Potsson's equation (acturily Laplace's equation at this polat since there is no space charge, hence r1ght-hand side (R.H.) equals zera). The description of the taput data for the example will bo interrupted here for a brief degcription of the mechanics of the solution of Polsson's equation.
The prograr solves the complete set of equacions for one colum at a time. Mathematically, a matrix for a column cunstscs of a tridiagonal matrix which pust be solved (Inverted) to find values for the potentials of each of the points $1 n$ one colum. To do this, the adfacent columens are assumed to contain "knom" yalues, and the ead points are slso "knouns." That 1s, elther the value is known or, in the case of a Neumann boundary, the adgacent point 15 assumed to be the sane as the poinc being solved since che derfvative is zaro. The relaxaction method is known as the "semi-tcerative Chebyshev" method and is described by Varga. 4

Each colum consists of two or more points, vith upper and lower end points being boundary polnts for which $-1.0 \leq$ DElTAR $\leq 1.0$, Thus each colum has at the top and bottow a condition, either Neunarin or ptrictlet, that perates the progtam to urite a set of nequntions in $n$ unknows for that column. $A$ zolumn of the problem area defined simply by the value of $z$, Eay have more than one segment which wust each meet the ahove definition of a "colurn." Each guch column wust have 1 ts proper ends. In the exnmple problet., there are two coltrors for each value of $z$ up to and Including $z=14$.

when a colury is solved, the adjacent colums are considired fixed. Altemate columers are solved so that on two passes f 1 ts.t the odd numbered fol tors and then the even nimbered columas are solved. Afrer so iterations, or less if the arror criterion is satiafled, the colculntion is stopped and a messoge 1s printed:

$$
x=51, \quad \quad E R R=x \cdot X X E-x x
$$


Th1s 1s the signal that after 50 1terationg (the counter 1a already set to 51) the maxioum orrot to expected to be gRF 10 volts. The actual test is on the largeat single change in the x-erarion, but the value printed takes into consideration the dimedstons of the problem. The convargence cxiterion can be adjusted by using the patarmeter ERROR (sec vI.A.(4)). It 16 automatically tightered by a factor of ten for the finsl cycle. Certain problews using large areas of jeuman boundartes, are subject to slow convergence so that the results may be incartect. Th1s can be remedied elther by lterating for more cycles or by glving the program a better otorting distriburion. Thede techniques will be described in a subsequent section. Genersily the iteration process is quite satisfactory and after 50 teerations the ficld is sufficienty deterwined to start ray tracing leading to the inclusion of space charge.

After finishing the first cycle of Poisson's equation, a potential ing, or poTuIst, is princed giving the potential (normalized to $100 \%$ of the maximum potentigl) for every pofnt in tha rLIM by ZLM space. Since thla includes backgtound points (points behind the surfaces) ope can usually trace the outline of the problet. The background points have the initial values and should not be confused with the internal points. The POTLIST is an exceptionally effecrive diagnostic device and should always be studfed for peculiatities. An error in bourdary data may, for example, leave a stsange zero in the aiddle of the high potential part of a device, thereby greatly distorting the fields. When used together with the equipotentiol plote, it is passtble to pinpoint exrors in a fev afnutes. The FOTLIST is suppregsed by the defrult value of LSTPOT $=0$.
VI, STAFTING CONDITIONS

Afcer the first ealculation of Poiszon's equation, the progran reads the stating condiclous. The fornat io NAFELIST consisting of defining equations in which the vartable is natred followed by an "equal" tign and the value. Only those variabies that nect to be altered frow the default conditions need to be spectflea. The sanple problem dewon5trates how iftcle data neads to be speciffed in many cagcs. Using the staple problem, the following remarks vill illustrate the technique. Is the rest of this section, a brlef description wlll be given for each of the options currently Included in the programs. Since other options can always be added, the user thest refer to the coments ip the progran for the up-to-date implempntation.

The sample problem is coded as a spherical diade or Pleree gun. The card with sINPt's signals that the namelist entries folles. The mitry START = 'GPHERE' Ulrecls that the spherical dtode conditions will be used. The catties $R A D=257$ and $R M A X=37.5$ give the spherical rudius and cactode codtus respectively. UNItis $=0.01$ speciftes that the scale of the problem 1 s 0.01 inches/mesh unit. Azl problem scaling is $1 \pi$ GKSA units so chat UNITIN is Immediately converted to UNIT in jeters. Alter reading these ltems che prograll prints a cable of all the starcing parameters.

The starting conditlong are described in the follaulng sections according to function as tallous: 
A. Untversal; apply to wore than one case.

B. Equipotential lines; controls equipotential plotting,

C. Plotting; plot controls,

D. Magnetic flelds; Input and calculation parameters for magnetic flelds,

E. General eathode; parameters controlling the geueral cathode option,

F. Spherical cathode; parameters epectifolly applicable to START - 'SPHERE'.

c. Card starting; paramecers controlisus the une of epectfied startiog conditions.

H. Laplace thareing; parameters controlling the use of the progran fur applicationg other than ray cracing.

A. Universal Parametera

For each starting paraneters, there is a default value which will bo the value used if it is not changed by the input. In the following diacugsions, the extriet will be given as doscribed by the program commeaca with the format:

$$
\text { TNSTRUGTION DEFAULT, MAX COMMENT }
$$

Th1e will be followed by a discusston of the use of the parameter.

When a second number, separated by a comma, appears for the default valuc, te refers to the maximum allowed value, ugwally determined by array linitg.

$$
\text { PERVO = X.XX PERVO } 0
$$

\section{ZERO USES LAPUACE/2}

PERvo to the Inltial value of the perveance of the bear for efther the START - 'SPHERE' or START $\times$ 'GENERAL' wethods. Petveance 28 defined as the constant $R$ in the expression

$$
I=\pi v^{3 / 2} \times 10^{-6}
$$

where $\mathrm{K}$ is expressed tn micropervs go that, for example, a aficroperveance 1.0 device operating at $10^{4}$ volts would have a current of 1.0 anpere, The entry $X . x x$ indicates that a decimal number is the expected value. When a siagle $X$ is uged, it inplies that an integer is expected. The $X^{\prime} s$ do not Indicate the laput format: the rumber of significant figures is not restr :-cred except by the computer hardware, and by the logic of tho prograst.

PERVO normally controle only tme perveance of the firat cyeta. Hovever, it may be "held" for any desired numbet of cycles by using HOLD $=x$. The process by which the program determines perveance is to average the perveance ealculated for a given cycle with the perveance actually used in the precoding cycle. The neu avergged value is then used to deteraine the currenk per ray. The averagteg process has proven very effective in quickly arriving at a scable value. It hato been so euccessful that it is frequently betfer to stait with the averaging wethod than with a value "known" to be "cotrect" from experiment ar from prior calculations. The default value PERVo - 0 is a code instruction which takes the value of perveance calculated for the LAPLACE solurion and simply divides it by two to arrive at the perveance for the first 
cycle. The new uset of the progran is adviaed to use the default value until gpecific oxperiences lead him to try something else.

(2) HOLD $=x$ HOLD $=1$ PERVO 'HOLDS' FOR HOLD ITERATIONS

HOLD - 2 or more causes the input value of Parvo to remoln unchanged by the averaging process for wow fteracions. Thert arc some problems, parcicularly with very non-ualfora cathade hasdirg, where using Hold helpo eatablish the necessary space charge environment for the process to stabllixe. A wore fxequent application is to staulate ctisaton limlted conditions by runsing the entire problem with a fixed reduced perveance. Then, of course, nol.D must be at least as large as NS.

(3) $\mathrm{PE}=\mathrm{X} . \mathrm{X} \quad \mathrm{PE}=\mathbf{2 . 0}$ INITIAI ENERGY AT CATHODE (EV)

PE to the incremental energy that is added to every trojectory to account for the combined effece of wotk function potential and therral cnergy. Like PERva and hOLD, $\mathrm{PE}$ is only used far gtarting with ore of the Chitd"a Law routines for calculating the initial condittons. It Is normally not necesaary to have any inttlal PE, bue some small changes may be obrerved by varying IC. In a few Iow emtssion devtces, it bas been found cosential to have some Initial energy to awoid fnatabilftics near the cathode.

(4) ERROR $=X . X$ ERROR $=1.0$ MILTIPLIES ERROR TEST

ERROR - 2.0 doubles the built in error test by which the progran determines that an adequate solution of Poisson's equation thas been resched. If the problen is slow to converge, particularly if there are large arcas of Neumann boundary, it way be necessary to reduce the allowed errot, e.g., ERROR. 0.1 , to get the program to converge at all. slow convergence is Indicated if each cycle only tterates three rimes, prints $N=3$, ERR $=$ nnn, and calculater the trafectorics, On the last cycle, the error cegr 19 reduced by of factor of 10 from shatever level was set by the user. Sone hincs abaut convergence problews uill be found in a later section.

(5) UNIT $=X-$ WOX UNIT $=0.001 \quad$ METERS/MESH UNIT

(6) UNITIN $=$ X.XOX (SEE UNIT) INCHES/MESH UNIT

The default seale value for the program 1a 0.001 meters/mesh unte.

If a value is given for LNITIN (Anches/mesh unlt) this value will be Iratediately converted to meters. Exiept for problens using wagnetle fields, the optics of an electron ght doch not depend on the scale factor. All the scandard rules oi scaling in electron optics can be used once a problem has been solved.

(7) MARRAY $=\mathrm{XX}$ MAXRAY $=27,51 \quad$ MUXIHUM NUMBER 0 RAYS

IF MAXRAY IS NEGATTVE, THE NUMAER OF RAYS-ABS(MAXRAYS)

Maxuly determines the maximum number of electron crajectortes that can be calculated. The arfays for trajectories have a 1 fmit of 51 . The nurber of rays used by START = 'GENERAL' or START . 'SPHERE' 13 determfred by a program algorithm unless the value read fin is negative. Within the limit MAtRaY, the progran tries to nake an integral nimbar of rays per mesh unit at the cathode.
(8) STEP $=0, x$
STEP $=0.4$
MESH UNCTS/STEP

STEP is the iteration step bength for ray tracting. It wusc be lesa than 1.0 for the prograg to properly account for space charge, calculate 
magnetic flelds, etc., when crossing a mesh 1ine. The equations of motion are time dependent, thus the program uses STEP to calculate step tiae from the veloctity at the starc of the step. Stace the electron can accelerate during a step, It may actually go slightly farther than stap. The defaule value is abour the largest that should be used. If wagnetic f1elda are present, STEP should usually be reduced at least a factor of two. On the last cycle, STEP is automatically reduced by a factor of two. Shortening the step means more time will be required for a problem. As a rule of thumb, the program spends roughly half of the time with Poisson's equation and half with che ray tracing. Thus reducins STEP by a factor of two could increase cost by about $25 \pi$ the fizst time but may nearly double it thi safter. The Rurge-Kut ta wethod 1s used to solve the differentiol equations of motion. Because of the necessity to take snall aceps anyway, and because of the tiae needed, the program does not use noy of the "predictor-corrector" techniques of verffying step length. Experience has shown that exrors due to STEP being too large, espectally If magnetic flelds are included, becote glaringly obvious when the plots are examined. The mosr frequent effect is for a trajectory ca get too clase to the axis, vialate conservation of angular mowentum in one scep. and fly out of the problet area with beta $>1.0$, where beta $=v / c$. An error message ro this effect is prinred then a ray ends with beta $>1.0$. At the very Least, this 15 a signal to reduce STEP in subsequent zuns.
(9) NS $=\mathrm{X}$
NS $=7$
NUMBER OF ITERATIONS

*S deftues the number of program cycles to be made. In the program, NL. is usel as the runing variable to record the number of cycles left to be run. Initially NL $=$ NS, The default value is usunlly acceptable unless the program 1s having trouble converging on the perveance. For the spectal case of no space charge, it 1 a advisable to still use NS 2 to gatr. the Insight afforded by the reduction of ERROA and STEP on the final cycle. For START - 'LATLACE'. NS is the nuber of tioes that Loplace's equation vill be cycled.

(10) SPC $=0 . \mathrm{XX} \quad$ SPC $=0.5$

ESTIMATED SPACE CHARGE

SPC SIMULATES Paghixial APPROXIMATION ON FIRSt CYCLE. SPC IS THE FRACTION OF THE RADLAL FORCE USED. SPC $=1$ FOR FHL EFFECT, SPC $=0$ FOR NO EFFECT.

SPC determines the fraction of the ordinary radlal electrostatic force that will be applied to the rays on the first cycle. In a device In which space charge forcet play a serong pars in the focusing, the electroktacic fields usually have a strong rodial rescoriug effect. If not opposed by space charge on the first cycle, these forces way cause the rays to strongly ouer focus leading to a poor infial diatribution of the space charge. The full contribution, SFC = 1.0, adds a tere to the radial equation of wotlon simulating all the current, of all the rays calculited, to lie in a conductor on the axis. Thus it ls assumed thac the rays are calculated in sequence starting with the ray nearest to the axis. In the case of an electron gum celculation scatting at the tathode, a better choice $t_{B} \mathrm{SPC}=0.5$ which attenuates the force by 0.5 . Near the cathode, ch1s corresponds to a current starting from the cathode and extending lnfinjtely in only one ditection. Further from the cathode, SPC $=0.5$ is a less logical choice, but the beas is less sensictve to 
radial forces as it goins in energy. Empirically, it has been found that SFC - 0.5 is a good choice for gun problers lnvolving ctarting fron the cathode. For other types of problems, the user should bn aware of the fact that SPC exists and can be changed. In rectangular coordinates, SPC gimulates an Infinite sheet of current on the axis. If the problem does not Involve roflection about the $R=0$ plane, then there is a transverse force (which loes not depend on distance frow the $x-a x i s$ ) which should be turned off by. SPC $=0,0$. Since SPC only affects the first cyclo, the program vill ugally forgive any misuse of 1c. SPC can be useful tn arriving at a satisfactory solution of one usually difficult problew. that of a long thin beam with magnetic fleids providing the focusing. This can be diffycult problem to get to stabilize hecause of the poor aspect ratio which frequently finds a large fraction of the bear within one or two mesh units of the axis. However, it is usualify well represented by the par ixial approximation so that a single cycle run, $4 S$ 1 , with SPC a 1, will frequently sesult in a good solution. in this case one must be pure that STEP is srall enough and that an adequate solution of Laplace's equation was atcained, since ERROR had no elfect on the ffrut cycle.

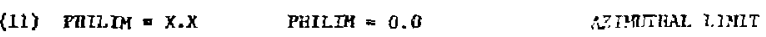 \\ PHILIY .NE. G ENDS TRAJECTORY AT PHT .GT. PHILIM}

For spectal applicartons, it is possible to establish im orbit that would continue unt1l the program is stopped. An example 15 an electron orblting in a uniform nagnertc fieid. PHILIM has the undts of PHI; radians fn cylindrical coordinates and mesh units in rectingular coordipaten.
(12) SAVE $=1$
SAVE $=0$
SAVE - I SAVES BOURDARLES

TO USE SAVE $=1$, OMIT BOUNDARY CARDS FROM NEXT PROBLEM

SAVE $=1$ is a sigral to the progras to expect a second problem run impediately after the first problea, and that the second problea wlll use the same boundary cendftens. It is always possible to run tandem problems al though, at most computer facilities, there is no portlauler incenfive to do so. Programs are usually rum from load godules, or frod a thrary of compiled subroutines to be linked with very little expense, and scparate probleas can be rum Inwisendently without the risk that a fallure in the first problum will affect or knock out the second one. Hortever, in the case whete successive problems use the same boundary conditions, considerable sayings in elfore ans conputer time crn result by saving the bousdarieg, whlch also saves the arrays of potentals and space charge.

The SAVE = 1 parameter is fut in the utarting fonditions of the first problen, nui the second one unless there ls sill to ie a third prablea. The dete deck fas the second proslem ararts 1madiately af ter the lost data card of the sirst deck with no gor or /th control cards. The second deck is cumplece in every respect including title. potential, mignetic ficlds, eis.. except that the brundary cards and the accompanyIng large potential nuber card are nutcted. The potentals can be cnanged between runs: If the largest potential is changed, the program will seake all potentials in the potentlal nop proportlonitely. OcharHae the prograse will start out fust as if a cold start was being made, exeate that the old solution, including the last space charge array. Is used is 3 "preload." 
One example of the use of SAVE 1 to to be able to trace rays with small changes of elther voltage or magnetic fields. Another use to in the case in thich the Lapiace scintion $15 \mathrm{~d}$ fffirult to achicve because of extended lengths of Meumann boundaries. In this case, it may help to run the first part with START = 'LAPLACE' (see section V1-H) and SAVE $=1$ and then do the ray trating in the following problem. This saveg the time and expense of ray tracing in an incorrect potential distribution. This procedure is nor notnally required since the usual procedure allows the program to imptove the soivtion on successive iterations as the space charge 19 entered.

The special case of a pair of electrodes separated by a long length of Netman boundary parallel to the $z$-axis causes spectal problens with convergence that wight respund to the approach using START = 'LAPLACE'. An alternative approach, which is easier, is to introduce a feu boundary points alorg the top or botton Neunann boudartes, with potentiaI numbers. If the carresponding voltages, which must be entered in the potential list, represent apptoximate values for the potentials in the final solution at that point, then the starting load to the program will be mueh tetter etan the norwal starting load. Uswally the starting load is of very little stgnificance, but in this special case te can be cruclal. The special boundary points are exactly like the usual Neumann polnts. except thar the potential number is given and refers to an appropriate element of the POT array. After the preload, the Neutann points relax as usual and the potentials change accordingly.
(13) SAVE $=2$

SAVE $=0$

USES FINAI DATA

FROY PREVIOUS RISY TO START THIS RIR, USE ONLY GHFN START - 'CARDS'.

Save = 2 allous consecut lve sung to use the final conditions of a preceding problen as the inftial conditions of the succeeding probles. Neccssary scaling and positioning adjustatents are oade as described under START = 'CARDS', below. The SAVE - 2 goes to INPUTS of the second run.

Note that the dual use of SAVE $=1$ and SAVE -2 in one problea $t s$ not perrolted, but that SAVE - 1 on the first problem followed by SAVE - 2 in the second is both permitted and quite comon. It slaulates the repeated use of a drift tube, pertodic focusing section, etc.

MASS IS THE MASS TO CHATCE RATIO, 1.0 FOR PHOTOHS

USE MASS > D FOR RAYS HITHDLT INERTLA: CAN BE USED FOR MAGNETIC

R.LX EINES OR ELFCTRIC FIELD LINES,

yass is used to signal the progran that particles other than eleccrons are to be followed. The unlte are in 1836 electron masses, so that a procon vould the 1.0 and I doubly fonlzed celtivan ton would be $3 / 2=1.5$, for exi.ple. The chlld"s Law ruutines for starting still functik. Sote that ethe fatrinstc charge bullt into the program te negatre. Ion problems ate nerally run as if charga ta negative, although negative currents (positive sharges) are peralted for START = 'CAROS'.

(15) $\mathrm{A}=\mathrm{X}$ AV $=0$ SPACE CHARGE AVERAGED LAST AV CYCLES

(16) AVR = X.X AVR -1.0 GEIGIT OF PREVIOUS CXCLE FOR AV

MV and AVR are companten parameters to help spopove stabllity by averagting the contrfbution of space charge over successive cyeles. It 
should not be confused with the different prosess of cmisston averaging to deternine perveance. In fact, to kep the exission everaging and space charge averaging from affecting eath other, it is suggested that AV be small enough so that the emission averaging is essentially complect before space charge averaging starts. Noto that $A V$ is for the last aV cycles, e.8., If $\mathrm{kS}-7$ and $N V=3$, then only cycles 5,6 and 7 are averaged. Horever, this way have a very small eflect gince the trajectory calculations of cycle 5 are not affected and the spuce sharge decerwined by the cycle 7 is never used (stice there is wo cycle B), Thus the effect of averaging is only observed for AV-1 cycles. AVR determines the veight of the prevlous cycle such that wth AVR = 1.0 , the space charge from the prevtous cycle is veighted equally with the present cycic. AVT can have any value, $0<A$ An $<-$.

Experfence with averaging has show the effect to be less dramatic than one ofght antictpace. A poorly designed gun, with stoong splierical abertations and resuling crossovers, is likely to be unstable and convarge poorly even with averaging. Also, applicatton of averaging to relativistic high intensity beams does not do much ta solue she trherens difficulty caused by the fact that the seff-mignetic ilo in forces nearly cancel the space charge forces. Wht the two-cycje forme of the program (1.e., fipace charge from the previous cyete and se!f-ficlds fram the present cycle) the program has difficulty converging on 'ong beam transport problems. The solution to this stuation is frequenty to use the f1rst rycle otily with the paraxial approxinacton and SPC $=1.0$ as described In VI, A. 10 above.
(17) BETD $=\mathrm{X} . \mathrm{X} \quad$ BENE $=0.0 \quad$ MCNETIC MENDING IIELD I: CAESS IN TH: DIfFCtTON NORHAL TO THE R-Z PLWE FOR THE NXLALLY SMMETRIC PROALES. YIEAT MTST BE UNIFORY. TIE EEFECTS OF SELFWONETIC FTELD ARE I,OST AND SPACE CHARGE IS STTLL AXLALLY SYMOETRIC SO THAT IF BEAM IS DEFLECTED, ChARGE DESTR IBUTION IS PROBABLY INCORRECT. AT ATIML FIELD MST BE INCLLDED IN THE INPUT, ENEN IF IT IS ZERO, E.G., BCथ IN INPLT2.

This feature is most useful for problens with litele or no space charge. Varlous typers of photo tubes have floht tolerance for eransverse magnetic fleld efferts. Fesidul transverse flelds, earth's ileld, etc.. can be calculated. Note that a eylis.tazil beas in a rectangulax coordinate geofnetry. Ins!uding cransverse fifeld and space charge, can be siawlaced as described below in Section VI.G.4.

\section{(18) MAGLI $=X . X$ MALYT:T $=1.0$ MTLTIPLIFS HZA ARRAY}

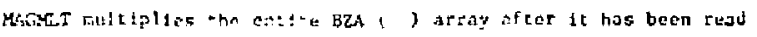

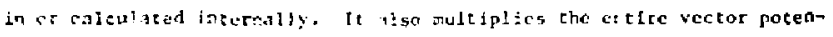
tial array ff that option is used. It can be thoupt: of as a ktub on all the magret le fiold girnrartag pourr supplies.

(19) $T P E P=K 1, K 2, \ldots ., \quad$ IPBP $=0 \quad$ tP TO SIX RAY NLMBFRS ERR POLZT-EY-EOTET PFINTULT:

r, RHO, 2ETA, RDCT. ZDOA, TONT, PHT, BR, gZ, STEP, HEH

In special sictations, especially whei progran behavior ts not is apected, it is us inl to be able to print oup every fierat twe step. Tris feature operaecs on the last program cyele. Thus if for exupple a bug is stopping the prostam in the first cycle. It is necessing to set 
NS - 1 and set IPBP = (the numbet of the trajectory at question). Nore that it 18 pogsible to generate a great deal of paper this way. In sote cases, one might rather have other $f$ tems printed than those in the above

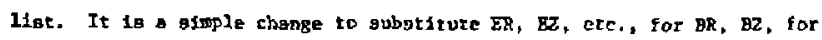
example.

\section{(20) ZEND $=x . x \quad$ ZEFD $=1000.0$ EXACT END OF TRAJECTORT}

CAUTION: IF 2END IS HOT THE RICHT-HAND BOUNDARY, THE SPACE CFARGE DI: RIBUTION MAY BE INCORRECT.

Normally s. Crafectory to calculaced untll the program can no langer deternine the electric flelds. Thus the irafectories ubually go up to one-half wesh unit beyand the boundarted. In speefal stcuations, guch as high-resolution photo tubes, this makes exace interpretation of the results difficult. Setting ZEND to a opecific value calses the program to back up to this value when a trajectory passes chrougn this value of zeta.

(21) VION $=x . X \quad$ VION $=-1 \mathrm{X} \quad$ LOWEST POTENTLLL PERMITTED USE VIOH TO SIIULATE SPACE CHAF,gE MEUTRAL.17ATION.

Space charge depresaton can be reduced in a real device by positive tong in an electron device or by electron clouds in an ion bram. Since the program normally ru is with negative charges, the above cases both result tia negative space charge depression. If it is destred to 1 latt the depresetion, VION can be set to the lowest depresscd potential that is degired. The default value is latended tu be low enough so that it will niver disturb a practical problem.
B. Equtpotentlal Flots

Under the heading:

INPUT FOR EQUIPOTENTIAL PLOTS,

the instructions 11 st the parameters which way to used to contral the output of the equipotential lines.

If the plot control parameter $\mathrm{HI}$, on the potential card, has been set to MI 5 , then the subroutines uhich dray equipotene tal lines will be called at the appropriate times. If the entire probles is at one potential, it is usually better not to call for equipotenilal ploca.

The method used in the progran to ind the equpasential lines consists of firsc flading a starting point for the potential to be folloued. and then following a line of constant potentiol f top that poias. This Jaes not gurantee that cvery point of that potent fil ulll necessarily be found and plorted. If POT $(2)+0$ the progras always draws the equiporenrial line for $v=b+$ POT (2) where $b=0.05,0.15,0.25,0.35, \cdots$ 0.95. Also if Por $(3) \neq 0$, the progran draws lines for $v=b$. Pot (3) where $b=0.2,0.4,0.6,0.3,1$.n worestly the lines are started at the pofris $2 n$ the axls which are at chat potentiat. The expectat ton is that POT (2) will be ised for the anode and port (3) wlll the used for tive grid, if any. If, for exanple, one 1 s designing a grtdded gun to the operated at $v_{G}=0.01 \mathrm{~V}_{A}$, then, by firgt designtag the gun ats a diode, ani Flotting Pot (3) at 0.01 PCr (2), one pets the ldeal conteut for the grid to be elertically invisible.

(1) EQUIFR $=X . X \quad$ EQUIPR $=0.0$ R-INTERSECT. FOR EQUT. LINES EQUIPR is the rodtus of the line along bitch the progran buts for the potentials which are to be ploted. It soretines happoas, particularly 
$-47^{-}$

In rectnngular coordinates, that the equipotential 1 ines do not intersert the 2-nxis, $(R=0$ 11ne), EQUIPR Lets the programer ind1eate along wheh harizontal line the program should look for the starting points.

(2) $\mathrm{LM}=\mathrm{xX}$ :

$$
I M=303
$$

LENGTI OF EQUIPDTENTIALS

LM 18 the srrity Iimit for the points to be plotred for any one equlpotential. If a line nimply atops in aldstream, it muy be desired to Increase 24. Arrays bX and BY mugt be as large as LM.

(3) EQLA $=0$ to 20 EQ̨LK $=1$

*No. OF CORRECTIONS

EQLN controls the Iteracive corrections made as each point is found along the equipotential ine. These corrections prevent the lines Iron deviating frow sharply curving equipotential 11nes. The defaut value, 3QLN - 1, is usun11y ndequate.

(4) $\operatorname{EQ̨ST} \cdot x$

EQST $=2$

\#STEPS REK YESH LNIT

EQST gives the deralty of polnts for the couiputential plots. Thi maximum length of a Iine is glven by the racio IAH/BQST. If EQST is too small (steps too long), fine detall may be smoothed over.

\section{*AJ.SO APPLIED TO GENERAL. CATHODE}

Th1s footnote warns that the stareing surface for the GESERAL. CATHODg ron:cine is generated fust like an equipotencial (bitt is not plucted), and thus the parameters EQLN and EQST may detecuine the accuracy of the starting surface. It is primarily for this application thiat EQLN and EQST are made varfabli parameters.
$-48-$

(5) $121-x, 122 \cdot x$, I2S $=x \quad 121=0,122=-1$, 175 $=10$ EXTRA EQUTPUTENT Lals at the INDICATED Valives of $z$.

[21 and 172 3re the end points of a 310 segrent, at EQUIPR, along which sone exro cquipotentia: lines will be storted. The lineg wlll be equaliy spaced by IZs, Instead of by voltage, so that their density will not mean field gradtent. The defaulc value, $I Z 2=-1$, turng this device off.

\section{Plotting Contrals}

(1) SCAl.E = 'YES' SCALE - ' 'YES'-DIFPEREMT X,Y SCALES

SCAIE = "YES" allows the axts rout 1 nes to adjust both the $X$ and $Y$ scales to take raxigum adyantage of the size of the popet. The Jefault value constralns the axis eo bave ehe same scale factor in boch direct1on, thus ptesierving the actual proportions. Lsing SCAlE - 'YES" alinss the plote to shrw wore detall beiween brajectordes in problems with lou hefght/length ratior.

(2) $5 \mathrm{x}=\mathrm{x} \quad 5 \mathrm{x}=22$

(3) $5 Y=x \times \quad 5 Y=9$ MAX. HORIZ. PLOT LESTH

SK and $S Y$ coneroi the area for each piecuse. Thu dimenslong are biven in laches. Sx can be adjusted to suit the iengeh of a glven problcm.

Plot data generated by the progian are stored on an external file (disk) in a format very simflar to that nomally used it input to the soltware supplled with cilcorf piotters. A separate joh, or second job step, can then be run to generate the olocs. A siapl: program is 
printed in the appendix to convert these data to make CALCorP plots. Other plotter software such as that used at Stanford can be programed by waking the appropriate calls to the local subroutines. With the ahanges that resulted in the above system, a programmex at mother Installation does not need to search for plotting comands uithin the electron trajectory program. Conversion to local sof ware is usually quire staplified.

\section{Magnetic P1e1dg}

Hagnetfc ffelds play a vital role in steering and focuglog many kind of eiectron beath devices. The capabilitieg and limitations of the magnetic field fmplementation in the program vill be described in this section. The following areas will be discussed:

1. Magnetic Fleld Input; (a) axial, (b) Ideal colls, (c) vectar potential data:

2. off-axis ffeld expansions;

3. Magnetic fields In Rectangular Coordinates.

1. Megnetic Field Input

In the present implementation of the progran, thete are thise mert. ods of Inputting magnetic field data:

(a) By reading in the field on the axis wing bithet a polynomial expansion or by readting the full artiy,

(b) By opecifying 1deal coils (rad1us, pasition and strength).

(c) By reading in vector potential data from the output of a two-dimangional magnet design progras auch as TRIM or POISSON. (a) The data cards for an axial ragnetic fleld are put in before the boundary data. The format vas briefly deacribed in Section V.B. The Input data for the polynomial mechod consist of MACSEC gegments of data fncluding: ' 21 ' to ' 22 ' with origin at ' 23 ' (three fntegers) and

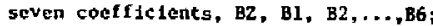

$B=B Z+B 1 * D Z+B 2 * D Z * 2+\ldots+B 6 * D Z * 6$, whete $D 2=2-23$.

For the sixth order expansion, the fluld mugt state gix unitg behind the cathode or starting point, and go six unieg past zLIM. In tectangular coordinates, the nomal magnetic fleld is in the trangverge (ph1) direction.

The NAMELIST Input for RLIM, efc., (SINPUR) Includes the parameter MAGSEG (defaule MAGSEG - D) whtch deiarmines how many gegmenta are to bo read, each with SINPUT2 and SEND cards. Eaci, Gegment conglete of the sata For 21, 22 and 23 followed by the arsay 36 10 Mayruist format.

$\mathrm{ZI}$ and $\mathrm{z2}$ are the end points of a tine segment on the axts $(21 \leq 22)$ in the range $-6 \leq \mathrm{zl}, \mathrm{z2} \leq \mathrm{zLDy}+6$. It ta necegsary co permit Eletds to be desrribed beyond the ends of the problem 1n order that the off-axis ficlds can be enleulated at the end of the probles. 231 s the local origin for the polymomial expangion in porers of DZ - $2-z 3$. Having a local origla glmplifieg the Input of, for example, a etraight Ihe that does not go through $(0,0)$. As arany of the coefficients $B Z$, B1, etc., can be used as are necegeary, afmply by setting the remaining onec to zero,

In cylindrical coordinates, this fle! must be in the axtal direstion. In rectangular coordinates, the field on the axis way be elcher In the direction normal to the plane of the plot, 1.e., In the PHI 
direction, whete PHI ig the oxthogonal linear rooxdinate to $R$ and $Z$, or in the $R$ (Vertical) direction.

With tha above format, data can be encered . th any degree of pulynomial up to 6. The date may be divided tito segraents ranging from a point at a time to the whole length of the problen. Typically, angnetic meaburements of an axially symoctic permanent magnet will be taken on the axis. The data are chen frequently smoorhed by a polyntomial least squares fitting progran and the resulting coefficients read into the program. Alternatively, a fichd may be designated by the user as in the exampie problew, segmented into short lengths of quadratic or linent dependance, and read in to the progras. E1the : aechod wil uswally glve a good representation of the field on the axis. However, difficuletes arise when the program needs to calculate the of $-a x+s$ ficids. These will be described in Section 2, belov.

A separace proviaton allowe one to Iend wil the BZA array directly. Note that thes array gtarta with $\operatorname{Bzn}(1)$ at $z=-6$ and gece to

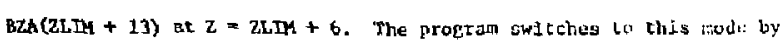
hav1ng MACSEG < 0 , 1.e., if MAGSEG $\mathrm{x}-1$, then a different NAMFi, 157 . SINPUr3, is called to read the array BLA ( ). If measurod andor plotted data are ubed, noce especially the finherent risks in exjopding such data for the oft-axis flels coupments. This format lends tiself readily to computer ealeulated output, properly ediced, and with up to 15 effective decimal digtes.

(b) The data for tdeal cofls are read in as part of the INrurs starting conditlons. The starting conditions pertuining to mignecle fielda are as follows:
MACNETIC FIELDS

HETHOD ONE: READ IN LUCAL FIELD.

$\begin{array}{lll}\text { RMAC }=\mathrm{x} \cdot \mathrm{x} & \text { RHAG }=\mathrm{RLIM/2} & \text { OFF-AXIS MAG FIELD LIST LNG } \\ \text { ZMAC }=\mathrm{x} \cdot \mathrm{x} & \text { ZKAG }=\mathrm{ZLIM}+6 & \text { B CONSTANT BEYONE ZMAG } \\ \text { MACORD }=\mathrm{x} & \text { MAGORD }=2 & \text { HICHEST ORDER FIELD TERM } 56\end{array}$

IF MAGORD < 0 , KECT. COORD. MAC FIETD ARRUY AZA IS IN TIE F DIRECTION NMAG $=\mathrm{X} \quad$ NMAC $=0 \quad$ NO. OF FTELD COILS (SEE BELOW) HETMOD THD: READ IN POSITION AND STRERGTH OF MTAG IDEAL COLLS
NELL $=1 \quad$ NELL 00 FOR ELLIPTIC IMTEGRALS
$C R(t)=X . X \quad$ CR(I) $=$ RLIM RADYUS OF COIL (MESH UNITS)
$C Z(I)=X . X \quad C Z(I)=0.0 \quad$ AXPAL POSITION OF COIL
$M(1)=x . X \quad C M(I)=0.0 \quad$ CURRENT IM AMPFRE TURNS

$8($ AXIS $)=0.2 * \mathrm{CI} * \mathrm{PI} * \mathrm{CR} * 2$ 'SORT $(((2-\mathrm{CZ}) \star * 2+\mathrm{CR} * 2)) * 3$ GAUSS WLERE I IS COHL :HQMBER, E.G., $\mathrm{xZ}(2)=20.0$.

'METHOD OXE' REFERS TO TKE POLMRONTAL INPUT JUST DESCRIBED.

(1) RMAC $=x . x \quad$ PQAG $=$ BL HM/2 OFF-NXIS MAG FIELD LISTINGS

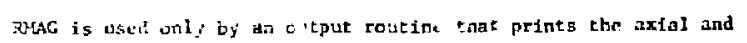
radial components of the magnetic fleld at che ridtus Ruh. The default value is chosen to be typical of the maximum rodius of the beam, but :i shouid be adjusted to sult the problea, For a pencil beam, RMag should be equah to the expected average beam radius (tn opesh units). Tnis printout is a useful diagnostic device to check on unrealistic off-axis eomponents that can result if the inputs have disnont frulties in one of the highet derivatives. 
(2) ZMAG $=\mathrm{X} . \mathrm{X}$

\section{ZMAC $=$ ZLIM +6 A CONSTINT HEYUND ZMAG}

ZMA permits sobe simplification of data by sitting the axial fiteld

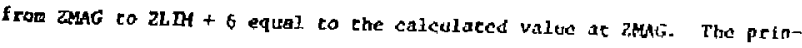
cipal use Eor zMAG is where a converging magnetic fluld in the gun region merges into the unfform field of a solenotd. The field expressions or coils must describe a field which converges to parallellsa at the solerotd entrance, and ZMAG is then the 2 coordinate (In mesh units) of this point.

The default value of ZHAC $(2 \mathrm{LIM}+6)$ ensures that it then has no effect in the working region up to Zlm.

ZHAG Is a posttive tnteger.

(3) MACORD $=\mathrm{x}$ HAGORD $=2$ HIGHEST ORRER FIEID TERM $\leqq$ Hacokd is the highest ofder cerm, in powers of $R$, thac will be used to calculate off-axis fleids. It is not related to the power of the polynomial input. Usually magord has onte of the values, 2,4 or 6 . If MACORD is higher than warranted by the ruality of che dara, parcicularly if data from magnetic measurements are uscd, then the of $f$-axis flalds may be just plalp nonsense. If Macoro : O (rectangular soordsnates only), the array BZA (), on the s-axis, is taken to be fn the $R$ directions. OEf axis expansion, in powers of $R$, are used to generate $B z$ (off axis). This case is suitable for quadrupole symotry in rectangular coordinatea as viewed end-on to the beam,

(4) NHA $=x$

$\mathrm{BMAC}=0$ No, OF FIELD COILS

"Hethod Twa" refers to the method of tdeal cofls. arag is the aum ber of idcal efrculer cutrent loops, centered on the axis and 1ying in planes perpendicular to th. axis. Mlac thay have any positlve integer value, bur practical fald shapes can usually be represented by no more than if colls, which is the irray size. Each coll is descrthed by three parapeters:

$$
\begin{aligned}
& \mathrm{CR}(I)=\text { radius of coll (meyh units); } \\
& \mathrm{CZ}(I)=\text { axial positsinn of coll; } \\
& \mathrm{CH}(I)=\text { ampere-eurns; } \\
& \text { where } \mathrm{I}=1 \text { to RMAG }
\end{aligned}
$$

The findex is noc related to the strengti or position of the colls. Some methods of obtaining $C R$ and $C M$ values that will lit a destred field are discussed In Ref. 7.

The subsidtary pararoterts RMAG and ZMAC which have been discusged abcre, apply equally to wethod two (coils) as to method one.

All CR() values must be postive (not zero, or a zero divide will nceur); CR is not rescricted to be vithin RLir, but nay have any posttive value. It neet no: be an inceger. The $C R$ values should be larger than the beath tadius to avold strong local nan-lni Eorwlteles.

Cz( ) values may be positiva, negative or zero, integer or dectrat, and ore noc restricted by ZLIM. The progran calculates the ficld only within the working sadce RiIM $\times$ ZLIM, but the colls may ba Lnside or outside this space.

Ca() values are untegrticted.

A11 the coil daca are entered in the dINPUTS WMELIST b]ock.

Examples of magnet field entry using colla (these data represent a field converging inco a solenold which starts at $2=100)$ : 
(last boundary card)

8.88

\section{\&INPUT 5}

(usual START cards)

RMAG $=3$,

ZMAG $=100$,

RHAG $=5$,

$\operatorname{CR}(1)=150$,

$C 2(1)=6.8$,

$G(1)=-900$,

CR(2) $=50.0$,

$C Z(2)=50.0$,

$\operatorname{CN}(2)=-2000$,

$\mathrm{GR}(3)=32.0$,

$C z(3)=100.0$,

CM(3) = 31000 .

SERTD

(Card start data, if any)

/t

2. Off-Axis Flcld Expansions

The tuo input mechods described above bath result in an array of flelds from $z=-6$ to $z=2 L I M+6$. The array is for the axial field and is in double precigion. With this number of significant figures, 1t to posstble to ger meaningful resules for finite differences up to the Blxth difference, which is necessary for the sixth order derivative used to find the off-axis finlds. Each difference requires one larger value of $n$ in 2 . $n$, the range used to 6 ind the fteld at $z$, at any radius. The range $z \pm 6$ requlres that the flelds be specifled beyond the flolts of the problem from $Z=-6$ to $Z$ DLIM +6 .

To s1xth order, the field expanstions are ${ }^{6}$

$B_{2}=B_{z}(z)-R^{2}\left(d^{2} B / d z^{2}-d^{4} B / d z^{4} \cdot R^{2} / 16+d^{6} B / d z^{6} \cdot R^{4} / 576\right) / 4$

$B_{I}=-R\left(d B / d z-d^{3} B / d z^{3} \cdot R^{2} / 8+d^{5} B / d z^{5} \cdot R^{5} / 192\right) / 2$

By specifying MACoRd $=2$ or MACORD $=4$, the derivatives higher than MACORD are set to zero. This results in a less accurate expangion, if the original data are worthy of the high order differences. If they are not, then the result ef the lower orjer expansion 13 apt to be far more acceptable. Cenerally, meagured data, no matter how smoothed, arz only worthy of becond order expansion. Systhesized data from an ideal curve, If there is only one segment, can generally be expanded to fourth order. Coll data can be expanded to s1xch arder. Note, houever, that it is virtually impossible to use the full sixth order expatalon with either measured data or arbitrary polynad lnls, especially if wose than ore segment is to be fit cogether whout running the risk of having a very unphystcal result. The of $f-3 \times 1$ s flelds generated by poor podels, of ones with insufficlent accuracy, are apt to show very wild fluctuations with extrenely large peak valucs.

3. Rectangular Coordiate Expansions

In rectangular coordinates, the usual expansion is normal to the plane of the paper. The central plane, thih coordinate PHI $=0$, ean be 
thought of as the median plane of a magnet whose pole face is normal to the $z-a \pi d s, 1, e ., d s / d R=0$.

The off-medien-plane expanston is

$$
\begin{aligned}
\mathrm{B}_{\mathrm{PHI}} & =\mathrm{B}_{\mathrm{PHI}}(\mathrm{z})-\mathrm{PHI}^{2} \cdot \mathrm{d}^{2} \mathrm{~B} / \mathrm{dz}^{2} \\
\mathrm{~B}_{\mathrm{z}} & =\mathrm{PHI} \cdot \mathrm{dB} / \mathrm{dz}
\end{aligned}
$$

The diteraative expansion has the median plane $1 y$ ing normal to the R-2 plane, at $R=0$. The of $f$-axis expansion is then in the $R$ direction.

The second order expansion has been edergute for the applicacions that have been mide. One example 1s the "alpha" magnet daflection syster used to bend the low energy SLAC beam from the gun to the Iine of the accelcrator. A proper choice of angle makes the vertical focusing of che pole face edge compensate for the vertical phase space of the beam. Runs at different entrance angles, using the aessured fleld profile of the rugnet, were used to determine the opteidur angle. Space charge of a cylindrical beas, in rectangular cuordinates tan be included in such rung by the features deseribed for CAR starting in spction VI,G.

\section{E1hptic Incegrals}

For coll input (Method Two'), if elliptle Integral tout ines are avallable ae compilation, a cable of off-axia ficlds with elliptic integral calculationa is printed. It NEL = 1 in diwPurs, the elliptic Inregralo are used for the ray traciog.

(c) Inputting Vector Potential Data

In SINPUT1, the option INTPA = ,TRUE. , calls for SINPUTA to be called next. The condensed Instructions are:

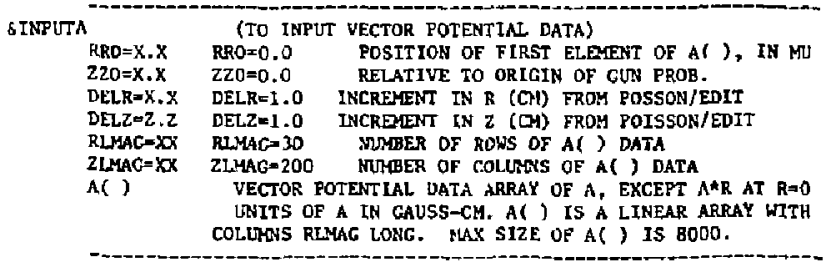

Use of this option requires the output from a magnet design program, such as POISsoN, which solves for the magnetic fteld including iran segments, which may even be partially saturated. The output of such programs is usually in the form of an array of the azimuthal component of the vector pocential $A()$. This array is currencly set to a maxtaum of 8000 elements, but may be reduced to one element to save space for users not interested in this option. The atray elements correspond to points it a rectangular mesh whlch dues not need to coincide with the mesh used for the electrostatic problem. To gave running time for the nagnet program and to reduce storage raquircaunts for the data, it 1 s preferable to Identify a rectangular area that is expected to fnclude the space that the electron trajcctorles will require. The array starts at RRO, zZo, proceeds in steps of DELR in colums RLMAG long, and contains ZIMAG colunns separated by inerements DELz. During operation, Line progran finds the differences fram the four points meacest the parficle to find the compopents $\mathrm{BR}$ and $\mathrm{BZ}$. 


\section{E. General Gathode and GENGARD}

\begin{tabular}{|c|c|}
\hline \multicolumn{2}{|l|}{ START GESERAL } \\
\hline START = 'GENERAL' & START = 'GENERAL' \\
\hline $\operatorname{AC}-x .200 x$ & $\begin{array}{ll}\text { RC }=0.0 & \text { LOHER END OF STARTTNG SUR- } \\
\text { FACE }\end{array}$ \\
\hline $2 c=x . x x$ & $\begin{array}{c}\text { ZC = 2+CATHODEZ GATHODEZ IS } 2 \text { VALUE OF } \\
\text { BOUNDARY FROM FIRST } \\
\text { DATA CARD. }\end{array}$ \\
\hline $\mathbf{C L}=\mathbf{X} . \mathbf{X X}$ & $\begin{array}{ll}C L & =\text { RLDM MAXTMUN LENGTI OF STARTING } \\
\text { SURFACE }\end{array}$ \\
\hline $\begin{array}{l}\text { DENS }=\mathrm{XX} \times \mathrm{X} \\
\text { GETA2 }=1.0\end{array}$ & $\begin{array}{ll}\text { DENS }=10.0 & \text { HAXTHUH EMISSION (A/CM**2) } \\
\text { BETA2 }=0.0 & \text { IF }>0.0 \text { USES LNNGHUR- } \\
\text { BLODGETT } & \end{array}$ \\
\hline $\operatorname{RAD}=x \cdot x$ & $\begin{array}{l}\text { USE RAD FOR WTRE RADIUS IN } \\
\text { RECTANGULAR COORDIHATES, } \\
\text { BETAZ }>0.0\end{array}$ \\
\hline \multirow[t]{2}{*}{ SURFACE $=x$} & STARTARC SURFACE ITERATION \\
\hline & $\begin{array}{l}\text { UISE POT (5) FOR NON-ERTTTINC SURFACE, E.C. } \\
\text { HOLIOW CATHODE OR SRADOW GRID. DO NOT USE } \\
\text { POT ( } 3 \text { ) OR POT (5) FOR FOCUS ELEGTRODE .... } \\
\text { USE POT( } 4 \text { ) TO STOP ELECTRONS ON IHPACT. }\end{array}$ \\
\hline \multicolumn{2}{|l|}{ START GENCARD } \\
\hline START = 'GEACARD' & START = 'GENENERAL' GENERAL HITUI CARD START \\
\hline 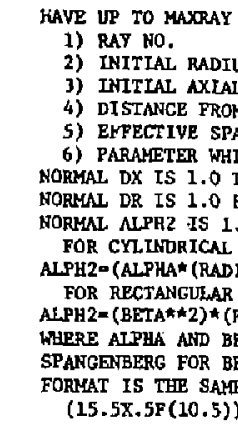 & 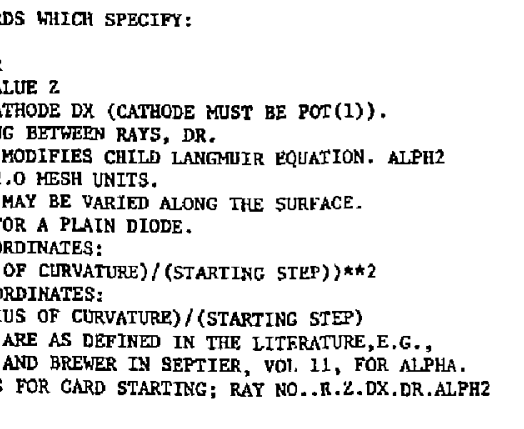 \\
\hline
\end{tabular}

This aection descrlbes the use of the Gaseral, catholle method which applien to anything that cannot be described using the assumptions of a spherical cathode. It inrludes the GEkiCaRd option.

In saleutacing starcing conditions using Chtld's tau. the baole assumption is that of space charge limited emission. Mathematically, this means that the electric field on the surface of the cathode is zern. Thus, in order to calculate the emisston current, the calculation must start some finite distance from the cathode. This leads to the use at Largmulr dlodes, or plll boxes. which become annulat in shape for cylindrical coordinates. The cypleal thickness is 2.0 mesh unite. with the range 1.0 za 3.0 generally acceptable.

The bastc chlld-tangmuir equation for ealssion in a plane dlode to 9

$$
J=\frac{2.335 \times 10^{-6} v^{3 / 2}}{x^{2}} \text { in arperes per unfe araa }
$$

The $3 / 2$ pouer dependence of the theraionic emisstion current density leads drectly to the concept of perveance here defined as the constant $R$ in the expression

$$
\tau=\mathrm{Kv}^{3 / 2} \times 10^{-6}
$$

Since $K$ depends only on geometrie factorg, the perveance becanes m identifying charactertstic of the device. Because of common usage, perveance for the progtar is exptessed with the taplied factor of $10^{-6}$, 1.e., microperweance hoy ing un-ts microanperes per volt ${ }^{3 / 2}$. 
The central problem for the GeNEFil cathode starting rout ine is to deftne the starting surface and to calculare the distance $x$ for the rhickness of the p111 box. The starting surface is fintifated at the point $(\mathrm{RC}, 2 \mathrm{C})$ with default values $\mathrm{RC} * 0$ and $z c=2.0+\operatorname{CATtiong} z$. The default point represents a point on the axis. 2 wesh units in front of the $z$ value of the first boundary point. If the cathode does not start on the axta, a different value for $\mathrm{RC}$ must be used. If the fIrst boundary point dons not describe the beginning of the cathode, then a different value of $\mathrm{zC}$ must be used.

The term catzodEz refarg $\exp 11 \mathrm{cit} l y$ to the value $z+\Delta z$ of the first boumdary point. It is frequently convanient to make the $R=0$ intercept of the cathode be the first boundary point, but there is no rule about this. The starting step (or diode thickness) of 2.0 mesh units can alson be adfusted by using a different value of $\mathrm{zc}$. The paramecer $5 \mathrm{~T}$, used for opherical starting, does not apply to GENERal starting.

The starting surface is calculaced by atarting an equipotentiat line at ( $\mathrm{RC}, \mathrm{2C}$ ) and following it, in one direction only, until one of three th1nge happena:

1. The line deaves the boundary of the problem.

2. The line becomes longer than the parameter CL. (default; CL = RLTh)

3. The boundary pointa intercepted by a line drawn at right angles to the starting ourface, extended to the left as viewed along the line atarting at $(\mathrm{RC}, \mathrm{zC})$, cease to be represcnted by POT(1) or POT(5). Fm16aion will occur from surfacos represented by POT(1). No emission vill accur fram Por(5) gurfaces; hollow carthodes or shadow grids may use POT(5). Any orleer potent $\{3$ l muber will cause the line to stop, with the mxcepthon that POr(3), usually used for grids, will not seop the line because it may be so close to the starting surface that contustion would result. Thus the notes suggest usting. POT(4) to and che gtarting surface.

Tests 1 and 2, above, are included as "safery valves." Tegt 3 is Intended tu determine the length of the starting surface. As the startIng surface has to follow a more tortuous curve, duc to holes, wires and corners, the equipotential paramecers EQLN and EQST may be adjusted as described in Section vi.A.

\section{DENS $=\mathrm{X} . \mathrm{X} \quad \mathrm{DEQSS}=10.0 \quad$ MAX EMISSION $(\mathrm{A} / \mathrm{CM} \star 2)$}

DENS 11a1ts the eurrent density ro a maxtmus value controlled by the user. It can be uged to 1 init the cmission as in teaperature lifited emission. The normal use fs to avotd extrece values of cutrent from local high-field points until space charge depression becones effective on subsequent iterations. Note that temperature linsted emisgien can also be simulated by using PEavo and HoLn as described in Section VI.A.

BETA2 $=1.0 \quad$ BETA2 $=0.0 \quad$ IF $>0.0$, USES LANGNUTR-BLODGETT RAD = $x \cdot x$ USE RAD FOR WIRE RADIUS IN RECT. COORD. BETA2 > 0.0 BETA2 and RAD refer to the parameters $B^{2}$ And $r_{5}$ in the LangauirBlodget ${ }^{10}$ theory of ealssion between coaxial cylinders. Tha wateris 1 is covered in Ref. 8. The Langmulr equations are included in the progratu for the particular case of exisgion from an atray of wires 10 
rectangular coordinates, BETAI Is calculated Internully once it has been activated by the user spectfying a value greater than 0,0 . The program uses the distance from the uire, the radius RAD of the wire, and the Langwuir equatione to calculate currents in each ray. More than one wire can be used provided that the starting surface can get from ane wire to the nexe by "geeing" FOT(5) Burfaces between wires. The wires that emit are of course POT(I). The currene per mesh unfe fn length (in rectangular coordinates) is

$$
I / 2=14.66 \times 10^{-6} v^{3 / 2} /\left(r \cdot B^{2}\right) \text { amperes/mesh unit }
$$

where $r$ is the otarting radius in aesh units and

$$
B^{2}=U\left(1-0.4 U+0.344 U^{2}\right) \text { where } U=\ln (\tau / R A D)
$$

The rore usual configuration of emission fram a flat or concave gurface in cylindrical ccordinates is treaced by the prograr: if BETA2 $=0.0$. Then the program treats the annular p111 boxes formed by dividing the gtarting surface into a nuber of equil segments. The number of rays is calculaced by the program to be the largest niwher (s MARAY) that can be distributea evenly along the stariing line, 1.e., 1 ar 2 per nesh unit, not 1.5:

The progriln determines the potential at the point on the ocarting surface from wilich the rays are to start and calculates the starting velocity and ing -urrent using either the equacion for cylindrical undsgion, if In rectangular coordinales, or the equation for emigsion froa concentric opheres ${ }^{\text {ll }}$ in cylindrical coordinates:

$$
I=\frac{2.335 \times 10^{-6} v^{3 / 2}}{x_{c}^{2}(-a)^{2}} \text { o so amperes pex cadian }
$$

where

$$
(-\alpha)^{2}=\left(\gamma-0.3 r^{2}+0.75 i^{3}-\ldots\right)^{2}
$$

and

$$
y=\ln \left[\left(r_{c}-x\right) / t_{e}\right]
$$

where, as in (14), $x$ is the thickness of the pill box, and fin which $r_{c}$ Is the radius of the cathode and $p$ and $\delta ;$ are the radius and chickness of the annular ring on the starelng surface. This equation calculateg the currene in a one radian segrest of the annular ring. The program prints this current in the one raiian segment in the table of initial condicions. Under final conditions, the current is printed divided by the Inttial radius, $\rho$. This column glves a aeasure of current density to detemine uniforolty of cathode joating. The cathode radius $r_{c} 19$ estimited for general cathodus by compuring the length of the cathode to the length of the starting suriace, Tht: tha be incorrect if the cathode daes not have a constant radius or curvature but the result is go Lose to the staple $L / K^{2}$ dependence thw the discrepancy does no: seen getheratly signiftcant.

For cases Involving cylindrical coordinates, for sphertcal and gencral cathodes, the starting step is auch smaller than the radiuy of curvature. Thus, it is possible to simplify (19) by expandtak it to second arder in $\left(x / x_{c}\right)$ :

$$
r_{c}^{2}(-\alpha)^{2}=x^{2}\left(1+1.6 \times / r_{c}+2.06 x^{2} / r_{c}^{2}\right)
$$


In which $x$ has been redefined as postetve far the usual case of a coneave spherical emitting surface. With this change, (14) and (18) are essentfally the save except for the correction factor, the terto in purentheses In (21), called ALPH2 in the program. It is this term that is called for explicitly in the input for CENCAFD.

\section{SURFAC $=\mathrm{x}$ SURFAC $=1$ STARTINE SURFACE CYCLES}

SURPAC controls the number of progxas cycles for which the st:urting gurface will be kegenerated. Frequently, the most satisfactory looklng starcing surface to generated on the E1roe cycle, without apace charge depression. The etarting surface, it should be recalled, is only a locus of starting points from which particles start out in the direction of the electric fleld. The potential difference between the starting poinc and the cathode determines the inftal particle velocity and the current for that ray. As space charge depression is included, the shape of the otarting surface may, or may nor cliange, although generally the poteucial on it will change. In any casc, it 18 well to 1 imit the number of cycles durting which the surface $1 \mathrm{~s}$ recomputed so that the final cycles converge to a stable solution. Surfac controls the number of such cycles and, whyle it may often be more chan one, it should generally be 2 r $j$ less than NS, the total number of cycles.

General Cathode Dlagnosties

If the START - 'GENERAL' option is selected, the program will print a spectal table of the appropriate consrants: $\mathrm{RC}, \mathrm{2C}$, CATHODE LENGTH, MaXrays, etc. After successful calculation of a starting surface, the message
STARTING SURFACE: LENCTH $=X . X$ ENDS AT RHO $=X . X . \quad$ ZETA $=X . X$

will appear. Next the headings for the initisl cenditions will be printed folloved by the initial condition diata.

If the starefng surtace talls by not being able to trace an equipotental for at least two mesil units, ur because it 19 asked for notnts outside of the problet, then the milssage

GENERAL CATHODE STARTING SURFACE FAILED : LENGTH = X.X

$$
\text { ENDS AT RHa }=\mathrm{X} . \mathrm{X} \quad \mathrm{ZETA}=\mathrm{X} . \mathrm{X}
$$

is printed. If SURFAC : 1 and this faflure occurs on the sccond program cycle, then the progran wil cycle once note with a smaller pervennce (eurrently BO\%) and try again to fit the starting suriace, Ochenise the program ofll terminate. but in efcher case the complete potential tas will be princed to atd in diagrosis of the diffieulty.

GENCARD is a starting option Introduced to pernit better response to highly nonuntforc catholes. A speetfic example would be the sharp outer corner of a right cyllnder emitting from the end face. This cornot is usually handled poorly by START = 'GEhERAL' bectuge of Impllcit assumptions that the radius of currature of the surface is much greater than the starting step. CEHCARS was specifically intended for use vith high current fleld alssion devices, but applles also to thetrionic enitters.

GENCARD combines yome $n^{t}$ the functions of GENERAL with the baste philosophy of Caros in which the user spectfled all the starting condi-

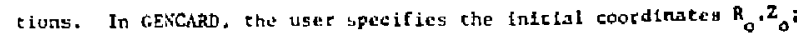


the effective distance to the cathode $D X$; the spacing between rays $D R$; and the "fudge factor" ALPH2. Thus the user has defined all the parareters needed to start the space charge lfmited problen except initial energy and drection. These are calculated by the second part of SUBROUTINE CHILDA which is the subroutine called by GEMERAI. The firet part of CHILDA calculates the starting surface, and 1s not needed by GENCARD.

The parameter ALPH2 LE the term in parentheses on the right side of (21). In rectangulat coordinater, ALPH2 correspends to the BETA ${ }^{2}$ of the literature with (STARTING STEP/CrLINDRIGAL RADIUS) ${ }^{1 \text { st }}$ pow +1 factored out. The effect of this is to make the normal, 1.e., plain diode, value of ALPH2 $=1$. Anything else is a perturbation at the user's control.

\section{F. Spherical Cechode}

\section{START SPHERE}

\begin{tabular}{|c|c|c|}
\hline \multirow{6}{*}{$\begin{array}{l}\text { START } \times \text { 'SPHERE' } \\
\text { RAD }=X . X X \\
\text { RMAX }=X . X X \\
\text { ORAD }=x . X X \\
\text { ST }=X . X X\end{array}$} & START $=$ 'GENERAL & ${ }^{*} \quad$ SPHERTCAL CATHODE \\
\hline & $\mathrm{RAD}=2 \star 2 L \Pi \mathrm{A}$ & SPHERICAL RADIUS \\
\hline & RMAX = RLTM & CATHODE RADIUS \\
\hline & ORAD $=$ CATHODEZ & CENTER OF CATHODE \\
\hline & $S T=2.0$ & STARTING STEP \\
\hline & $\begin{array}{l}\text { 'SPHERE' ALSO WO } \\
\text { CATHODE IN RECTA }\end{array}$ & $\begin{array}{l}\text { RRKS FOR CYLINDRICAL } \\
\text { WGULAR COORDINATES }\end{array}$ \\
\hline
\end{tabular}

IF START = 'SPHERE' 15 elected, the program olll first print the special table of parameters for the spherical cathode: SPHERICAL RADIUS, CATHODE RADIUS, CATHIDE CENTER, ete. The first two values, IAD and RHX, deterning the essential geometry of the spherical cathude

as show 1n F1g. 5. Obviously the default values, $2 \times$ ZLTM and RLIM

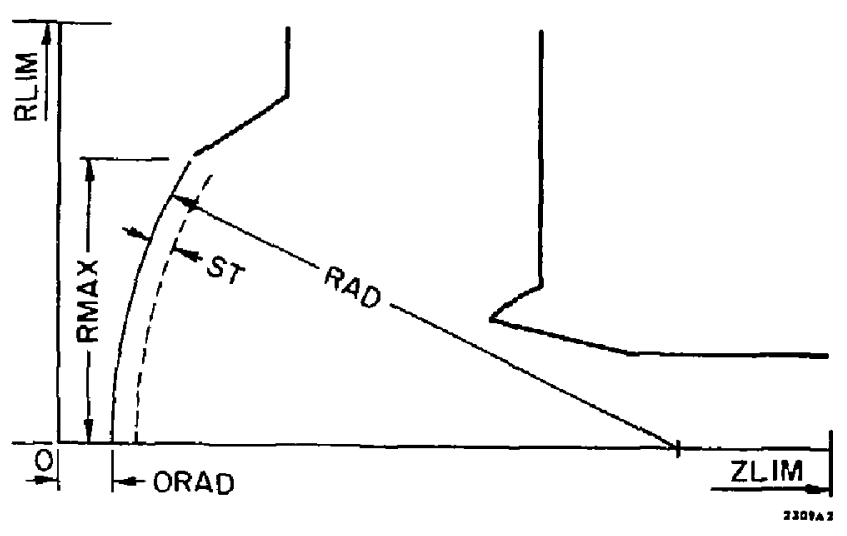

Fig. 5. Basic geosecty for spherical cathode configurations defining the inpur parameters. 
Iebpectively, have almost wo chance of being correct, so the user wuat apec1fy them. The default value for oRAD, the cathode center, is at

curmonez, the first boundary point as defined for the general cathode in section VI.E. The atarting step ST, is th value used for the thickness of the Langmulr pill bexes. As in the START = 'GENERAL' eage, In cyitndrical coordinates these pill boxes are innular rings and the current is that current in a one radian gegment of that ring. The eurrent is calculated in Eqs. 18-20 using the geametry of F18. 5. Figure $E$ in the ploted output of the eample ptoblem of Fig. 2 using SIART = 'SPHERE'.

In rectangular coordinates, START = 'SPHERE' operates with the same Input and the aame geometry t: calculate the current per wesh umit in the direction normal to the plane of the paper. Agatn, as in START 'C NNERAL' Eq8. 16-17 ate used according to Ref. 8.

Imediately after printing the headings the sphertcal cathode roytines priot a message:

ITERATION NO, $\mathrm{X}, \mathrm{I}$ - $\mathrm{X} . \mathrm{X}$ HICROAHPS, PERVEANCE $=\mathrm{X} . \mathrm{X}$ MICROPERV.

The curreot and perveance pripted are those calculased according to the flelds and geometry by the approprtace equartons as indicated above. In other words, theae are the unnorralized valuce. After printing this megsage, the program averages the perv'ance according to the method desertbed under PERVo in Seerion VI.z. The Intfial currents that are printed but with the ialtial conditions reilect thls averaging process.

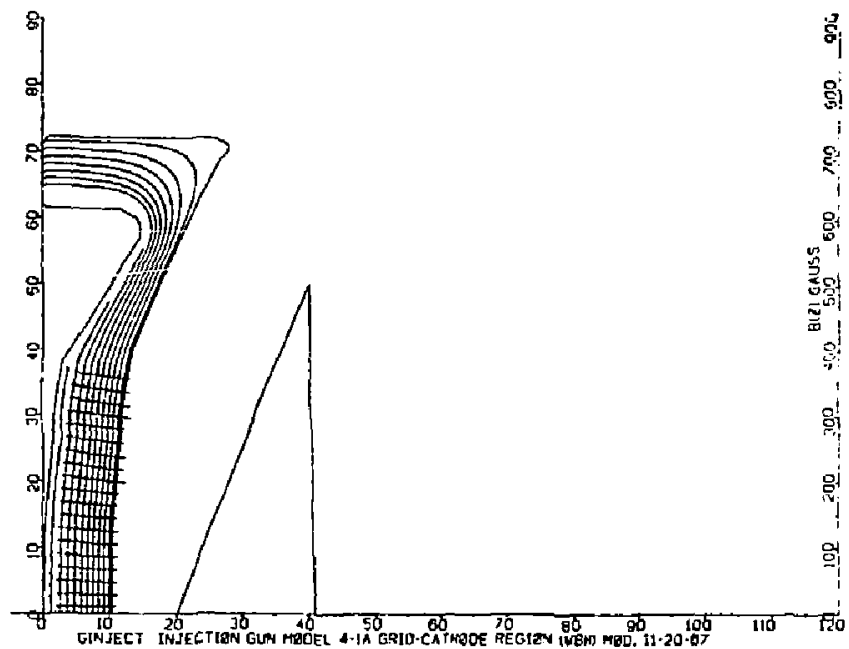

F1g. 6. Ploted output of sample problibo ghow to Fig. 2. Between the fnitial and final conditions, the game ressuge as above ts printed, except wth the norralized values for current and pervease.

As in START = 'GENERAL' the currente priated with the final conditione 
are divided by the intitial radius (if in cylindrtcal coordinates) and thus give a measure of uniformity of cathode loading.

The spectal case of magnetic flelds reaching the cathode, $1 . c$. , "1tmersed flow" 1s exeated by both SPHEHE and GENERAL accotding to Busch's theorem. ${ }^{22}$ The program muse use ragnetic fields on the cathode and an the statting surface to integrate the azinuthal motion through the gap between the cathode and the starting surface. If there is any Inconsistency in the off-axis magnetic flelds within \pm 6 mesh units of the entire range of the starting area, then pecultar bunching of the ing will occur. That is why the proper use of MagoRd and the careful input of fields near the cathode vere stressed in Section VI.D. Fortunacely, any prohlem of this sort becomes frmedtately obvfous on examinatton of efther the starting conditions or the plots.

\section{G. Card Starting}

The pregram starting instructions are as follaws:

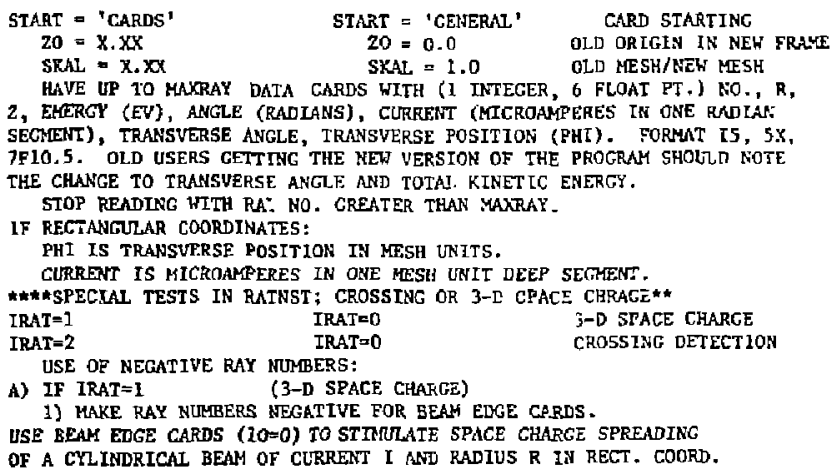

USE EEAM EDGE CARDS ( $20=0$ ) TO STT $I$ ANI RADIUS $R$ IN RECT. COORD.

PAIFS GF BLM EDGE CARDS FRECEDE SETS OF RAY CARDS DEFINTNG PAKT OF BENM FOR WHICH T-D SPACE CHRRGE SPREADTKG IS TO QE SLNULATED. SEVERAL PARTS, DIFFERENT LATED RY SELECTEO ATTRLBUTES; E.G., ENERGT ALPUL OR RADTUS. CAN BE USEO SIMRLTANEOISLY UTTH AVY MURBER OF RAYS IN EACH PART. INII OF PART IS DEF'LNED GY NEKT RAY WITH NECATIVE RAY NIMBEH, HHICH BELINS THE SEXT PART.

TO STYMUATE CYLINDRICAL. BEAM SPACE. CHARCE IN RECT. COORD. MAKE

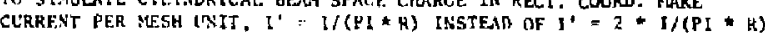
WHICH HOVLD IUVE TIE SAAE CLEREST DENSITY. IN OTHER LORDS. MAKE $I^{\prime}(K)=t(k) /(2-R(K))$ INSTEAS OF $I(K) / R(K)$. NOTE THAT THIS REQU:RES TWICE AS YUNY RATS AS FOR CYLISDRICAL BEAII HITH SMMETRY.

BENM EDCE. CARDS (RNY \& D) SRELY TO OFF-AXIS PENCIL IN CYL. COORD.

The START a 'CARDS' mode uses dats eards for the injtial candtions rather than computeng the initial cunditions from a themionic model. There are several typlical upplicotions for this fcature that vilf be described in some detail. These are:

I. The simplest case of usur specifled data.

2. Ise of cardfi kentrsitud by a priceding run tn restart in a new sergent of the name nroblum.

3. Scudy themal in: other perturbing influences on a beam.

4. Rectangular coordinate application ufth a cylindrical bears, includeng cylfndrital spare charge and off-axts bends.

1. Format for User Specified Dats

If START = 'CARDS' hus besen sclected, the progran wll tespond by printing a table of appropriate patumecers: STEP. NS, Z(0). SkAl.

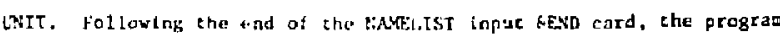
wit expec to read ip to MuRAY carda with the starting daca. A card with ray nuaber greater than Maxkiy will teminate this lepul. If MaxRAY cards are present, the turmination catd should be used anyway. How aver, no effort should be mate to make MLYRA agree with the number of cafds uged, so long as it is biag enough. The computer can, after all, counc betcer than nos bums. 
Data to be entered on the zay cards consigt of a ray number and the inftial values for $R, z$, ENRRG, ANGLE, CURRENT, TRANSVERSE ANGLE and TRanSVERSE POSITLON. The format is $15, \mathrm{X} 5,7 \mathrm{~F}(10,5)$.

(a) Ray Number: che ray number is only included for usir convenlence, and for the terminatian purpose described above. Rays are numbred by the program, equentially as the cords are read 10. Hegative ray numbers have special implicut lons that will be described below.

(b) R: the inftial radial position in meeh units,

(c) Z; the Initid: axial position in mesh units.

(d) ENRRGY (24): The Inftial klaetic energy of the partfcle in clectron volts. It should be obvious, but sometimes requires otatiog, that ENERG has nothing whatever to do with the porentlal values on the boundarles, or on the potential at which the ray tracing starts. For ray tracing, only lietds are 1oportant, not absolute potentfals.

(e) ANGLE: the inttial angle that the rny mikes with rinepect to the 2 - ax1s, in radians.

(f) GURREAT: the current In microamperes for a one radian segment of that ray. In rectangalar coordinates, it $t_{6}$ for a one mesh unit deep segment.

(B) TRANSUERSE ANGLE: the angle normal to the $R-Z$ planc.

(h) PHI: the Intelal transverse position. In sectangular symuetry, PHI ig a IInear coordinate, measured in mesh units. In cylindrical eymetry, PHI is the azimuthni positton in radians.
2. Use of Progratin Generated Cards

At the end of a run, the program generates a set of cards with the final conditions of each ray according to the above format. These cards may be punched, or saved as a data sec in card format on a ditect accens device. If it is planned co use the cards in 4 subsequent rus, it is only necessary to be sure they are saved somehos. In a pinch, Lile save data are princed in the final conditens of the output and can be hard punched.

Typteslly, these cards are Intentes to be used in a subsequent segwitit of a problem. Thus the results of the sample problew, Fig. 2, are intended to be used in the complete gur with card gtarting just past the grid. Between runs, it is nortal to expect that a different scale and orfgin will be used, otherulse there $f \mathrm{~s}$ not wuch reason for the second run. The companion parareters 20 and shal arc used to modify the data, as read in on the cards, as tollow:

\begin{tabular}{|c|c|c|}
\hline $20=x . x x$ & $20=0.0$ & OL ORICLN DN NEW PRMNE \\
\hline SRAL $=X \cdot x X$ & SKAL $=1.0$ & OLD MESH/NEH HESH \\
\hline
\end{tabular}

In words, if the first problew 15 plotted on the game graph with the second protlem, then the origln of the Exrst problex will be found displaced lefe or right by 20 mesh unles in the new coordinate aystem. Uswally 20 is negative. SkaL is 1nterpreted as the rate of sizes of resh units (in meters). Thus a problem in which many wogh trites vere uged to calculate cathode conditions urll have a relarively amaller wesh tha the follow an problest and SkAL 51.0 in ehis example. 


\section{Thermal Effect}

SUBROUTINE THERM IS CALLED IF THE PARAMETER TC : 0 .

$T C=X O X X . X$ THE $X$

TC=XOCX.X
TWO MODELS ARE INCLLOED IN THIS VERSION

TWD MOD KRAY=1

KEIVIN TERP. OE CATHODE

KRAY $=5$

THREE RAY SPLIT

FIVE RAY SPLIT

THREE RAY SPLIT FUTS CTIREEAS IN 1-2-1 RATIO WITH 2 PARTS IN

TN R-2 PLAFE, UP AND DOWN BELATTVE TO UNDEFLECTED RAY.

FIVE RAY SPLIT PUTS CURRENTS IN 1-9-0-9-1 RAT IO IIITH

$V($ PERP $)=2 *$ SORT (2KT/M) FOR 1 PART PAYS AND $V($ PERP $)=1 * 5 O R T(2 \mathrm{KT} / \mathrm{M})$

V(PERP) $=2 *$ SORT $(2 K T / M)$ FOR 1 PART PAYS AND V
FOR 9 PART RAYS. HO CLRRENT IN CENTER RAY.

USERS SHOULD FEEL FREE TO MODIFY SUBROUTINE THERM.

therr can be called for stakt='SPhere', 'General', 'Cards'.

OR 'GEMCARD'.

II CAMHOT UE USED FOR SIART =' CARDS' WITH SAVE=2.

\section{Rectangular Coordinates with Cylindrical beams}

The bastc assumption in rectangutar coordluates is that the beam consists of a sheet extending infinitely in the drections in-and-out of the problew. The space charge forces on such a beat are much preater than in cylindrieal symerry because che field does not fall off by $1 / R$. However, if the curcent is properly reduced, the Iransverse space charge forces can be made the same as they would be for a cylindrical beam. Further reduetions in the current can compensace for furthcr expansion of the bent.

Conolacr first a uniform density cylindrical beam of totnl current $I$ and radius $R$. The curtent densticy is $T=I / \mathbb{R}^{2}$. If one whed to have a rectangular symetry beam of thickness $2 R$ at the same current densicy, the total current per unit length would be

$$
I^{\prime}=2 R J=2 \pi / \pi R \text { (equal densit1es) }
$$

Utw could divide $1^{\prime}$ by some int ger $n$ and make $n$ r.lys, sultably spaced, each with a current of $1 \mathrm{M} / \mathrm{n}$. If one wishes to use starting daca from a provinus run, then cath ray has a current per unte tengch $I(K) / R(K)$. Irless: the rectingular beam has raflection symecty on the z-axis, there wuld have to be twice as mathy trajectorie's created as in cylindrical s) manetry to reptesent both halves of the heam.

Cunsider nut a particle of charge $e$ un the edge of a cylindrical beas of ratios $R$ and current 1. The radtal space ciarge force on the partivie is

$$
\mathrm{md}^{2} \mathrm{R} / \mathrm{dt}^{2}=\operatorname{el} /\left(2 \pi \mathrm{R}^{2} \mathrm{c}_{\mathrm{O}}\right)
$$

The force on the similar particle next to a current sheet in rectangul.n syouteticy is

$$
\pi d^{2} y / d^{2}=e I /\left(2 \% c_{0}\right)
$$

To make $d^{2} R / d t^{2}=d^{2} y / d t^{2}$ we have only to requite

$$
I^{\prime}=I / \mathrm{R} \quad \text { (equal farces) }
$$

Thls is juat one half of the result for equal densites in Eq. (21). Thus, if the resules from the previlous run were trated as described above. except divided by two, then thu thitial space charge forces on the rays vould be the same as in cylindrical coordinates.

A spectal featur? allows the user to dealgnate groups of rays, as few as one per group, to be bounded by "bean edge" cards uhich do not carry current. As the beam edge cards spread apart. the current on all 
reys utthtn the group is reduced proportlonately. The groups maly cross or overlap, but should not crose their awn beam edge rays. The fnitlal conditions of the bean edge rays can be chosen so that they do nat cruss the rays of the group. Beam edge cards are deglgnated by belng injerted, wh negative ray numbers, in pairs fust before the members of their Broup. Successive groupe wowld thus be separated by the pair of bent edge cards for the next group.

Beam edge cards thay also be used tn cylindrteal coordlnates. In thic cese, the effect would be of an . If-axis pencil beam, 1.e., not an annular xing. Assuming that the thicknesg of the pencil is sowall compared to the radial displacement, the game factor of one-half should be applied to the fintial currents as was derived for recrangular coordinates.

\section{B) IF LRUT-2 (R-Z AND PHI CROSSOVEKS )}

1) H-2: MAKE RAY NUMBERS NRGATTYE TOR SEQUERTIAI RAYS FOR WHICH FIMAL CROSSOVER SHOUTD DE DETECTED. CROSSTYGS YILA BE IISTED AND PLOTTED. NEGATIVE RAY MUMBERS SHOULD BE IN PAIRS. TO PIMO CROSSOVERS WITH $Z$ AXIS, RUN A RAY WIYH R=0, ALPHA=0 PRECEDING THE HAY TO TEST AXIS CROSSING.

2) FHI: LEAVE RAY NUMBERS FOSITIVI FOR TRANSVERSE RAYS TO DETECT LAST CROSSIRC OF PHI $=$ PI * INTECER,

A opecial appification of beam edge cards ls to specifically detect crossovers. For this application. the beam edgr control code is set to IPAT-2 in timpirts. The program instruction comments appear above. This feature ig used to find the locus of foci to determine the position of the ocintillator surface in image intensiffer tubes. No space shatge is Involved. Palrs of trajectorfan, started sequentially from the same point with different initial conditions (energy and disection) are focused to a srogeing, which must be located exactly. The program find such crossovers and prints a cable of thetr coordinates.
H. Laylace's Equation Applicationg

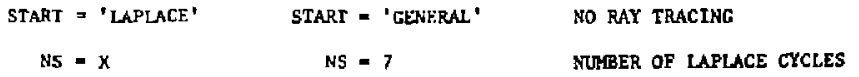

ADD DATA CARDS WTTH ( $R, Z$ SPACE CHARGE) FOR NON-ZERO POINTS. END PONT INPUY BY R 2 RLIH.

Laplace's equarion has many applications besideg solving electrostatic potent lal problems. Sonc ckaples are temperature distributions and magnetic fields

As a reginder, by Laplace's equation one usually weans $\nabla^{2}=0$ while Poisson's equation is $\nabla^{2} \phi-\rho$. The program aluays solves Polson' $\theta$ equation but with $p=0$ on the firsc iteration. However, if one selects START = 'IAPIACE', one can then add data carda with the coordiratux $(R, A)$, and the right hand or space churge term for any non-zero pofint. These daca are appended after the end of the eturting nanelist and are cerainated by $\mathrm{R}>$ RLIM.

The progran will then cycle for NS cycles on jugt these daca, with no ray tracing. It prints the potential unap or poTLIST before and atcer the last cycle to show how ehings any be changlig. Following the last eycle, the program prints a list of the fields, 1.e., the derivatives of the potentials, on all the boundartur. Ficlds at speciffed interior pointy can be obtalned by making a duw boundary go through such points. Dumaty boundary polats have DETTAR = DELTAZ -1.0 and can be ficted accorring to the same ruleg as Neutum boundartes, 1,e., along wesh lines The fields are norpalized to $100 \%$ of the ffeld on the first boundary point. Choose it carefully, f.e., not where the fleld is near zero. 
To do ray tracing with the arbitrary space charge solution found by IAPLACE, it $1 ;$ simply necessary to sct SAVE 1 in SINPUTS of the first, LAPLACE, problem rollowed by a second problem, without boundary daca, bue with ray tracing gtarting ingtructions. See the discussion under SAVE $=1$ in Section VI.A.12.

\section{Dielectric Boundaties}

The Input proviston for apecial boundary points, described in section $U$ can be used for the particular case of a dielectric boundary. The difference equations are only affected on the boundary of the dielectric. The normal method of using this feature is to specify demoy boundary points, 1.e., points with DELTAR $=$ DELTA? $=2.0$, which can be put in point-by-point or with the fitting (three-point) wethod as If the polnts vere Neumann boundaries. That 1s, they must ile on megh IInea.

The difference equations were dertved by Seeger ${ }^{13}$ for the special canes of hortzontal and vertical dielcctic boundartes. These relativuly gimple cases are sufficlent for mogt applicacions because the actual position and angle of eyen a curved dielectric are telatively less 1aportent 2 , the ficlds in the vicinfty than the fact that the boundary 1n locoter ndesrby. Thus a Bood approximation results from a stepwise almulation of the dielectric and a small dioplacement to the nearest meah polnt does very little to the flelds a feu mesh units away.

The coefficienti of the difference equation are given by Eq. (3) in Section IV, and can be expresged as

$$
\begin{aligned}
& \text { LEFT }=\text { RIGHT D R } \\
& \text { VP }=R+1 / 2 \\
& \text { DOWW }=R-1 / 2
\end{aligned}
$$

For a horizontal dielectic. where $c_{l}$ is the dielectric constant for the lower region and $s_{2}$ is the constant tor the upper region, the coefficients become:

$$
\begin{aligned}
& \text { LEET } \left.=\text { RICHT }-C_{1}(R-1 / 2)+\varepsilon_{2}(R+1 / 2)\right] / 2 \text { (Rorlzontol) } \\
& \text { UP }=\varepsilon_{2}(R+1 / 2) \\
& \text { DOWN }=\varepsilon_{1}(R-1 / 2)
\end{aligned}
$$

For a vertical dbelectric boundary. the coeffictents becou

$$
\begin{aligned}
& \text { LEFT }=c_{1}^{R} \quad \text { RIGH }=c_{2}^{R} \quad \text { (vert1eal) } \\
& \text { UP }=\left(\varepsilon_{1}+c_{2}\right)(R+1 / 2) / 2 \\
& \text { DOLN }=\left(c_{1}+\varepsilon_{2}\right)(R-1 / 2) / 2
\end{aligned}
$$

where $\varepsilon_{1}$ is the dfelectric constant for the lefe aide regten and $c_{2}$ is the constant for the right side rcgion. For rectangulas cootdintes. set all the $R$ "s and $(R \leq 1 / 2)$ 's co undry.

The terms LEFT, RIGHT, UP and DOWN refer to the points, $1,2,3$ and 5 respectively in Fig- 1 . The notes sumarizing Eqs. (27) and (28) in the program instructione nre reporinted below;

SPECLAL BOUNDARY FOINTS (INCLUDING GENERAL MEULWN BOLTDARTES) USE 999 IN COLURAS 3-3 TO END BOUNDARY INPUT. BOLNDARY RUST TKCUDE ALL rOINTS TO BE USED AND ALI POT NUMBERS. THEN INCILDE ANY NITMER OF CARD3 WITH $R, 2$ AND FOUR DIFFERENCE MLHBERS FOR LEFT, RIGHT, UP AND DOWN, 
SEQUENTIAJLY. NOMBERS SHUULD ADD TO 4 * $R$ OR 4 IF RECTANGTHAR COORDINATES, END WITH $R>$ RLDH. FOR GENERAZ LEUMANN, SEE APPENDLX 11. IERMS

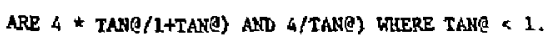

HORIZOFTAL DIRIECTRIC BOUNDARY;

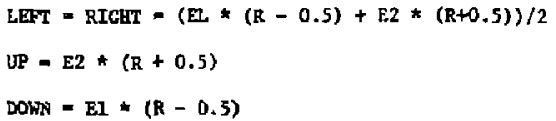

where E1 OR E2 - 1.D FOR VAGUUM AND E2 IS UPPER 'MATERLAL'.

VERTICAL DIRIECTRIC BOUTOARY:

$$
\begin{aligned}
& \mathrm{LEFT}=\mathrm{E} 1 * \mathrm{R} \quad \text { RICET }=\mathrm{E} 2 * \mathrm{R} \\
& \mathrm{UP}=(\mathrm{EI}+\mathrm{E} 2) *(\mathrm{R}+0.5) / 2 \\
& \mathrm{DOHN}=(\mathrm{E} 1+\mathrm{E} 2) \star(\mathrm{R}-0.5) / 2
\end{aligned}
$$

WHERE E2 IS RIGHT IUND 'MATERTAL'.

\section{v11. TRAJECTORY CALCULATIONS}

The program veesi a fourth-order Runge-Kutca method of solving the relativistic diffexcotial equations given below. Sultable subscitucions are used to reduce the three gecord-urder equations to six first-order differential equations.

The independent variable is time but the cime Interval is calculated from the allowed iteration step and the velocity. It is necessary to tse fatrly ohort steps because of the auxillary calculations that wust be made at each mesh unit. Thus it is generally not helpful to use any self-check Ing "corrector" 3olvirig rautine. If somz unusual application requices shorter iteraciun sleps, the results usually show this by their intemal tnconsistency.

The relativistic differential equations are derived in Appendix 1 and are

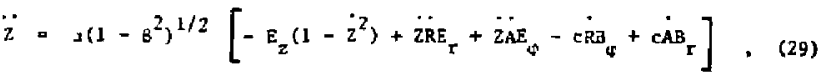

$$
\begin{aligned}
& \ddot{R}=a\left(1-B^{2}\right)^{1 / 2}\left[-E_{r}\left(i=\ddot{R}^{2}\right)+\ddot{Z R E} z+\ddot{R A} E_{b}+\dot{C Z B_{S}}-\dot{C A B} z\right]+\frac{\dot{A}^{2}}{R}
\end{aligned}
$$

and

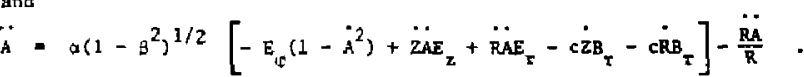

where

$$
B^{2}=\dot{Z}^{2}+\dot{R}^{2}+\dot{A}^{2} \text { and } B=v / c
$$

The constant $a=a h / m a^{2}$ where $e$ is the magnteude of the electron charge (the "-" 81 gn 15 in the equations), ${ }_{0} e^{2}$ is the rest cnergy of the electron and $\lambda 15$ the constant of proportionality between the real coordinates and the ditenstonless coordinaces. Thus

$$
z=\lambda I_{1} \quad \mathbf{r}=\lambda R, \quad \mathrm{a} \times \lambda \mathrm{A} \text { and } \mathrm{ct}=\lambda \mathrm{T}
$$

By an arbitiary chotce, $x=5-11 \times 10^{5}$ gesh un1es so that a a 1.0 mesh unit for volt. Ittspection of the differential equations shoss that they ate dimensteinally correct if the electic ficlds are specified in volts por mesh unft. 
Dimensionally $E=V B$, so that in mksa units $E$ is in volts per meter, $v$ is in meters per second and $B$ is in webers per meter. ${ }^{2}$ Then CB has units of volts per meter. To convert to program fielda of volts per mesh untt, fields are multiplied by the value UNIT in meters per mesh unit. Hagnetic field 1nput to the program is in gausy, which is the comon engineering unit, and is internally converted to uebers/meter ${ }^{2}$.

The azimuthal magnetic ficld $B_{\varphi}$ cowes from the cutrent in the electron beam and 18 called the self-magnetic field of the beam. The magnetic field created by an axfal current is

$$
B_{Q}=\frac{\mu_{D}}{2 \pi} \frac{I}{r} \text { webers } / \text { meter } T^{2}
$$

The field ts assumed to be due to an infinite conduetar which is a pretty goad approximation in the area in which the field 18 signiticant. Aftex aulciplying ${ }_{F}$ by the scale factor and expressing $r$ in meters which requires multplying I by the scale factor also, the scale factor canceis as mighe expected. Thus the scale factor ofly enters for external magnetic flelde. The current $I$ in Eq. (34) is che sumation of the current in the trajectories at lower radif than the trafectory being calculated, but including the one betng calculated.

Two fteld components are neglected. The azimuthal electric fleld 1s neglected because of the axial sytmetry assmed. The axial magnetic fleld can have a contribution froln the beall due ta aztouthal velocicy of the beam. The magnitude has been thown to be lens than ane gaugs in most practical cases and of to neglected.
The space tharge is culculated to supply the right side of Polsson's equation which $1 \mathrm{~s}$

$$
\nabla^{2} v-\frac{\rho}{\varepsilon_{0}}=\frac{J}{v \varepsilon_{0}}
$$

The element of area for $f$ to $(r \times 1.0)$ mesh units ${ }^{2}$ where $r$ is the particle radius. The veloctty is only the $z$-component since the space charge is being spread between adyacent points on the same colum. The one mesh unit sproe between adjacent points accounts for the 1.0 in the area expression above.

In the finite difference fort, Eq. (3) replaces Eq, (35), and the righe hand side becowes

$$
\mathrm{RD}=\frac{36 \pi \times 10^{0} \mathrm{IO}(K) \times 10^{-6}}{\operatorname{ABS}(2 D O T) \times 3 \times 10^{8}} \cdot(3.77 * 4-4) 10(\mathrm{~K}) / \operatorname{ABS}(2 D O T)
$$

where to $1 \mathrm{~s}$ to be spread between no potnts in inverse ratio to the distance the ray is between thea, $10(k)$ is the current in the one radian segment of che ray (An microamperes) and $200 \mathrm{~T}$ is the velocity in units of $c$. If the angle of inelinaton, $d R / d Z$, exceeds $45^{\circ}$, the calculation is made for RDot. The absoluce value of tDot is used to allow a negative 7LOT. The explicit value of $\mathrm{K}$ in Eq- (3) is canceled by the $R$ which would convert the current co current denglty, thus avolding epeckel prablews as $R+0$.

In practlce, however, therc ate sthll same space charge problems near the axis. In rectangular coordinates, if the axis is a plane of symmetry, then any trajectory between $R=0$ and $R=1$ has a pilror image 
between $R=0$ and $R=-1$. To account for all the space charge on the axis, the calculared charge is doubled. In cylindriral coordinates, it has been found necessary to mulctply the axlal space sharge by an empirfeal factor of 5.5. While no satisfactory explanation of chis has ever appeared, the behavior of 1deal laminar benns in test problems is markedly 1mproved and highly convergent beams appear to bchave as expected.

\section{TRAWECTORY ANALYSIS}

The program does some analysis of the quality of the beam Iesulting In a quatity which is similat to the phase volume, or euftcance, of the seam. For thace not familiax with the concept of phise volume, the material presented by Steffan ${ }^{13}$ is a good intraduction. The direct application of the concept of phase volume to alectroa guns uas derived by Miller. 14

The simplest formulation of phase volume is to consider the area of an ellipse plottad $10 \mathrm{dr} / \mathrm{dz}$ vs. $r$. Assume that the beam (e.g., the first atandard deviation) fills this ellipse. Subsequent drifting and focusing can be ghown to affect only the aspect ratio of the allipse, and the rotation of the major axis, but not the area. The ellipse can becose uarecogufzable through nonlinear elements.

At the end of each consputer run, two extra plots are generated. One is a plot of current density as a function of flnal radius, L.e., the beam profile. The secund plot 16 a point plot of the location in $\mathrm{dr} / \mathrm{dz}$ vg. $r$ of the final condictions of each ray. Figurc 7 is the plot la $d z / d z$ for the sample problen 1n Fig. 2. Using this gecond plot, the

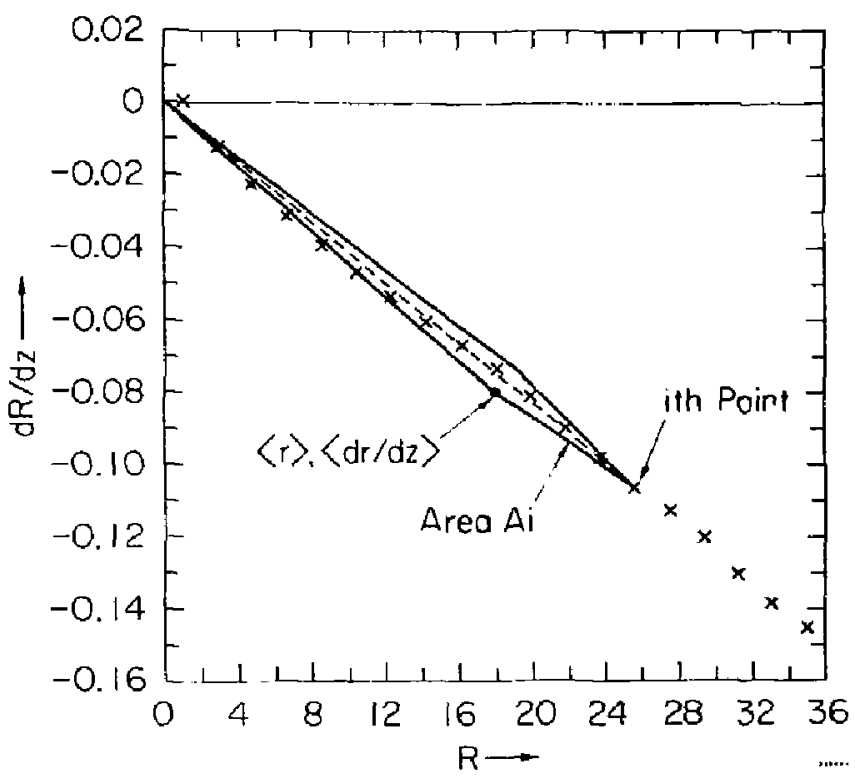

Fig. 7. Phage space calculation for problem shown in Fig, 2. 
effective phase area is calculated at the end of each run according to the method described by Miller. ${ }^{14}$ First the center of the distribution Is calculated, wich sultable ueighting for the current of each ray. This results in a location $\{r\rangle,\langle d r / d z\rangle$ in the half-plane. Then the area $A_{1}$ for the tch trajectory 13 calculated as the wetghted cross product between the 1 th point, $r_{1},\left(d r_{1} / d z\right)$, and the center of the distribution. The resulting expression thich is used in the progran is

$A_{x}=\frac{3 \pi^{2}}{2}\left[\frac{\sum_{1} I_{1}\left\{\frac{d r_{j}}{d z}\left(\sum_{I} I_{j} I_{j}\right)-r_{1}\left(\sum_{j} I_{j} \frac{d r_{j}}{d z}\right)\right\}^{2}}{\left(\sum I_{i}\right)^{3}}\right]^{1 / 2}$

This definition for the enttance area of a number of discrete points has the followng desirable characteristics:

1. It vantohes when the points ife on a straight line through the origin.

2. It approaches the area of the ellipse for a very large number of equally weighted points uniformly distribuced in the Interior of an ellipse.

3. It is invartant under 11near trangformations which congerve phase area such as that representing an aberrationless lens.

When multiplied by the particle momentum, Eq. (37) tetains the jatse ipvariance through aubsequent acceleration. That is, transverse nomertum timeg radiug is conaerved.
APFEIPIX I

UERIVATIOL UF EQUATIONS OF MOTIOF*

The equations of wotion are derived rros the torentz force equation

$$
\frac{\mathrm{d}(\mathrm{m} \overrightarrow{\mathrm{v}})}{\mathrm{dt}}=-\mathrm{e}(\overrightarrow{\vec{E}}+\vec{v} \times \overrightarrow{\mathrm{B}}) \text {, }
$$

where $e$ is the ragnitude of the ctarge of an electron. The electron velocity vector $\mathrm{v}$, expressed in cylindrical coordinates is

$$
\dot{v}=u_{z} \dot{z}+u_{I} \dot{r}+u_{\Phi} \dot{a} .
$$

Here $u_{z}, t_{r}$ and $u_{\psi}$ are unit vectors and $\dot{\theta}=r \dot{\Phi}$ is the azimuthni or peripheryl velocity. The left side of Eq. (1) can be found from

$$
\frac{d(m \vec{v})}{d t}=\frac{d}{d t}\left(\mathrm{~m}_{0}\left(1-\frac{v^{2}}{c^{2}}\right)^{-\frac{1}{2}} \vec{v}\right)
$$

where $t_{0}$ is the electron rest mass. Differentiating Eq. (3) 'ylelds

$$
\frac{d(\vec{v})}{d t}=m_{0}\left(1-\frac{v^{2}}{c^{2}}\right)^{-3 / 2} \quad\left[\frac{v}{e^{2}} \frac{d v}{d t} \vec{v}+\left(1-\frac{v^{2}}{c^{2}}\right) \frac{d \vec{v}}{d t}\right]
$$

where

$$
\frac{\overrightarrow{d v}}{d t}=u_{z} \ddot{z}+u_{r}\left(\ddot{r}-\dot{r}^{2}\right)+u_{\varphi}(2 \ddot{r} \dot{\psi}+\mathbf{r} \ddot{\phi})
$$

which beccmes

$$
\frac{d \vec{v}}{d t}=u_{z} \ddot{z}+u_{r}(\ddot{r}-\dot{a} / r)+v_{p}(\ddot{r} / r+\ddot{g}) .
$$

From $v=\left(\dot{z}^{2}+\dot{r}^{2}+\dot{a}^{2}\right)^{\frac{1}{2}}$ where $v$ is the sealar veloctly,

we have

$$
\frac{\mathrm{dv}}{\mathrm{dt}}=\frac{1}{\mathrm{v}}(\dot{z} \ddot{z}+\dot{r} \ddot{r}+\dot{a} \ddot{a}) .
$$

FTris deritation vas suggested by Dr. Gene Leng in a private conmunication. 
Substituting Eqs. (6), (7) and (8) in Eq. (4) yiclds

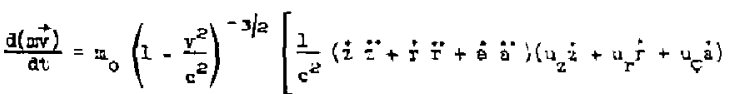

$$
\begin{aligned}
& +\left(1-\frac{v^{2}}{c^{2}}\right)\left\{u_{z} \ddot{z}+u_{r}\left(\tilde{r}-\vec{\theta}^{2} / r\right)+u_{\phi}(r \dot{a} / x+\ddot{a}) \mid\right\} \text { ] }
\end{aligned}
$$

Equation (9) can be expanded and grouped by vector conponerts yieldire

$$
\begin{aligned}
& \frac{d(u+\vec{v})}{d t}=m_{a}\left(1-\frac{v^{2}}{c^{2}}\right)^{-\not{z} / 2}\left\{u_{2}\left\{\frac{1}{c^{2}} \dot{z}(\dot{r} \ddot{r}+\dot{a} \ddot{a})+\ddot{z}\left(1-\frac{v^{2}}{c^{2}}+\frac{t^{2}}{c^{2}}\right)\right\}\right. \\
& +u_{1} \cdot\left\{\frac{1}{c^{2}} \dot{r}(\dot{z} \ddot{z}+\dot{a} \dot{u})-\frac{\dot{a}^{2}}{r}\left(1-\frac{v^{2}}{c^{2}}\right)+\ddot{r}\left(1-\frac{v^{2}}{c^{2}}+\frac{\dot{r}^{2}}{c^{2}}\right)\right\} \text { (10) } \\
& \left.+u_{\varphi}\left\{\frac{1}{c^{2}} \dot{a}(\dot{z} \ddot{z}+\dot{r} \ddot{r})+\frac{\dot{r} \dot{a}}{r}\left(1-\frac{v^{2}}{c^{2}}\right)+\ddot{a}\left(1-\frac{v^{2}}{c^{2}}+\frac{\dot{a}^{2}}{c^{2}}\right)\right\}\right] \text {. }
\end{aligned}
$$

A simblar vector component expension can be agde for the right side of Eq. (1) Heldine

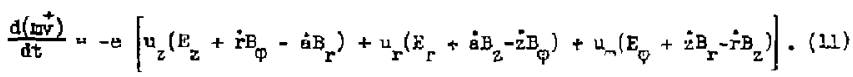

Equating vector components we have flayliy

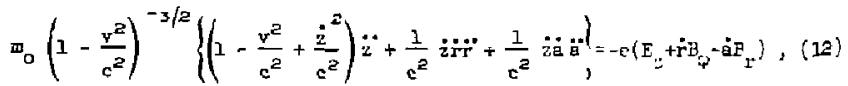

$m_{0}\left(1-\frac{v^{2}}{e^{2}}\right)^{-3 / 2}\left\{\frac{1}{c^{2}} \ddot{r} \ddot{z}+\left(1-\frac{v^{2}}{a^{2}}+\frac{\dot{r}^{2}}{c^{2}}\right) \ddot{r}+\frac{1}{c^{2}} \ddot{r} \ddot{a}-\frac{\dot{a}^{2}}{r}\left(1-\frac{v^{2}}{c^{2}}\right)\right\}$

$=-e\left(E_{r}-\dot{i} B_{p}+\dot{i} B_{z}\right)$ and

$$
\begin{aligned}
& H_{c}\left(1-\frac{v^{2}}{c^{2}}\right)^{-u^{2}}\left\{\frac{1}{c^{2}} \ddot{a} \ddot{z}+\frac{1}{c^{2}} \ddot{3} \ddot{r}+\left(1-\frac{v^{2}}{c^{2}}+\frac{\dot{a}^{2}}{c^{2}}\right) \ddot{a}+\frac{\ddot{r} \dot{a}}{z}\left(1-\frac{v^{2}}{c^{2}}\right)\right\} \\
& =-E\left(E_{g}+\dot{i E_{r}}-\dot{r} E_{z}\right) .
\end{aligned}
$$

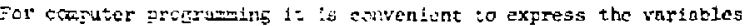
in a rortelized tor. Aceordintiv, we let

$$
z=x, z=x, g=M \text { and } c^{t}=x \mathrm{x} \text {. }
$$

We differertiate ifth respect to $\mathrm{F}, \frac{\mathrm{ct}}{\lambda}$ te set

and

$$
\begin{aligned}
& \dot{z}=\dot{\vec{z}}, \Xi=\frac{c^{2 \mu}}{T}, \\
& \dot{r}=\mathrm{e} \dot{\mathrm{k}}, \ddot{\mathrm{r}}=\frac{\mathrm{c}^{\mathrm{z}_{\overrightarrow{\mathrm{R}}}}}{\hat{\Lambda}}, \\
& \text { i }-\therefore, \ddot{a}-\frac{\mathrm{n}^{2} \mathrm{a}}{\mathrm{h}} \text {. }
\end{aligned}
$$

Frora the definttions in Eqs. (10) it fullows that

$$
\vec{r}^{2}=\frac{V^{2}}{e^{2}} \cdot \dot{2}^{2}+\dot{R}^{2}+\dot{A}^{2}+
$$

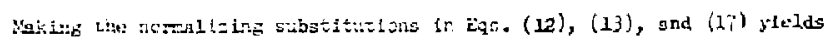

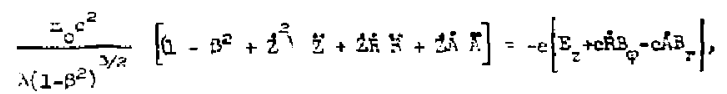

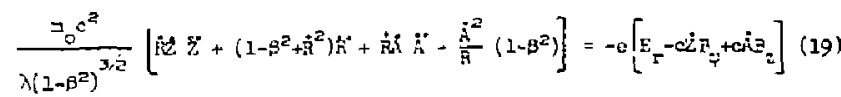


and

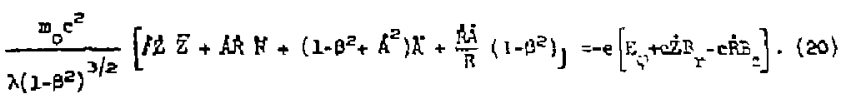

Our gosl is to get separated rawefions solved for the second order derivative of each of the arthogonal variables. To solve the equations, ve arrange them in the form

$$
\begin{aligned}
& A_{1} Z+B_{1} B+C_{1} R=D_{1} \\
& A_{2} Z+B_{2} B+C_{2} A=D_{2} \\
& A_{3} Z+B_{3} B+C_{3} A=D_{3}
\end{aligned}
$$

and apply the standard deterwitunt method of solving simulaneous equations. Reerranglng Eq5. (19), (19) and (20) in the ford of Eq. (21) yelas

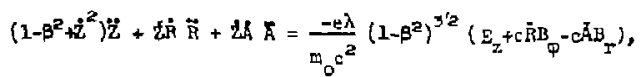

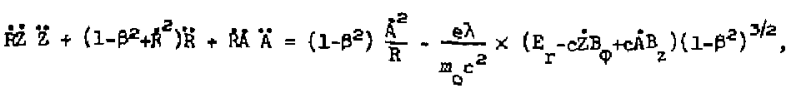
end

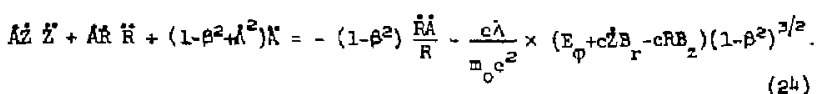

The detcralnant of the sevifiefonts is

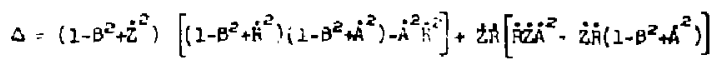

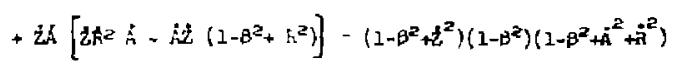
$-2^{2} A^{2}\left(1-\theta^{2}\right)-2^{2} R^{2}\left(1-\theta^{2}\right)-\left(1-\theta^{2}\right)^{2}\left(1-\beta^{2}+2^{2}+B^{2}+A^{2}\right)$

winteh is stply

$$
\Delta=\left(1-\beta^{2}\right)^{2} \text {. }
$$

It 15 convenient to let $\alpha=e \lambda / t_{0} t^{2}$. The axial acceleration $\bar{z}$, is given by

$$
\ddot{Q}=D_{1}\left(B_{2} C_{3}-C_{2} B_{3}\right)+D_{2}\left(C_{2} B_{3}-B_{1} C_{3}\right)+D_{3}\left(B_{1} C_{2}-C_{2} B_{2}\right)
$$

wh1ch becases

$\left(1-\beta^{2}\right)^{2} \ddot{z}=\left[-\alpha\left(1-\beta^{2}\right)^{\not 2}\left(E_{z}+C^{A} B_{\theta}-C A^{\prime} B_{r}\right)\right]\left[\left(1-\beta^{2}+\dot{R}^{2}\right) \times\left(1-\theta^{2}+A^{2}\right)-\dot{R}^{2} A^{2}\right]$

$$
\begin{aligned}
& +\left[\left(1-B^{2}\right) \frac{A^{2}}{R}-\alpha\left(1-B^{2}\right)^{3 / 2}\left(E_{r}-c t B_{Q}+\alpha B z\right)\right] \times\left[\operatorname{LA}^{2}-2 A\left(1-\beta^{2}+A^{2}\right)\right]
\end{aligned}
$$

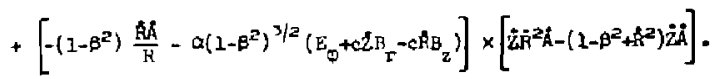

Simplified, the above equation ylelde.

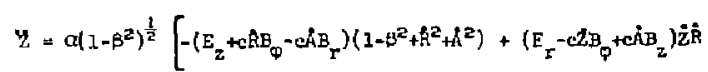

$$
\left.+\left(E_{\phi}+c i B_{z}-c B_{z}\right) \dot{z} A\right] \text {. }
$$

Noting that $\left(1-2^{2}+\mathrm{A}^{2}+A^{2}\right)$ : $1-\mathbf{Z}^{2}, \because 0$ have finally

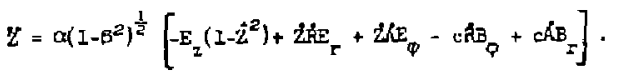


The radial acceleration $\ddot{R}$, is given by

$$
\Delta \ddot{A}=D_{1}\left(A_{3} C_{2}-A_{2} C_{3}\right)+D_{2}\left(A_{1} C_{3}-A_{3} C_{1}\right)+D_{3}\left(A_{2} C_{1}-\lambda_{1} C_{2}\right)
$$

\section{which becomes}

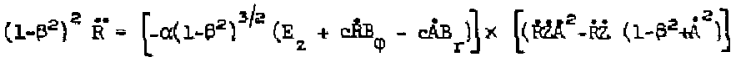

$$
\begin{aligned}
& +\left[\left(1-\beta^{2}\right) \frac{A^{2}}{\bar{R}}-\alpha\left(1-\beta^{2}\right)^{3 / 2}\left(E_{\gamma}-\dot{2} \dot{B}_{\psi}+\dot{\alpha} \dot{B}_{2}\right)\right] \times\left[\left(1-\beta^{2}+\dot{L}^{2}\right)\left(1-E^{2}+\dot{H}^{2}\right)\right. \\
& \left.-2^{z_{\dot{A}}^{2}}\right]+\left[-\left(1-\beta^{2}\right) \frac{\dot{R} \dot{R}}{R}-\alpha\left(1-\beta^{2}\right)^{3 / 2}\left(E_{\varphi}+c \dot{Z} B_{T}-c \dot{R}_{z} z\right)\right] \times[\dot{Z} \dot{H} \\
& \left.-\dot{\alpha} A\left(1-\beta^{2}+2^{2}\right)\right] \text {. }
\end{aligned}
$$

Simplified, the obove equation yselds

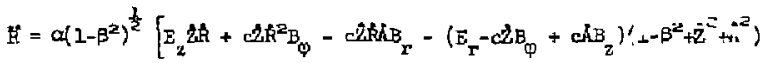

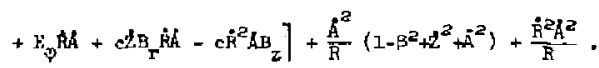

Foting that $\left(1-\beta^{2}+\dot{2}^{2}+\dot{A}^{2}\right)=\left(1-\dot{E}^{2}\right)$, we have finally

$\bar{F}=\alpha\left(1-B^{2}\right)^{\frac{1}{2}}\left[-E_{T}\left(1-\dot{R}^{2}\right)+E_{z} z \hat{R}+E_{T} \dot{R} \dot{A}+c \dot{Z} B_{\varphi}-c \dot{A}_{Z}\right]+\frac{\dot{A}^{z}}{\mathrm{R}}$.

The azinuthul acceleration $\ddot{r}$, in given by

$$
\ddot{A}=D_{1}\left(A_{2} B_{3}-A_{3} B_{z}\right)+D_{2}\left(A_{3} B_{2}-A_{1} B_{3}\right)+D_{3}\left(A_{2} B_{2}-A_{2} B_{1}\right)
$$

Hich verese

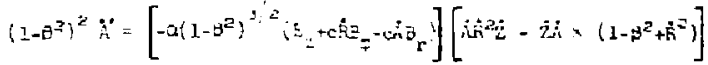

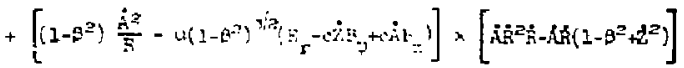

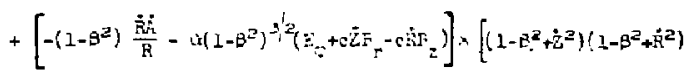

$$
\begin{aligned}
& \left.-z^{2} R^{2}\right] \text {. }
\end{aligned}
$$

Simfifled, the above equation ylelds

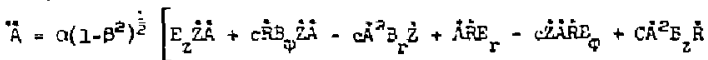

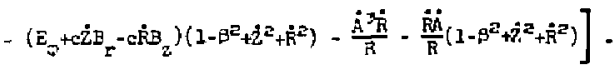

Noting tilat $\left(1-\beta^{2}+\dot{2}^{2}+\overline{5}^{2}\right)=\left(1-k^{2}\right)$ we have finnlly

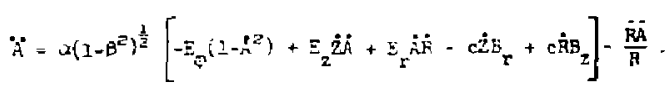


APFBMDE II

GEMERAL NEUMANI BOUMLARIES

If a loundary with normel derivative squal to zero 1 s as shown, then a problen boundary 18 drawn as show by the deched Ine. A point of " $\mathrm{a}$ " 1s shogor such that $V_{u}=V_{b}$. Polnt "a" is secn to lie on the normal to the boundary through the point " $b$ " at the Intersection betwcen foints

"c" and " $d$ ". The slope of the boundery is glven by tan $\alpha$.

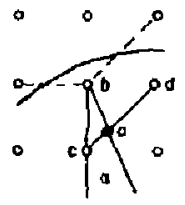

Sterting froe

$11-19$

$$
v_{a}=v_{b}
$$

we bave

$$
\frac{v_{a}-v_{c}}{\overrightarrow{a c}}=\frac{v_{d}-v_{a}}{\overrightarrow{s d}}
$$

where, for exsople, $\widetilde{a c}$ is th a distance frow point "a" to point " $\mathrm{c}$ ". The mesb intersal is taken to be unity. Cross-multipintab, we bave

$$
\overline{a d} v_{a}-\overline{a d} v_{c}=\overline{a c} v_{a}+\overline{a c} v_{a}
$$

or

$$
(\overline{a d}+\overline{a c}) v_{a}=\overline{a c} v_{d}+\overline{a d} v_{c} \text {. }
$$

But, $\overline{a d}+\overline{a c}-\sqrt{2}$ and $v_{a}=v_{b}$, hence

$$
\sqrt{2} v_{b}=\overline{a c} v_{a}+\overline{a c} v_{c} \text {. }
$$

Fral the Law of a dneo,

$\frac{\overrightarrow{\alpha g}}{\sin \alpha}=\frac{1}{\sin \left(\pi \frac{\pi}{4}-\alpha\right)} \cdot \frac{1}{\cos \left(\frac{\pi}{4}-\alpha\right)}=\frac{1}{\cos \frac{\pi}{4} \cos \alpha+\sin \frac{\pi}{4} \operatorname{\theta in} \alpha}$
Hicis kocous

$$
\bar{\theta}=\frac{\sqrt{2} \sin \alpha}{\sin \alpha+\cos \alpha}-\frac{\sqrt{2} \tan \alpha}{1+\tan \alpha} .
$$

Then the wher sestent 10

$$
\overline{\mathrm{ad}}=\sqrt{2}-\overline{\partial r}=\sqrt{\overline{2}}\left(1+\frac{\tan \alpha}{1+\tan \alpha}\right)=\frac{\sqrt{2}}{1+\tan \alpha} .
$$

The ecoplete difference equation from in. (4) is

$$
\sqrt{2} v_{t}=\frac{\sqrt{2} \tan c}{1+\tan \alpha} v_{d}+\frac{\sqrt{2}}{1+\tan } v_{c}
$$

which in the notation used in the coin toxt is

$$
\frac{\tan \alpha}{1+\tan \alpha} v_{1}+\frac{1}{1+\tan \alpha} v_{t}-v_{0}=0 \text {. }
$$


APPENDIX III

INSTRUCTION COMMENTS FROM THE PROGRAM

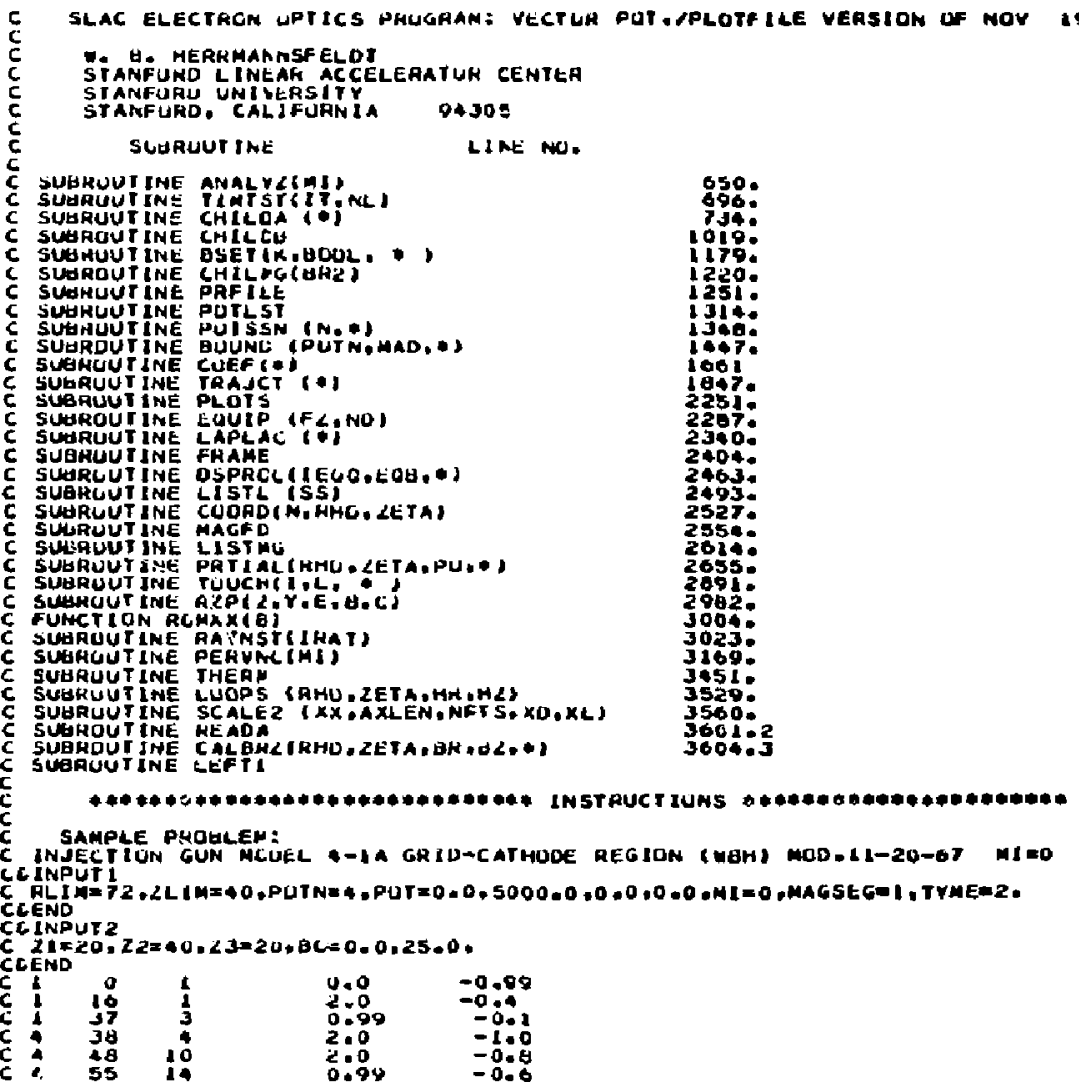




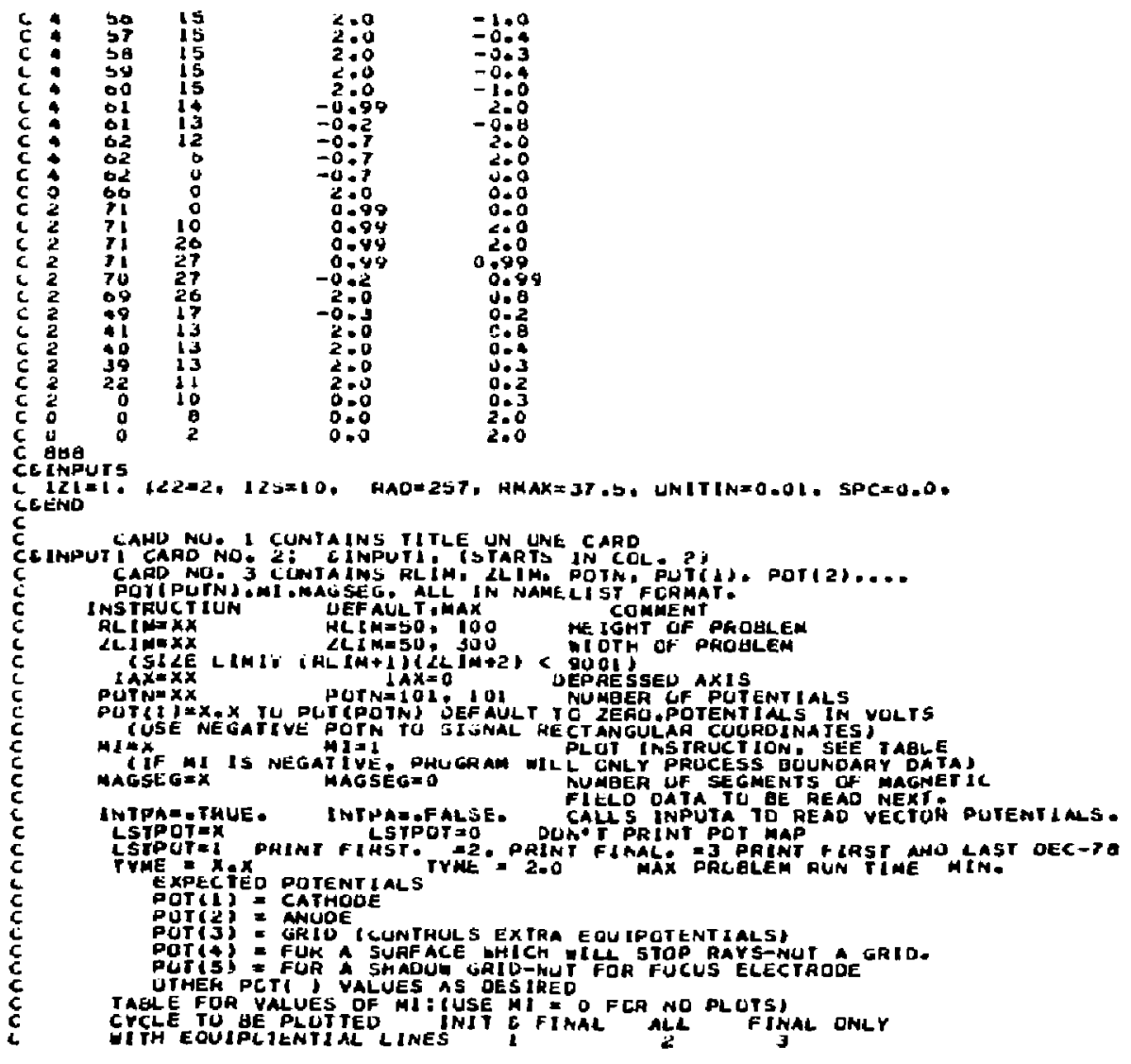




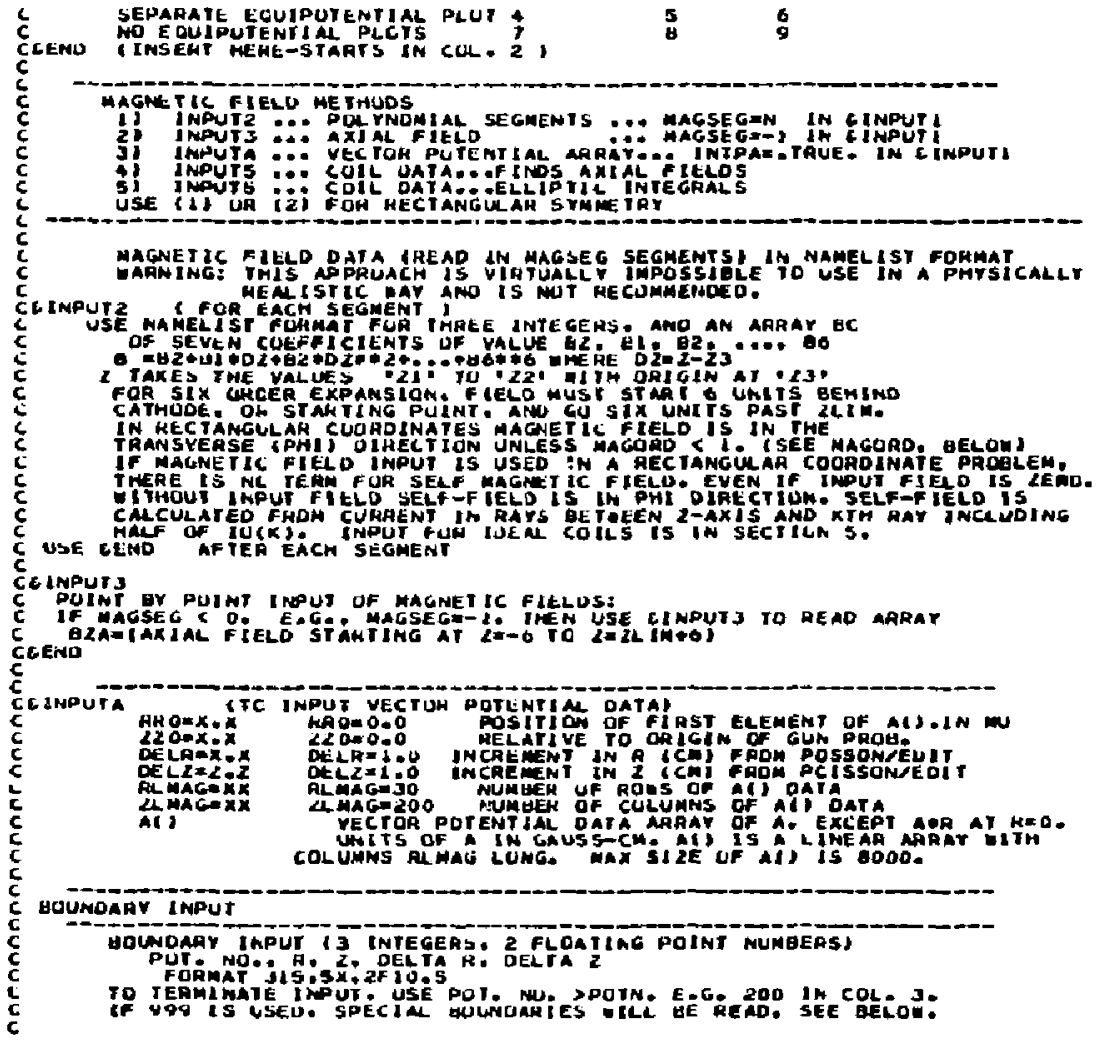




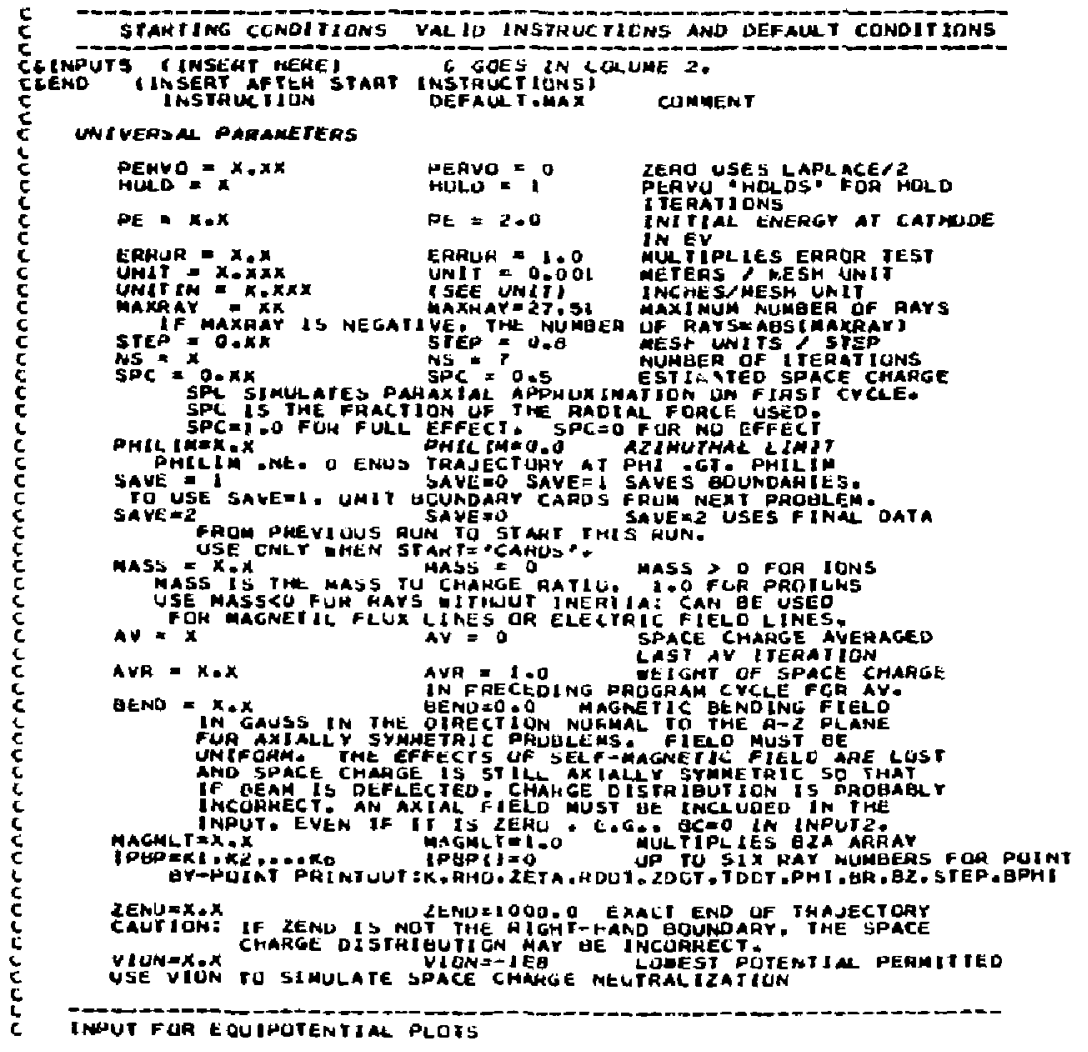




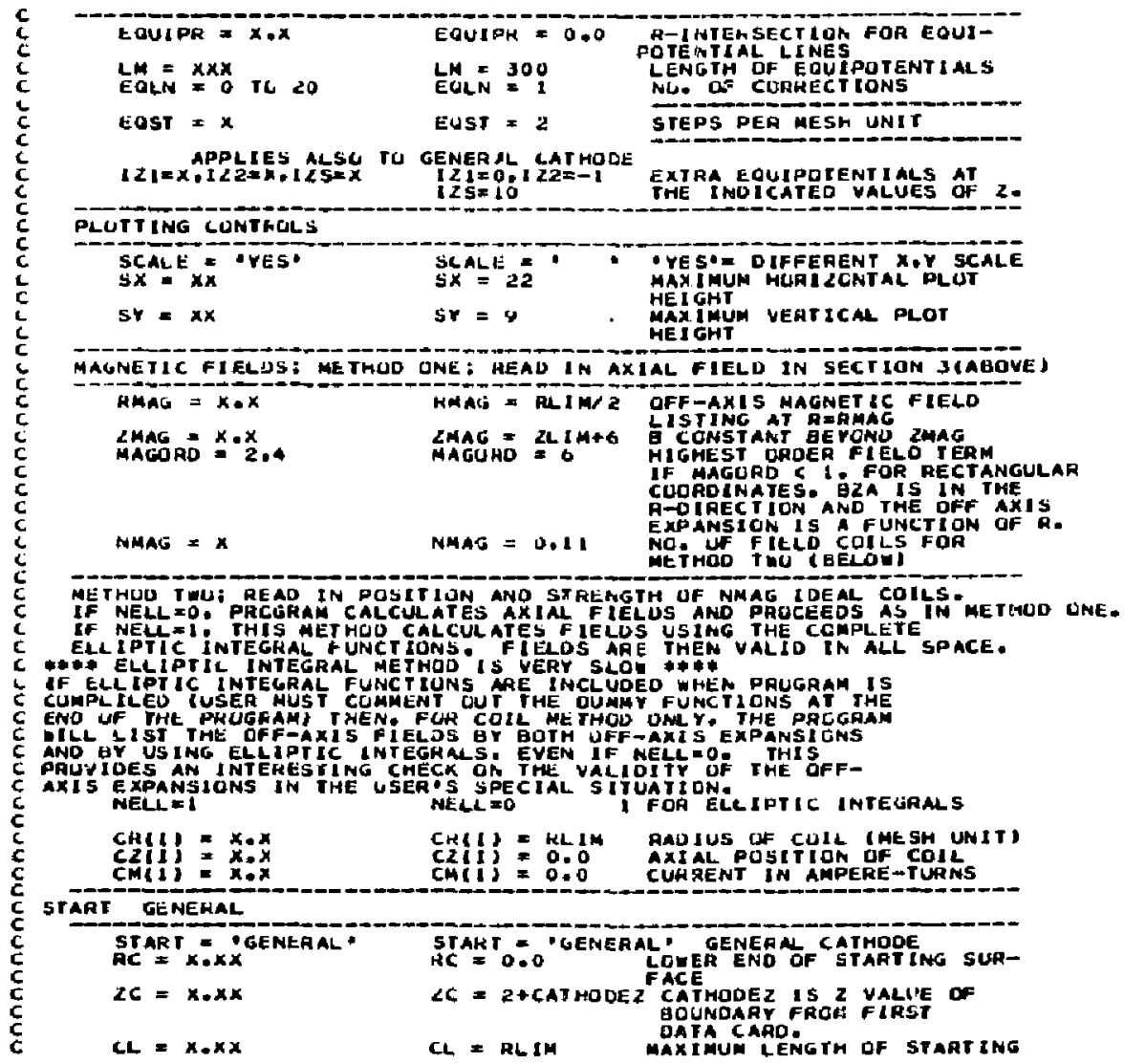




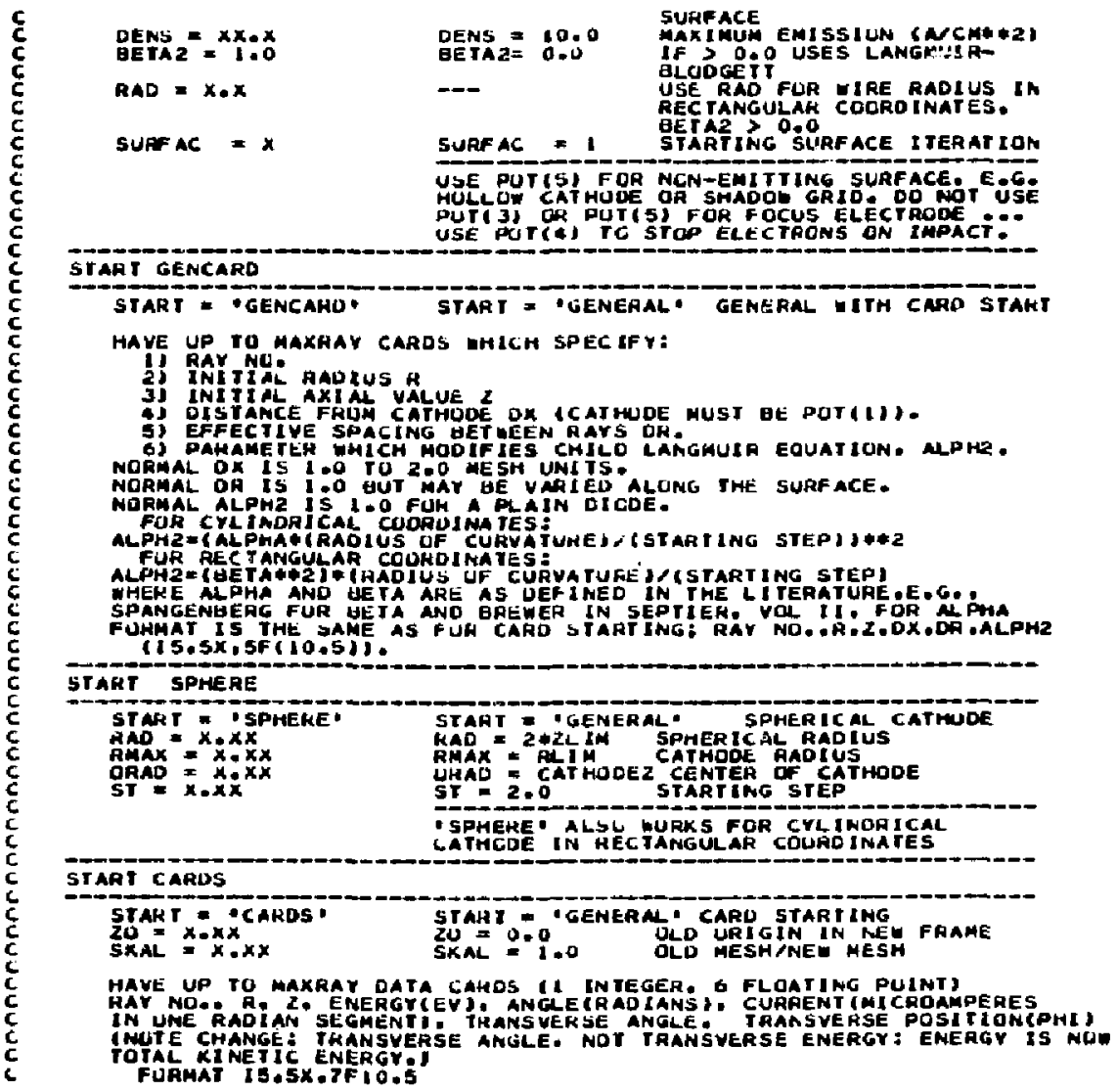




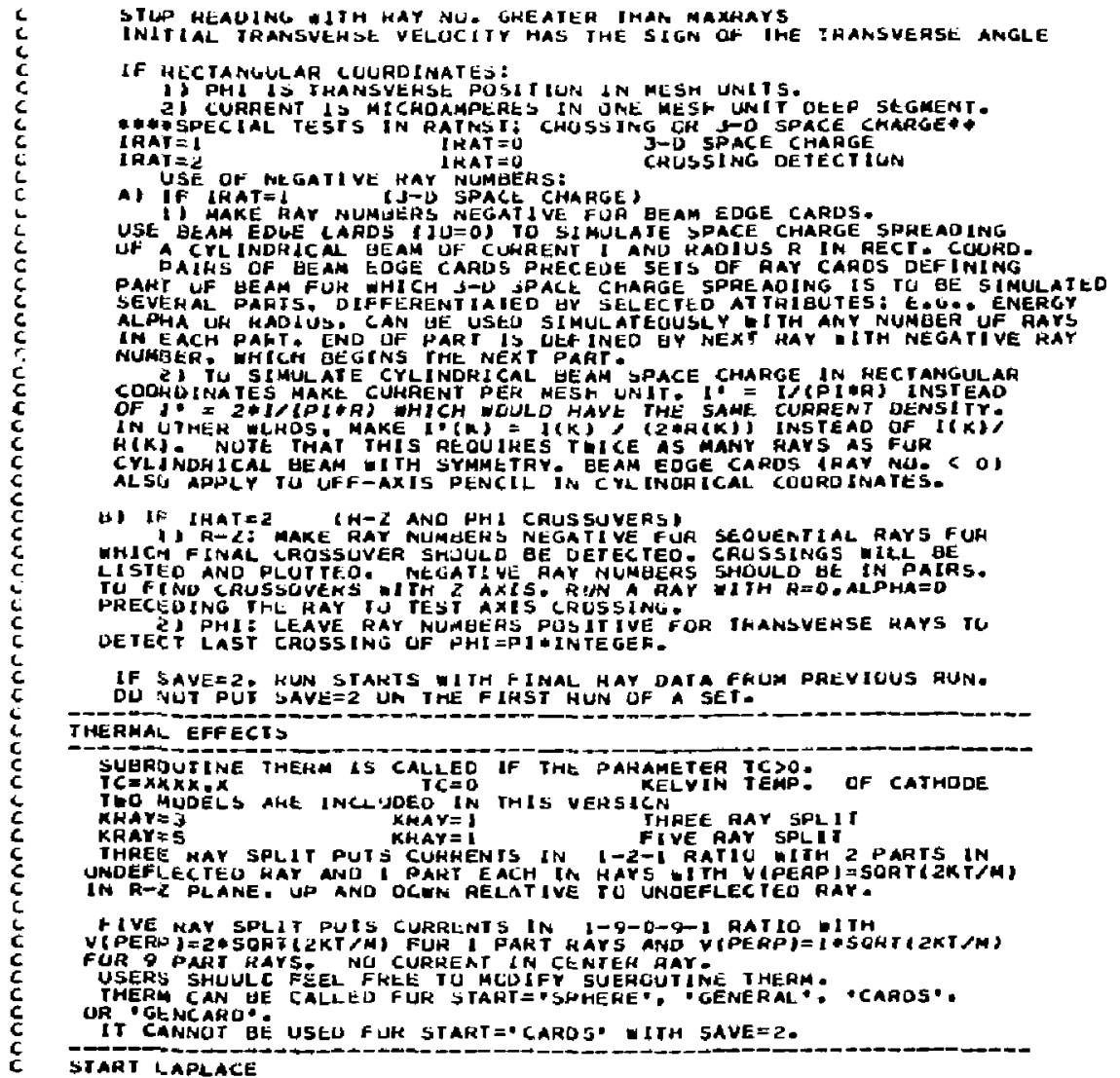




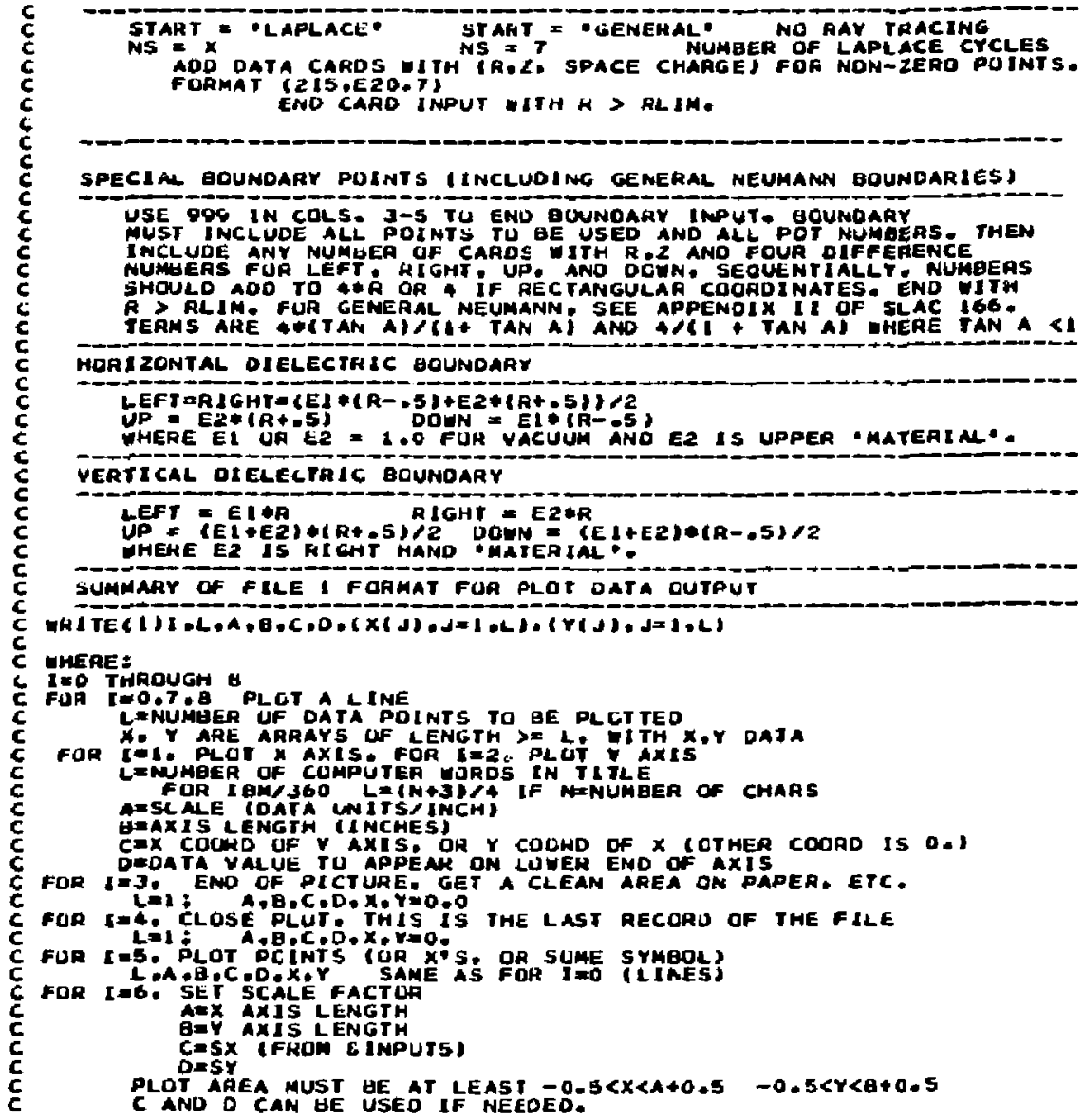




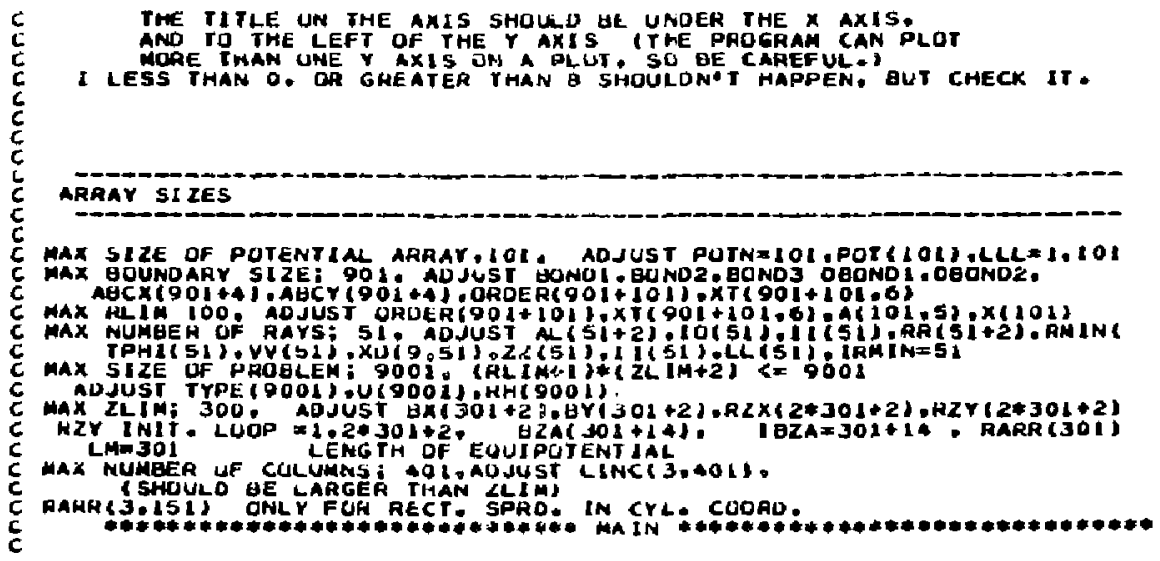


APPENDIX IV

SAMPLE PLOTTER INTERFACE PROGRAM

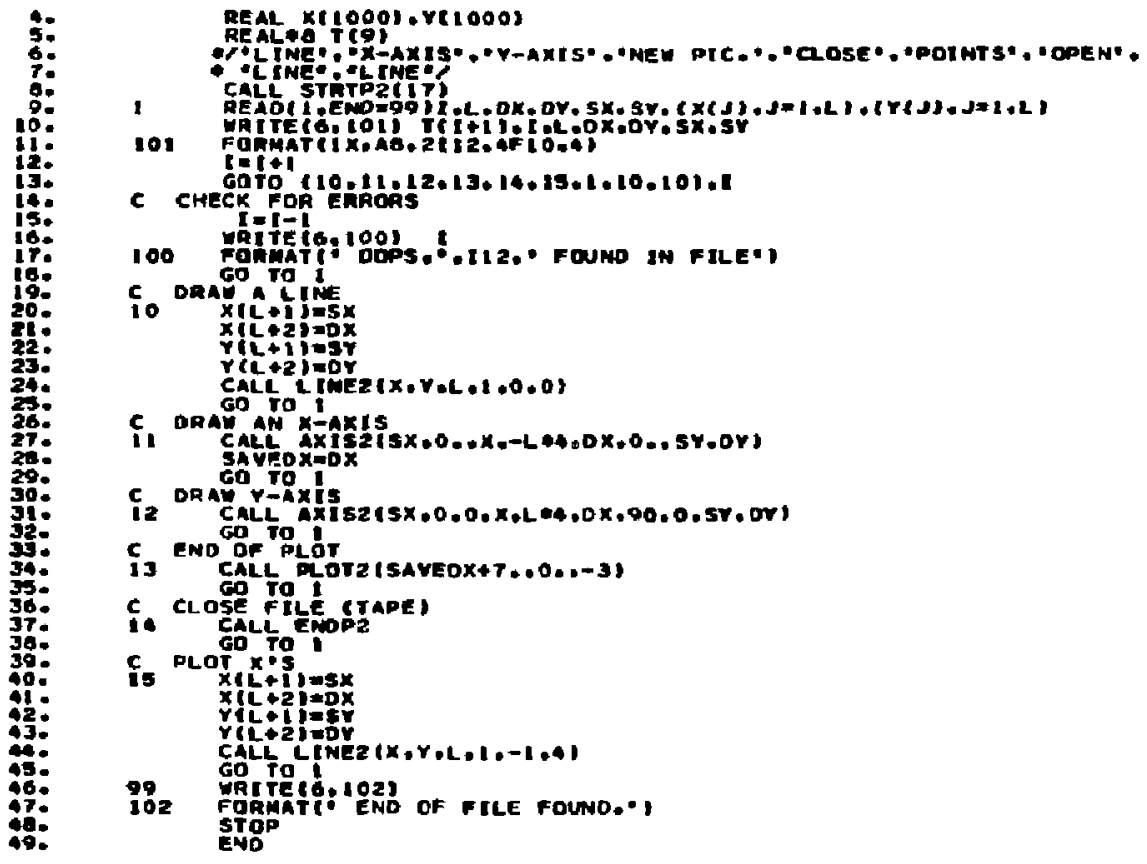




\section{APPENDIX V}

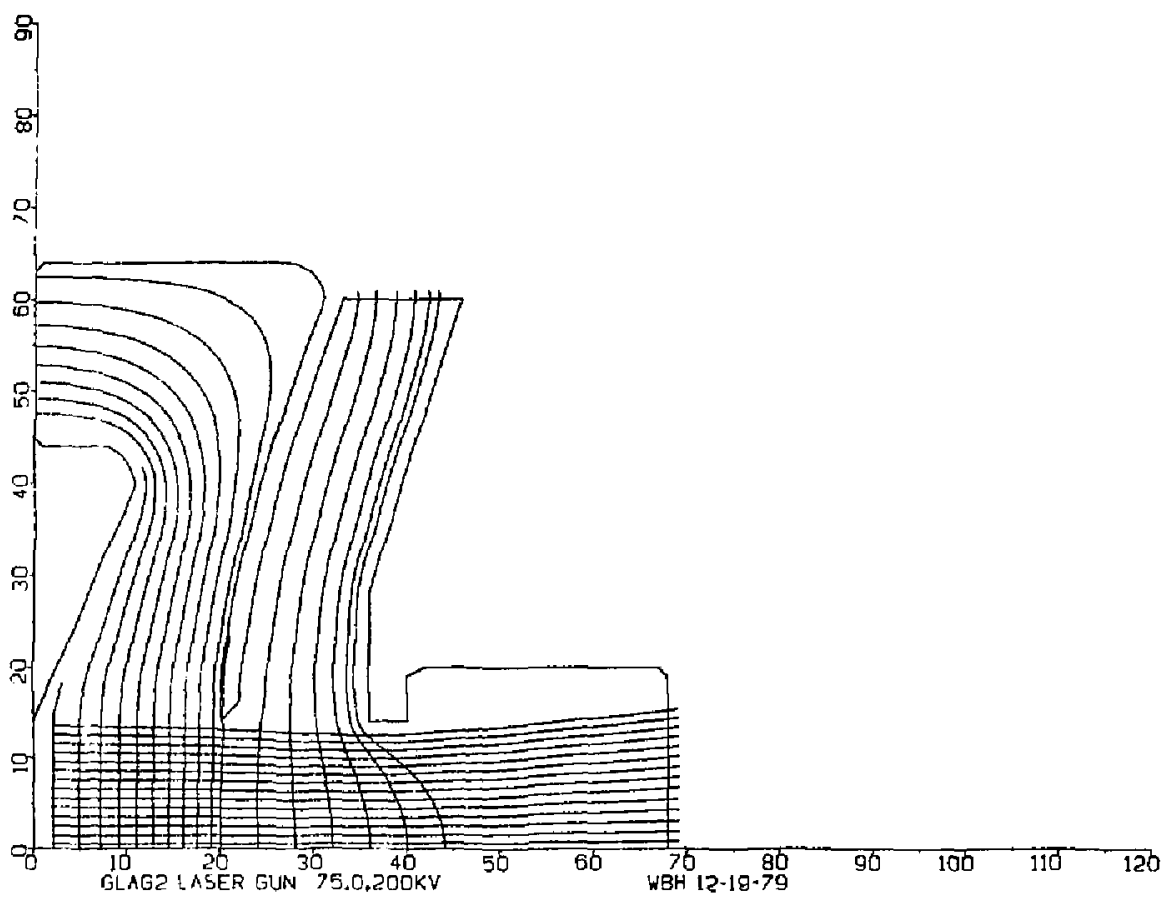

Fig. 8. Sample output for a very high perveance gun. 


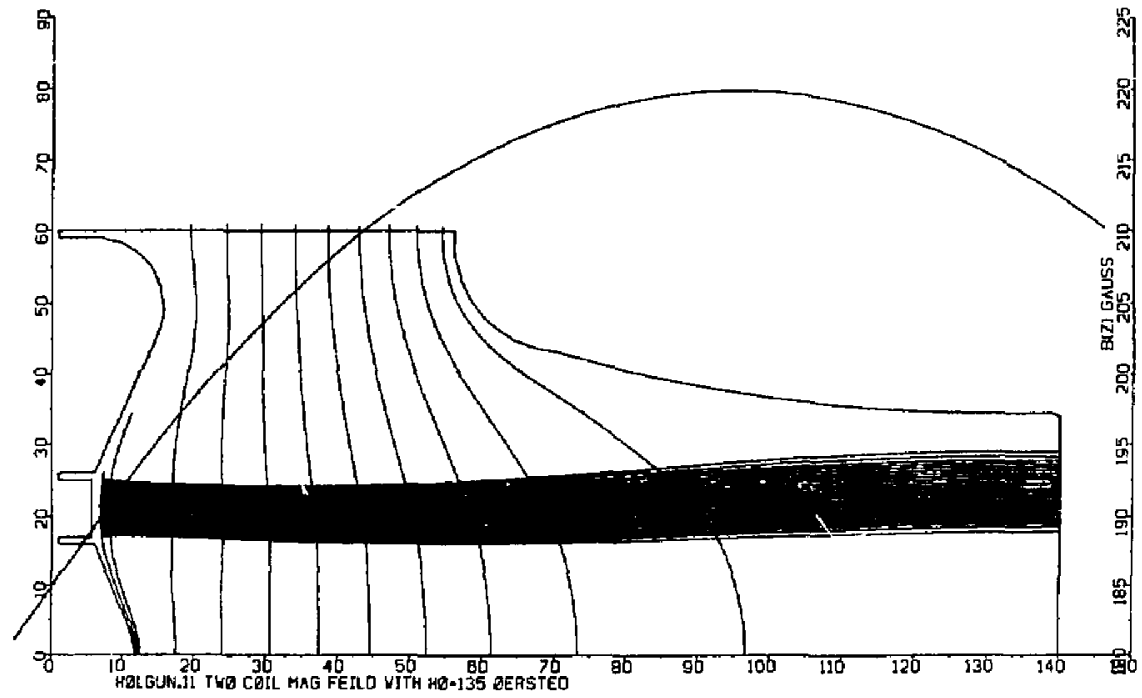

F1g. 9. Sample output for a hol: weam gun. 


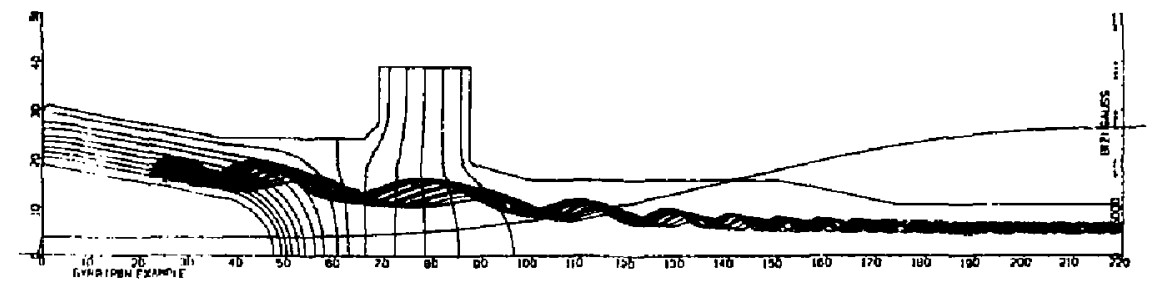

Fig. 10. Sample output for a gyrotron gun. 


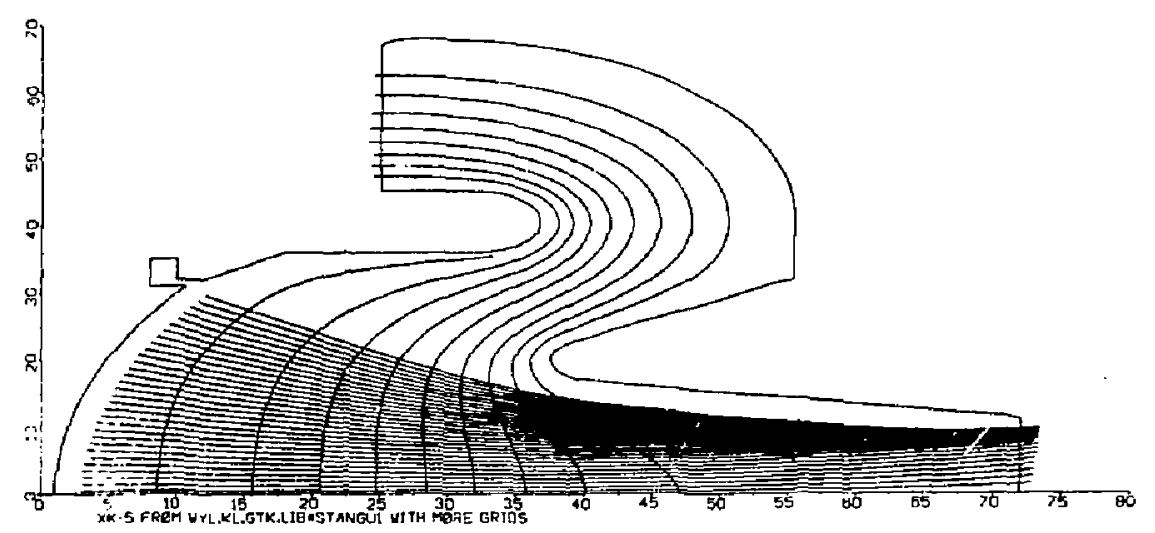

F1g. 11. Sample output for a klystron gun. 
REFLRANCES

1. Forgythe and Hasow, Funite Diffarence Methads for Partial Differential Equntiong, Hiley and Sons.

2. D. N. de G, Mlleh, M.A., Relnxution Mechods, MeGras H1:1.

3. F. S. Shaw, p.texcation Methodg, Dover Publicartons.

4. Btehard S. Varga, Marrix Icerative Analysig, Prentice Hall.

5. Vlarimte Hanza: NASA TN 1323, TN 1665, TN 1711.

6. A. Septjer, Focusins of Charged Partieles, Academtc Press (1967). See Chapter 1.2 by $C$. Weber in volume I for the most relevant material to this application.

7. J. R. M. Vaughan, "Representation of Axfsymetric Magnetie Flelds In Computer Program," IEEE Tranguctions on Electron Devices, ED-19, No. 2, Peb. 1972, PP. 144-1,51,

B. K. R. Spangenburg, vaculm Tubeg, Mciostaw H111, New York (1948).

9. K. R. Spangeoburg, Fundamentale of Electron Devices, McGraw H111, Nev York (1957).

10. I. Langguit and K. B. Blodgete, Phys, Rev, 22, 347 (1923).

11. G. R. Brewer, RLgh Intengity BIectron GUne, Focusing of Charged Particles, Vol. II, A. Septlex, Ed., AcudemIc Press, New York (1967).

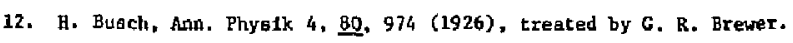
Focusing of High-Density Electron Beams, Facusing of Charged Part1cleg, Vol. II., A. Septier, Ed., Acsdemte Pregs, New York (1967).

13. J. A. Seeger, Proceedings of the IREE, 56, 1393, August 1968.
24. X. G. Steffan, High Energy Beam Optics, Intersctence Monograph, John Wlley and Sons, Nev York (1965).

15. R. H. MHller, I. Berk and T. O. Mekinney, The Electron Gun for the Stanford Two-Mil. Accelerator, IEEE Transactions on Nuclaar Sc1ence, June 1967, Vol. Ns-17, No. 3. 